\title{
Hypothalamic Tanycytes: A Key Component of Brain-Endocrine Interaction
}

\author{
Esteban M. Rodríguez, ${ }^{*}$ Juan L. Blázquez, ${ }^{\dagger}$ Francisco E. Pastor, ${ }^{\dagger}$ Belén \\ Peláez, ${ }^{\dagger}$ Patricio Peña, ${ }^{*}$ Bruno Peruzzo, ${ }^{*}$ and Pedro Amat ${ }^{\dagger}$ \\ * Instituto de Histología y Patología, Facultad de Medicina, Universidad Austral \\ de Chile, 5678 Valdivia, Chile \\ †Departamento de Anatomía e Histología Humanas, Facultad de Medicina \\ Universidad de Salamanca, 37008 Salamanca, Spain
}

Tanycytes are bipolar cells bridging the cerebrospinal fluid (CSF) to the portal capillaries and may link the CSF to neuroendocrine events. During the perinatal period a subpopulation of radial glial cells differentiates into tanycytes, a cell lineage sharing some properties with astrocytes and the radial glia, but displaying unique and distinct morphological, molecular, and functional characteristics. Four populations of tanycytes, $\alpha_{1,2}$ and $\beta_{1,2}$, can be distinguished. These subtypes express differentially important functional molecules, such as glucose and glutamate transporters; a series of receptors for neuropeptide and peripheral hormones; secretory molecules such as transforming growth factors, prostaglandin $E_{2}$, and the specific protein P85; and proteins of the endocytic pathways. This results in functional differences between the four subtypes of tanycytes. Thus, $\alpha_{1,2}$ tanycytes do not have barrier properties, whereas $\beta_{1,2}$ tanycytes do. Different types of tanycytes use different mechanisms to internalize and transport cargo molecules; compounds internalized via a clathrin-dependent endocytosis would only enter tanycytes from the CSF. There are also differences in the neuron-tanycyte relationships; $\beta_{1,2}$ tanycytes are innervated by peptidergic and aminergic neurons, but $\alpha_{1,2}$ tanycytes are not. Important aspects of the neuron- $\beta_{1}$ tanycyte relationships have been elucidated. Tanycytes can participate in the release of gonadotropin-releasing hormone $(\mathrm{GnRH})$ to the portal blood by expressing estrogen receptors, absorbing molecules from the CSF, and providing 
signal(s) to the GnRH neurons. Removal of tanycytes prevents the pulse of $\mathrm{GnRH}$ release into the portal blood, the peak of luteinizing hormone, and ovulation. The discovery in tanycytes of new functional molecules is opening a new field of research. Thus, thyroxine deiodinase type II, an enzyme generating triiodothyronine $\left(T_{3}\right)$ from thyroxine, appears to be exclusively expressed by tanycytes, suggesting that these cells are the main source of brain $T_{3}$. Glucose transporter-2 (GLUT-2), a low-affinity transporter of glucose and fructose, and ATP-sensitive $\mathrm{K}^{+}$channels are expressed by tanycytes, suggesting that they may sense CSF glucose concentrations.

KEY WORDS: Tanycytes, Cell lineage, Subpopulations, Neuron progenitors, Barrier properties, Polarized endocytosis, GnRH release. ๑ 2005 Elsevier Inc.

\section{Introduction}

Early authors paid attention to ependymal cells of the floor of the third ventricle, which established a close spatial relationship with the capillaries of the hypothalamo-hypophysial portal system (Löfgren, 1958, 1961; Wingstrand, 1951) (Figs. 1A, B and 2A-C). In 1954, Horstmann described the elongated bipolar ependymal cells lining the infundibular recess of the third ventricle, with a proximal pole in the ventricular wall and a distal pole contacting the portal vessels. Because of their shape, Horstmann called these cells "tanycytes" (from the Greek word tanus, "elongated"). A distinct structural feature of tanycytes is that they possess a single, long basal process that project to discrete regions of the hypothalamus. This led Löfgren $(1958,1959,1960)$ to suggest, for the first time, that tanycytes may link the cerebrospinal fluid (CSF) to neuroendocrine events.

During the 1970s and 1980s, tanycytes were the subject of numerous publications dealing with their morphology, histochemistry, ultrastructure, and functional relationship with neuroendocrine mechanisms. Although evidence was presented that they might perform transport functions between the CSF and the portal blood, and that they may participate in the release of hypothalamic hormones to the portal system, the lack of appropriate methodological tools and experimental designs contributed to the confusion and disagreements between different authors with respect to the role(s) tanycytes play (Flament-Durand and Brion, 1985; Knigge and Scott, 1970; Leonhardt, 1980; Wittkowski, 1998). More recently, tanycytes have again become the subject of investigations that have thrown some light on molecular and functional aspects of this rather enigmatic cell group of the brain. 


\section{Ontogeny, Cell Markers, and Cell Lineage}

\section{A. Development and Aging}

In studies on the embryological development of the hypothalamus carried out by Ströer (1956) and Coggeshall (1964) there is only a minor mention of tanycytes. The first report on the ontogenetic development of tanycytes is that carried out in the rat by Schachenmayr (1967), who indicated that tanycyte differentiation starts on day 19 (E-19) of embryonic life and continues after birth. According to ultrastructural criteria, rat tanycytes start to differentiate on E-18 (Rützel and Schiebler, 1980). Altman and Bayer (1978), Das (1979), and Korr (1980) have reported that, in the rat, differentiation of the ciliated ependyma precedes that of tanycytes. The use of $\left[{ }^{3} \mathrm{H}\right]$ thymidine and radioautography led Altman and Bayer $(1978,1986)$ to conclude that the bulk of common ependymal cells forms from E-16 to E-18, whereas most tanycytes are generated during the first postnatal week, and few during the second week of life. At variance, in the baboon, differentiation of tanycytes appears to occur at midgestation (Scott and Pepe, 1987).

In the rat, tanycytes are generated during the last 2 days of pregnancy and the first postnatal days, achieving their full differentiation during the first month of life. According to cytological, histochemical, and ultrastructural criteria tanycytes would be fully differentiated by the end of the first postnatal month (Bruni et al., 1983, 1985; Monroe and Paull, 1974; Rützel and Schiebler, 1980; Schachenmayr, 1967; Seress, 1980). Walsh et al. (1978) have studied the fine structure of the median eminence of male and female rats at postnatal day (PN)-1, PN-5, and PN-10 and found no sexual dimorphism in tanycytes. Walsh et al. (1978) reported that those tanycytes projecting to the arcuate nucleus ( $\alpha_{2}$ tanycytes?) closely resembled those of the adult rat, suggesting that the adult function of this population may be operative in the early postnatal period. At variance, the differing cytology between adult and developing tanycytes of the ventromedial nucleus region ( $\alpha_{1}$ tanycytes?) suggests that the function of this tanycyte group is age dependent.

In aged male and female rats the most obvious ultrastructural changes in tanycytes are a progressive increase in the number and size of lipid droplets (Brawer and Walsh, 1982). Zoli et al. (1995) have investigated the expression of dopamine- and cyclic AMP-regulated phosphoprotein of $32 \mathrm{kDa}$ (DARPP-32) and glial fibrillary acidic protein (GFAP) in 3-month-old and 24-month-old male rats, and found opposite changes during aging: DARPP32 decreased by about $70 \%$, whereas GFAP increased by $300 \%$. These changes were accompanied by a progressive loss in the number of tanycytes. The authors concluded that tanycytes undergo important modifications during aging, including impairment in the intracellular cascade linked to DARPP-32. 

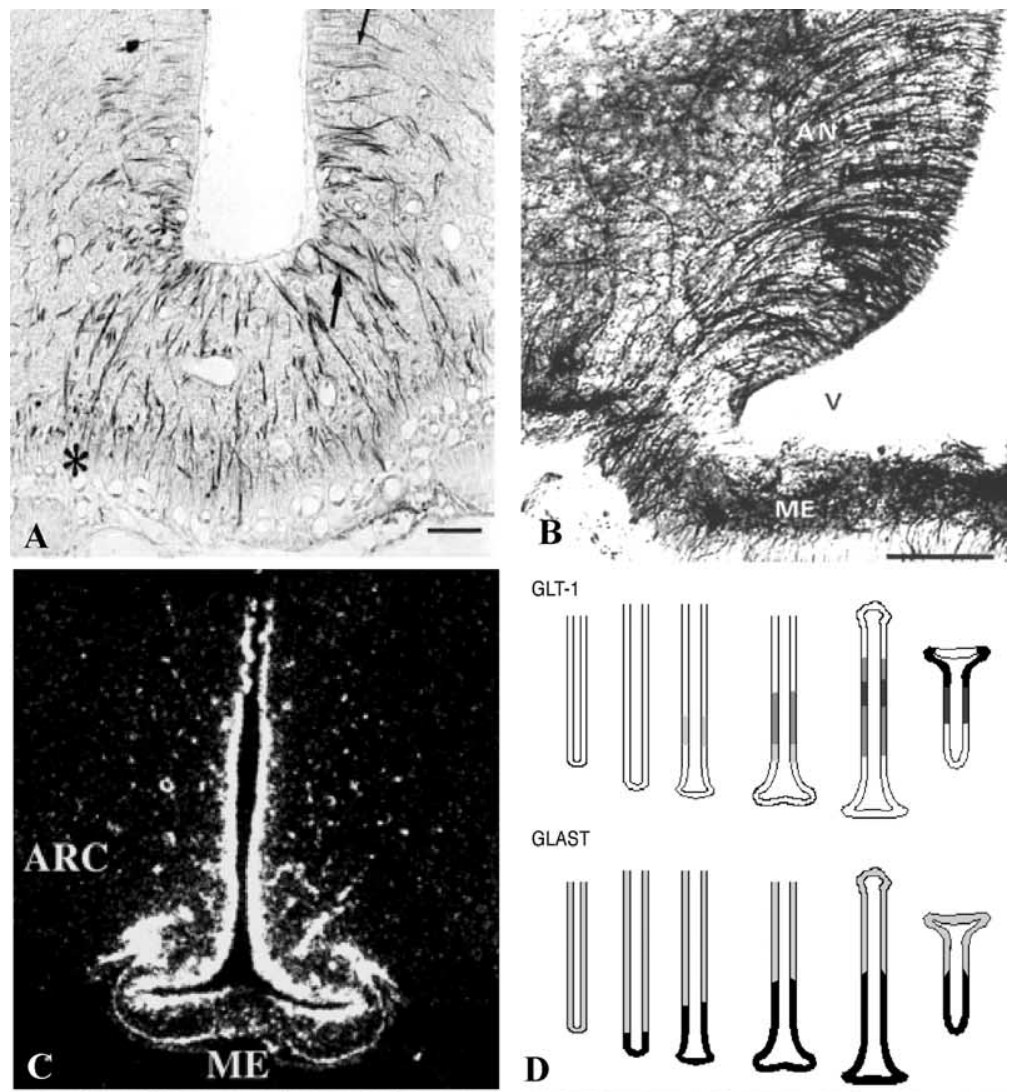

GLAST

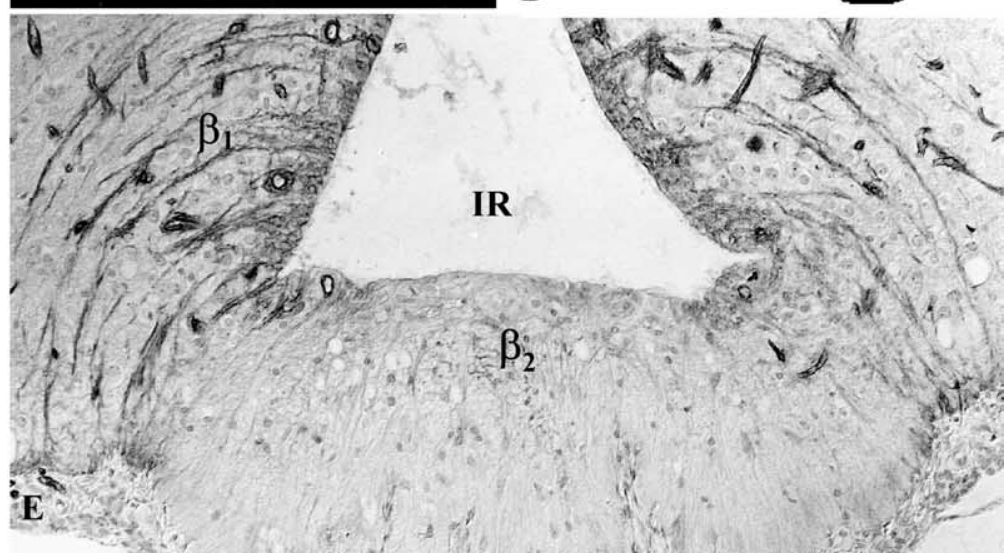

FIG. 1 Tanycytes express or absorb proteins in a selective or specific way. (A) Frontal sections through the mediobasal hypothalamus of female adult rats. Immunoreaction using anti-P85 shows strong immunostaining of $\beta$ tanycytes (large arrow) and a weak reaction of $\alpha$ tanycytes (small arrow). Asterisk points to the weakly reactive tanycyte terminals at the palisade layer. 


\section{B. Compounds Detected in Tanycytes}

Numerous compounds have been detected in the hypothalamic tanycytes (Table I). With the exception of a protein of $85 \mathrm{kDa}$ (P85) that appears to be exclusively expressed by tanycytes (Blázquez et al., 2002) (Fig. 1A), none of them has been shown to be selectively present in these cells. Some of the detected compounds are cytoskeletal proteins, such as GFAP (Redecker et al., 1987), vimentin (Leonhardt et al., 1987) (Fig. 2C), and plectin (Errante et al., 1994); others correspond to transporters, such as the glucose transporters 1 and 2 (García et al., 2003; Peruzzo et al., 2000) and glutamate transporters GLT-1 and GLAST (Berger and Hediger, 2001; Shibata et al., 1997) (Fig. 1D), receptors, and growth factors. Several plasma membrane receptors have been detected in tanycytes, namely, fibroblast growth factor receptor-1 (Matsuo et al., 1994), insulin growth factor-I (IGF-I) receptor (Cardona-Gómez et al., 2000), insulin growth factor-binding protein2 (Cardona-Gómez et al., 2000), transforming growth factor- $\alpha$ receptor (Ojeda and Ma, 1998), prolactin receptor (Lerant and Freeman, 1998), and glutamate 5-7 kainate receptors (Diano et al., 1998; Eyigor and Jennes, 1998). Interestingly, the ligands of most of these receptors have been immunocytochemically detected in the hypothalamic tanycytes, such as basic fibroblast growth factor (Gibson et al., 2000), transforming growth factor- $\alpha$ (Ojeda et al., 1990, 1992, 1997) and transforming growth factor- $\beta$ (Martini et al., 1997; Melcangi et al., 1995), and IGF-I (Dueñas et al., 1994; García-Segura et al., 1991) (Fig. 1B).

DARPP-32, which is present in neurons bearing dopamine D-1 receptors (Hökfelt et al., 1988), is highly expressed in tanycytes of the medial basal hypothalamus (Everitt et al., 1986; Fekete et al., 2000; Hökfelt et al., 1988; Meister et al., 1988) and in pituicytes of the neural lobe (Meister et al., 1989).

Neuropeptides, such as growth hormone-releasing hormone (GHRH; Carretero et al., 2002), gonadotropin-releasing hormone (GnRH; Pestarino

Original magnification: $\times 160$. (From Blázquez et al., 2002.) (B) Mediobasal hypothalamus of a 40-day-old rat: Immunostaining for IGF-I immunoreactivity. All tanycytes appear strongly labeled. AN, arcuate nucleus; ME, median eminence; $\mathrm{V}$, infundibular recess of third ventricle. Original magnification: $\times 150$. (From Dueñas et al., 1994.) (C) Rat mediobasal hypothalamus of a hypothyroid rat. In situ hybridization for the mRNA of deiodinase type II. Hybridization is present in tanycytes and missing from the ciliated ependyma. Original magnification: $\times 80$. (From Tu et al., 1997, with permission from The Endocrine Society.) (D) Schematic representation of the differential expression of glutamate transporters GLT-1 and GLAST. GLT- 1 is expressed by $\alpha$ tanycytes and GLAST is preferentially expressed by $\beta$ tanycytes. (From Berger and Hediger, 2001.) (E) Rat medial basal hypothalamus: Immunocytochemistry for GLUT-1. The cell body and the basal processes of $\beta_{1}$ tanycytes are reactive but those of $\beta_{2}$ tanycytes are not. IR, infundibular recess. Original magnification: $\times 200$. (From Peruzzo et al., 2000.) 

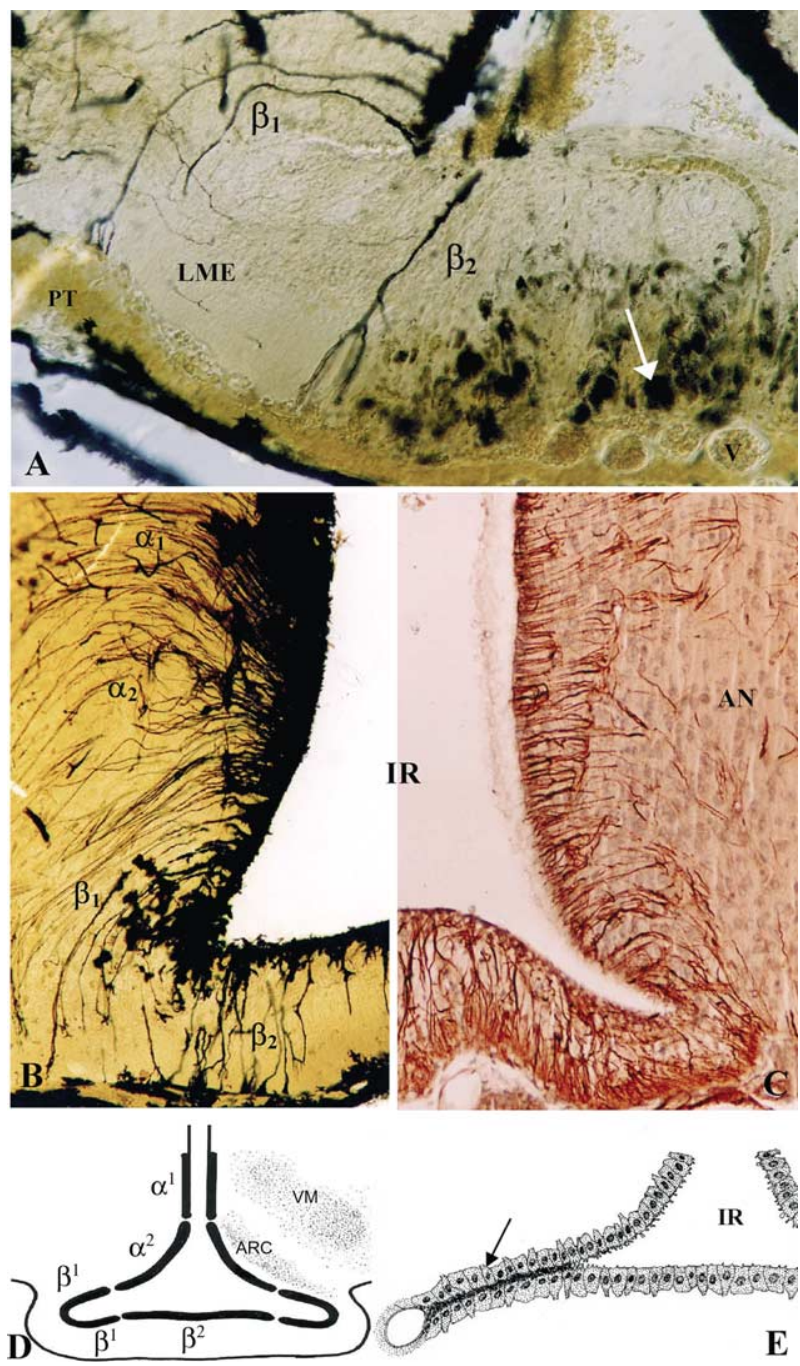

FIG. 2 (A) Rat median eminence processed according to the Golgi method. A clear-cut difference is seen between the medial and lateral (LME) regions. The trajectory of $\beta_{1}$ and $\beta_{2}$ tanycytes is distinct. Only $\beta_{2}$ tanycytes and pituicytes of the medial region contain abundant lipid inclusions (arrow). V, portal capillary; PT, pars tuberalis. Original magnification: $\times 170$. (From Rodríguez et al., 1979.) (B) Golgi staining revealing the spatial distribution of $\alpha_{1,2}$ and $\beta_{1,2}$ tanycytes. Original magnification: $\times 90$. (C) Immunocytochemistry for vimentin; the cell body and the proximal segment of the basal processes of $\alpha_{1,2}$ tanycytes are reactive; $\beta_{1,2}$ tanycytes are reactive throughout. IR, infundibular recess; AN, arcuate nucleus. Original magnification: $\times 90$. (D) Schematic representation of the tanycyte subtypes according to Akmayev and Popov (1977). VM, ventromedial nucleus; ARC, arcuate nucleus. (E) The infundibular recess projects two lateral extensions (arrow) lined by $\beta_{1}$ tanycytes. IR, infundibular recess. (From Amat et al., 1999.) 
TABLE I

Compounds Shown to Be Present in Tanycytes

\begin{tabular}{|c|c|}
\hline Substance & References \\
\hline Vimentin & Leonhardt et al. (1987) \\
\hline GFAP & Redecker et al. (1987) \\
\hline Plectin & Errante et al. (1994) \\
\hline Nestin & Wei et al. (2002) \\
\hline S-100 protein & Gudiño-Cabrera and Nieto-Sampedro (2000) \\
\hline Basic and acidic FGF & Cuevas et al. (1991); Tooyama et al. (1991) \\
\hline FGF receptor-1 & Matsuo et al. (1994) \\
\hline IGF-I & García-Segura et al. (1991) \\
\hline IGF-I receptor & Cardona-Gómez et al. (2000) \\
\hline TGF- $\alpha$ receptor & Ojeda and Ma (1998) \\
\hline TGF- $\beta$ type I receptor & Prevot et al. (2000) \\
\hline erbB-1 and erbB-2 receptors & Ma et al. (1994b) \\
\hline Neurotrophin receptor $\mathrm{p} 75$ & Borson et al. (1994) \\
\hline Somatostatin receptor & Hashemi et al. (2001) \\
\hline $\begin{array}{l}\text { Glutamate transporters } \\
\text { GLT-1 and GLAST }\end{array}$ & Berger and Hediger (2001); Shibata et al. (1997) \\
\hline GluR 2/3 (AMPA) & Kawakami (2000) \\
\hline GluR 5-7 (kainate) & Diano et al. (1998); Eyigor and Jennes (1998) \\
\hline O4 seminolipid sulfatide antigen & Gudiño-Cabrera and Nieto-Sampedro (2000) \\
\hline$\mu$ opioid receptor & Beauvillain et al. (1992) \\
\hline Prolactin receptor & Lerant and Freeman (1998) \\
\hline $\mathrm{GABA}_{\mathrm{B}}$ receptor $1 \mathrm{~b}$ & Poorkhalkali et al. (2000) \\
\hline DARPP-32 & Everitt et al. (1986) \\
\hline Estrogen receptor & Langub and Watson (1992) \\
\hline $\begin{array}{l}\text { Glucose transporters GLUT-1 } \\
\text { and GLUT-2 }\end{array}$ & García et al. (2003); Harik et al. (1990) \\
\hline GnRH & Pestarino et al. (1998) \\
\hline GHRH & Carretero et al. (2002) \\
\hline$\alpha-\mathrm{MSH}$ & Chiba (2001) \\
\hline Glial-derived neurotrophic factor & Ikeda et al. (1999) \\
\hline $5 \alpha$-Reductase & Pelletier et al. (1994) \\
\hline Type II thyroxine deiodinase & Tu et al. (1997) \\
\hline Macrophage migration inhibitory factor & Nishibori et al. (1997) \\
\hline$\alpha_{2}$-Laminin & Hagg et al. (1997) \\
\hline Amyloid precursor protein & Chauvet et al. (1997) \\
\hline Aquaporin-9 & Elkjaer et al. (2000) \\
\hline
\end{tabular}


et al., 1998), and $\alpha$-melanocyte-stimulating hormone ( $\alpha$-MSH; Chiba, 2001); hormone receptors [prolactin (Lerant and Freeman, 1998), somatostatin (Hashemi et al., 2001), and estrogens (Langub and Watson, 1992)]; and neurotransmitter receptors [GABA (Poorkhalkali et al., 2000), glutamate (Diano et al., 1998; Eyigor and Jennes, 1998; Kawakami, 2000), and opioids (Beauvillain et al., 1992)] have been reported to be present in tanycytes.

Hormone-related enzymes, such as $5 \alpha$-reductase involved in the synthesis of steroids (Pelletier et al., 1994), and type II thyroxine deiodinase, responsible for the conversion of triiodothyronine $\left(T_{3}\right)$ to thyroxine $\left(T_{4}\right)(T u$ et al., 1997) (Fig. 1C), are highly expressed by tanycytes.

\section{Tanycyte Lineage}

Tanycytes share some features with radial glia and with astrocytes. The shape and location of tanycytes, namely, a cell body lining the ventricle and a long basal process penetrating the hypothalamus and/or reaching the external limiting membrane of the brain, have led some authors to regard them as radial glia that remain in the hypothalamus throughout the life span (Bruni, 1998; Chauvet et al., 1996, 1997; Kozlowski and Coates, 1985; McQueen, 1994; Wittkowski, 1998). This view, which appears to be an oversimplification of a complex phenomenon, has gained support by findings indicating that tanycytes retain immunological and biochemical features of radial glial cells. Indeed, both radial glia of the embryonic mammalian brain and tanycytes of the adult mammalian brain express GFAP (Levitt and Rakic, 1980; Redecker et al., 1987), the intermediate filament vimentin (Leonhardt et al., 1987; Pixley and De Vellis, 1984), nestin, an intermediate filament contained in all CNS precursors (Hockfield and McKay, 1985; Wei et al., 2002), the astrocyte-specific glutamate transporter (GLAST) (Berger and Hediger, 2001; Shibata et al., 1997), and the functional receptors for the neurotransmitters $\gamma$-aminobutyrate (GABA) and glutamate (Diano et al., 1998; Eyigor and Jennes, 1998; LoTurco et al., 1995; Poorkhalkali et al., 2000). A monoclonal antibody raised against radial glia (RC1) labels radial glial cells of the embryonic mouse brain and tanycytes of the adult mouse brain (Edwards et al., 1990; Ma et al., 1990). The amyloid precursor protein, a transmembrane glycoprotein that is believed to promote neural cell adhesion, neural survival, and neuritogenesis, is expressed by both radial glia and tanycytes (Chauvet et al., 1997; Trapp and Hauer, 1994).

Another important feature apparently shared by radial glia and tanycytes is the property to serve as neuronal progenitors (see Section VII). In mammals, neurogenesis is largely complete at birth, at which time radial glial 
cells disappear when they become transformed into astrocytes (Campbell, 2003; Chanas-Sacré et al., 2000; Schmechel and Rakic, 1979). Radial glia, which have long been regarded as glia or glial progenitors (Levitt et al., 1983), can also serve as neuronal progenitors and may be stem cells during embryonic life (Alvarez-Buylla et al., 2001, 2002; Malatesta et al., 2000; Noctor et al., 2001) or in discrete areas of the adult brain (Alvarez-Buylla et al., 2001; Anthony et al., 2004; Götz et al., 2002). Furthermore, vertebrates with neurogenesis throughout adulthood maintain radial glial cells into adulthood (Götz et al., 2002). As is shown in Section VII, tanycytes of adult rats can give rise to neurons under certain experimental conditions.

However, tanycytes display several properties that clearly distinguish them from radial glial cells. In mammals, radial glia are a key resident of the embryonic brain whereas tanycytes differentiate relatively late after birth (see Section II.A) and remain fully active during the life span. Tanycytes express a large number of proteins, such as receptors, transporters, and enzymes that are not known to be expressed by radial glial cells (see Table I). Furthermore, there are important differences in the control of the expression of certain molecules that are present in both cell lineages. Thus, in tanycytes, the expression of GFAP is under the influence of ovarian hormones (García-Segura et al., 1994). Consequently, tanycytes are under mechanisms of control, and perform functions different from those of radial glia (see Sections IV-VI).

GFAP, the water transport molecule aquaporin-9 (Elkjaer et al., 2000), the calcium-binding protein S-100 (Gudiño-Cabrera and Nieto-Sampedro, 2000), and the glutamate transporter GLAST (Berger and Hediger, 2001; Shibata et al., 1997), present in tanycytes, are all regarded as markers of astrocytic functional phenotype (Goldman, 2003). To date, neither the aquaporins nor any other excitatory amino acid transporters, apart from GLAST, have yet been detected in radial glial cells (Goldman, 2003).

The evidence available at present leads to the conclusion that tanycytes may be regarded as genealogical descendants of the transient embryonic radial glia. During the perinatal period most radial glial cells become transformed into astrocytes, whereas a subpopulation of radial glial cells becomes differentiated into tanycytes, a cell lineage that shares some properties with astrocytes and with the radial glia proper, but that displays unique and distinct morphological, molecular, and functional characteristics. Furthermore, tanycytes do not constitute a homogeneous cell population; instead, they further differentiate into four subtypes, each with distinct features (see Section III and Table II). Worth mentioning is the finding that radial glia lineages appear to be heterogeneous both within and across different brain regions (Kriegstein and Götz, 2003). 
TABLE ॥

Differential Characteristics of $\alpha_{1}, \alpha_{2}, \beta_{1}$, and $\beta_{2}$, Tanycytes

\begin{tabular}{|c|c|c|c|c|c|}
\hline & $\alpha_{1}$ Tanycytes & $\alpha_{2}$ Tanycytes & $\beta_{1}$ Tanycytes & $\beta_{2}$ Tanycytes & References \\
\hline $\begin{array}{l}\text { Localization of } \\
\text { cell body }\end{array}$ & $\begin{array}{l}\text { Facing the } \\
\text { dorsomedial } \\
\text { and } \\
\text { ventromedial } \\
\text { nuclei }\end{array}$ & $\begin{array}{l}\text { Facing the } \\
\text { arcuate nucleus }\end{array}$ & $\begin{array}{l}\text { Lateral } \\
\text { evaginations of } \\
\text { infundibular recess }\end{array}$ & $\begin{array}{l}\text { Floor of } \\
\text { infundibular } \\
\text { recess }\end{array}$ & $\begin{array}{l}\text { Akmayev et al. (1973); } \\
\quad \text { Rodríguez et al. (1979) }\end{array}$ \\
\hline $\begin{array}{l}\text { Zone of projection } \\
\text { of basal processes }\end{array}$ & $\begin{array}{l}\text { Dorsomedial } \\
\text { and } \\
\text { ventromedial } \\
\text { nuclei }\end{array}$ & Arcuate nucleus & $\begin{array}{l}\text { Lateral zones } \\
\text { of external } \\
\text { region of } \\
\text { median } \\
\text { eminence }\end{array}$ & $\begin{array}{l}\text { Medial zone of } \\
\text { external region } \\
\text { of median } \\
\text { eminence }\end{array}$ & $\begin{array}{l}\text { Akmayev et al. (1973); } \\
\text { Millhouse (1971); } \\
\text { Rodríguez et al. (1979) }\end{array}$ \\
\hline Bridging arrangement & $\begin{array}{l}\text { Bridge CSF with } \\
\text { medial basal } \\
\text { hypothalamus }\end{array}$ & $\begin{array}{l}\text { Bridge CSF with } \\
\text { medial basal } \\
\text { hypothalamus }\end{array}$ & $\begin{array}{l}\text { Bridge CSF } \\
\text { with portal } \\
\text { blood }\end{array}$ & $\begin{array}{l}\text { Bridge CSF } \\
\text { with portal } \\
\text { blood }\end{array}$ & $\begin{array}{l}\text { Akmayev et al. (1973); } \\
\text { Knigge et al. (1976); } \\
\text { Löfgren (1958); } \\
\text { Rodríguez (1969, 1972); } \\
\text { Rodríguez et al. (1979) }\end{array}$ \\
\hline $\begin{array}{l}\text { Spines in the } \\
\text { proximal segment } \\
\text { of basal process }\end{array}$ & Present & Present & Present & Missing & $\begin{array}{l}\text { Millhouse (1971); } \\
\quad \text { Rodríguez et al. (1979) }\end{array}$ \\
\hline $\begin{array}{l}\text { Adenosine } \\
\quad \text { triphosphatase }\end{array}$ & Present & Missing & Missing & Missing & Firth and Bock (1976) \\
\hline $\begin{array}{l}\text { GPDH, LDH, and } \\
\text { G6PD activity }\end{array}$ & Low & Low & High & High & Akmayev et al. (1973) \\
\hline $\begin{array}{l}\text { Sexual differences } \\
\text { in GPDH, LDH, }\end{array}$ & Missing & Missing & Present & Missing & $\begin{array}{l}\text { Akmayev and } \\
\text { Fidelina (1976) }\end{array}$ \\
\hline
\end{tabular}




\begin{tabular}{|c|c|c|c|c|c|}
\hline $\begin{array}{l}\text { Reaction to } \\
\text { adrenalectomy }\end{array}$ & No reaction & No reaction & $\begin{array}{l}\text { Decreased } \\
\quad \text { metabolic } \\
\text { activity }\end{array}$ & $\begin{array}{l}\text { Decreased } \\
\quad \text { metabolic } \\
\text { activity }\end{array}$ & $\begin{array}{l}\text { Akmayev and } \\
\text { Fidelina (1974) }\end{array}$ \\
\hline $\begin{array}{l}\text { Expression of } \\
\text { GLUT-1 }\end{array}$ & Present & Present & Present & Missing & Peruzzo et al. (2000) \\
\hline $\begin{array}{l}\text { Expression of } \\
\text { IGF-Bpr }\end{array}$ & ND & ND & Present & Missing & $\begin{array}{l}\text { Cardona-Gómez et al. } \\
\quad(2000)\end{array}$ \\
\hline $\begin{array}{l}\text { Expression of } \\
\text { GLT-1 }\end{array}$ & Present & Present & Missing & Missing & $\begin{array}{l}\text { Berger and Hediger } \\
\quad \text { (2001) }\end{array}$ \\
\hline $\begin{array}{l}\text { Expression of } \\
\text { GLAST }\end{array}$ & Missing & Missing & Present & Present & $\begin{array}{l}\text { Berger and Hediger } \\
\quad(2001)\end{array}$ \\
\hline $\begin{array}{l}\text { Expression of } \\
\text { sst }_{2(a)} \text { receptor }\end{array}$ & High & High & Low & Low & Hashemi et al. (2001) \\
\hline Caveolin-1 & Missing & Missing & Present & Present & Peruzzo et al. (2004) \\
\hline Rab4 & Missing & Missing & Missing & Present & Peruzzo et al. (2004) \\
\hline $\begin{array}{l}\text { Transport } \\
\text { throughout } \\
\text { the cell of WGA } \\
\text { injected } \\
\text { into the CSF }\end{array}$ & Yes & No & Yes & Yes & Peruzzo et al. (2004) \\
\hline$\alpha$-Catenin & $\begin{array}{l}\text { At ventricular } \\
\text { cell pole }\end{array}$ & $\begin{array}{l}\text { At ventricular } \\
\text { cell pole }\end{array}$ & $\begin{array}{l}\text { Cell body, } \\
\text { basal process } \\
\text { and terminal }\end{array}$ & $\begin{array}{l}\text { Cell body, } \\
\text { basal process } \\
\text { and terminal }\end{array}$ & Present review \\
\hline$\alpha$-Cadherin & $\begin{array}{l}\text { At ventricular } \\
\text { cell pole }\end{array}$ & $\begin{array}{l}\text { At ventricular } \\
\text { cell pole }\end{array}$ & $\begin{array}{l}\text { At ventricular } \\
\text { cell pole }\end{array}$ & $\begin{array}{l}\text { Cell body, } \\
\text { basal process, } \\
\text { and terminal }\end{array}$ & Present review \\
\hline Zonula adherens & $\begin{array}{l}\text { At ventricular } \\
\text { cell pole }\end{array}$ & $\begin{array}{l}\text { At ventricular } \\
\text { cell pole }\end{array}$ & $\begin{array}{l}\text { Throughout } \\
\text { the cell body }\end{array}$ & $\begin{array}{l}\text { Throughout the } \\
\text { cell body }\end{array}$ & Present review \\
\hline
\end{tabular}




\begin{tabular}{|c|c|c|c|c|c|}
\hline & $\alpha_{1}$ Tanycytes & $\alpha_{2}$ Tanycytes & $\beta_{1}$ Tanycytes & $\beta_{2}$ Tanycytes & References \\
\hline Tight junctions & Missing & $\begin{array}{l}\text { Between basal } \\
\text { processes }\end{array}$ & $\begin{array}{l}\text { Between basal } \\
\text { processes }\end{array}$ & $\begin{array}{l}\text { At the } \\
\text { ventricular pole }\end{array}$ & $\begin{array}{l}\text { Brightman and Reese (1969); } \\
\text { Krisch et al. (1978); } \\
\text { Rinne (1966); } \\
\text { Rodríguez et al. (1979) }\end{array}$ \\
\hline $\begin{array}{l}\text { Permeability to HRP } \\
\text { injected in the CSF }\end{array}$ & Yes & Yes & Yes & No & $\begin{array}{l}\text { Brightman et al. (1975); } \\
\quad \text { Rodríguez et al. (1982) }\end{array}$ \\
\hline Lipid inclusions & Virtually missing & Virtually missing & $\begin{array}{l}\text { Abundant in } \\
\text { cell body }\end{array}$ & $\begin{array}{l}\text { Abundant in } \\
\text { basal process }\end{array}$ & Rodríguez et al. (1979) \\
\hline $\begin{array}{l}\text { Type of ending of the } \\
\text { basal process }\end{array}$ & Type 1 & Type 1 & Types II and III & Type I & Rodríguez et al. (1979) \\
\hline $\begin{array}{l}\text { Large cisterns in the } \\
\text { basal process }\end{array}$ & Missing & Missing & Present & Missing & $\begin{array}{l}\text { Akmayev et al. (1973); } \\
\text { Blázquez et al. (2002); } \\
\text { Brion et al. (1982); } \\
\text { Peruzzo et al. }(2000)\end{array}$ \\
\hline $\begin{array}{l}\text { Ependymal terminals } \\
\text { form a continuous } \\
\text { cuff }\end{array}$ & No & No & Yes & No & Rodríguez et al. (1979) \\
\hline Innervation & Missing & Missing & $\begin{array}{l}\text { At preterminal } \\
\text { region of } \\
\text { basal process }\end{array}$ & $\begin{array}{l}\text { Throughout } \\
\text { basal process }\end{array}$ & $\begin{array}{l}\text { Akmayev et al. (1973); } \\
\quad \text { Rodríguez et al. (1979) }\end{array}$ \\
\hline Neurogenic property & Not evident & Evident & Not evident & Not evident & present review \\
\hline
\end{tabular}

Abbreviations: GPDH, glyceraldehyde-3-phosphate dehydrogenase; LDH, lactic dehydrogenase; G6PD, glucose-6-phosphate dehydrogenase; GLUT-1, glucose transporter 1; IGF-Bpr, insulin growth factor-binding protein; GLT-1, glutamate transporter; GLAST, glutamate transporter; sst $_{2(a)}$, somatostatin receptor; Rab4, a protein involved in endocytosis and transport of synthesized proteins; WGA, wheat germ agglutinin; CSF, cerebrospinal fluid; HRP, horseradish peroxidase; ND, not determined. 


\section{Tanycyte Subtypes}

Tanycytes do not constitute a homogeneous cell population. In the rat, four types of tanycytes have been distinguished (Akmayev et al., 1973; Akmayev and Fidelina, 1976; Akmayev and Popov, 1977; Rodríguez et al., 1979) (Fig. 2D). They present different characteristics with respect to their location, spatial relationships, morphology, cytochemistry, ultrastructure, and certain functions.

\section{A. Distribution and Spatial Relationships}

$\alpha_{1}$ Tanycytes line the area of the ventromedial nucleus and part of that of the dorsomedial nucleus, and project their basal processes to these nuclei (Figs. 2B, D and 4A); $\alpha_{2}$ tanycytes line the area of the arcuate nucleus and most of them project their processes within this nucleus; the processes of a few of them terminate on the lateral aspect of the tuberoinfundibular sulcus (Akmayev et al., 1973; Rodríguez et al., 1979) (Figs. 2B, D and 4A). $\beta_{1}$ tanycytes line the lateral evaginations in the infundibular recess (Amat et al., 1999) (Figs. 1E, 2A-D, 3A, and 4A, B) and project their processes to the lateroexternal region of the median eminence and end on the perivascular space of the portal capillaries located in the lateral region of the median eminence; $\beta_{2}$ tanycytes line the floor of the infundibular recess and their basal processes end on the portal capillaries of the medial zone of the median eminence (Blázquez et al., 2002; Flament-Durand and Brion, 1985; Kozlowski and Coates, 1985; Peruzzo et al., 2000; Rodríguez et al., 1979) (Figs. 1E, 2A-D, and 4A, E).

Thus, $\alpha$ tanycytes bridge the lumen of the third ventricle with the neurons and blood vessels of the medial basal hypothalamus and $\beta$ tanycytes establish an anatomical link between the ventricular CSF and the portal blood (Akmayev et al., 1973; Knigge and Scott, 1970; Löfgren, 1958; Rodríguez, 1969, 1972; Rodríguez et al., 1979).

\section{B. Morphology and Cytochemistry}

The Golgi impregnation of tanycytes has revealed distinct morphological characteristics of the tanycyte subtypes (Bleier, 1971, 1972; Bruni et al., 1983; Card and Rafols, 1978; Joy and Sathyanesan, 1981; Millhouse, 1971; Rodríguez et al., 1979). $\alpha_{1}$ tanycytes are located in the lateral walls of the infundibular recess and project their basal processes into the dorsomedial nucleus, following a lateral trajectory, and into the ventromedial nucleus, following a dorsal and then lateral trajectory. At variance, the processes of 


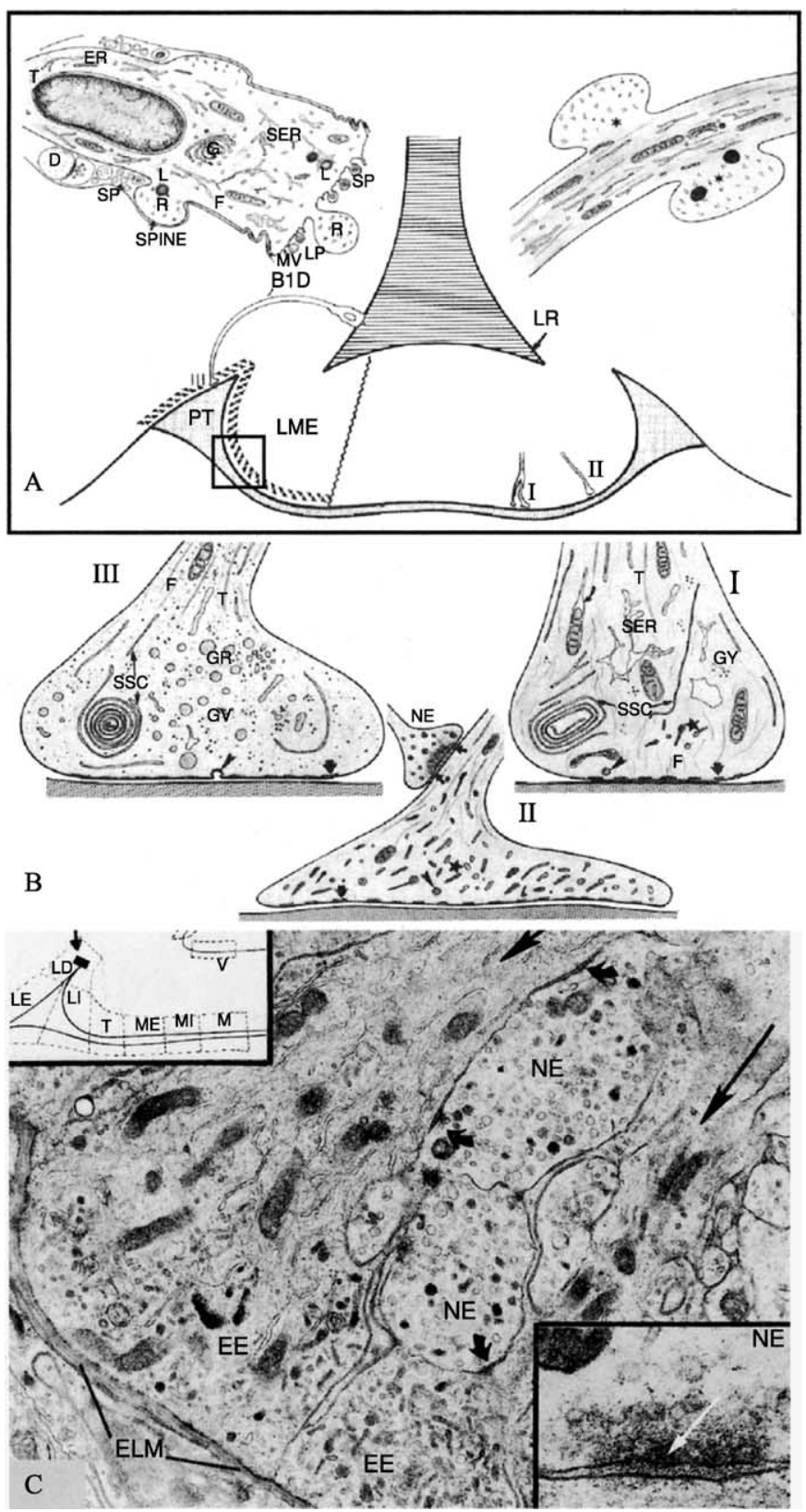

FIG. 3 Schematic drawings of the ultrastructure and distribution of $\beta_{1}$ tanycytes. (A) Median eminence showing the location of $\beta_{1}$ tanycytes and the preferential distribution of the three types of ependymal endings (I, II, and III). The dotted area shows the location of the continuous ependymal cuff. LR, lateral extensions of the infundibular recess; LME, lateral region of median eminence; PT, pars tuberalis. Rectangle frames the area shown in (C). Left: 
$\alpha_{2}$ tanycytes penetrate into the arcuate nucleus, following a lateroventral trajectory (Millhouse, 1971) (Fig. 2B). The proximal segment of the basal process of $\alpha$ tanycytes, described as the neck region by Millhouse (1971), is thick and rough due to spinelike formations; the smooth distal part terminates into one or a few dilatations that contact blood capillaries of the medial basal hypothalamus (Bleier, 1971, 1972; Card and Rafols, 1978; Millhouse, 1971, 1975; Rodríguez et al., 1979). Whether or not the processes of $\alpha$ tanycytes end on neurons is a matter of controversy. In Golgi preparations, some authors have found the presence of such an ependymo-neuron contact (Bleier, 1971, 1972; Rodríguez et al., 1979), whereas others have not (Card and Rafols, 1978; Millhouse, 1971, 1975). Unfortunately, ultrastructural studies of this aspect are missing.

The cell bodies of $\beta_{1}$ tanycytes line the lateral extensions of the infundibular recess and their basal processes follow an archiform lateroventral trajectory to end in the vicinity of the portal capillaries located laterally in the median eminence (Figs. 1E, 2A-C, and 3A). None of these processes have been seen to end on a neuron (Rodríguez et al., 1979). The proximal segment of these processes is thick and rough due to spinelike formations; their smooth distal part terminates into a few short branches that contact the external limiting membrane of the brain (Fig. 2A, B). The cell bodies of $\beta_{2}$ tanycytes line the floor of the infundibular recess and their basal process is characterized by a smooth surface, straight trajectory, and a distal ramification formed by several thin, long, and parallel branches that contact the portal capillaries lying along the midline of the median eminence (Fig. 2A-C).

The morphological characteristics of tanycytes previously described have been confirmed and extended by immunocytochemical studies. Thus, antibodies against the glial fibrillary acidic protein (Redecker et al., 1987), vimentin (Leonhardt et al., 1987) (Fig. 2C), and a protein of $85 \mathrm{kDa}$

Perikaryon of a $\beta_{1}$ tanycyte. SP and LP, small and large ventricular protrusions, respectively; MV, microvilli; ER and SER, rough and smooth endoplasmic reticulum, respectively; G, Golgi complex; L, lipid droplets; R, ribosomes; F, filaments; T, microtubules; SP, small nerve profiles; $\mathrm{D}$, dendrite. Right: Proximal segment of the basal process of a $\beta_{1}$ tanycyte. Stars indicate spinelike structures. (B) Type I, II, and III ependymal endings. F, filaments; T, microtubules; SSC, smooth-surfaced cisternae; GR, granules; GY, glycogen; arrowhead, coated vesicle; short arrow, hemidesmosome; star, electron-dense tubules; NE, synaptoid contact. (From Rodríguez et al., 1979.) (C) Conventional transmission electron microscopy of the lateral region of the median eminence, showing the processes (large arrows) and terminals (EE) of $\beta_{1}$ tanycytes (for orientation see the inset at top left). The latter form a continuous layer separating the neurosecretory terminals (NE) from the portal capillaries. The NE establish synaptoid contacts with the preterminal portion of the tanycyte process (thick bent arrows). ELM, external limiting membrane of the brain. Original magnification: $\times 13,000$. Inset: High magnification of a synaptoid contact. At the presynaptic side (NE) the small vesicles appear embedded in a dense material. The arrow points to a dense projection. The synaptic space is widened and filled with an electron-dense material. Original magnification: $\times 60,000$. (From Rodríguez et al., 1979.) 


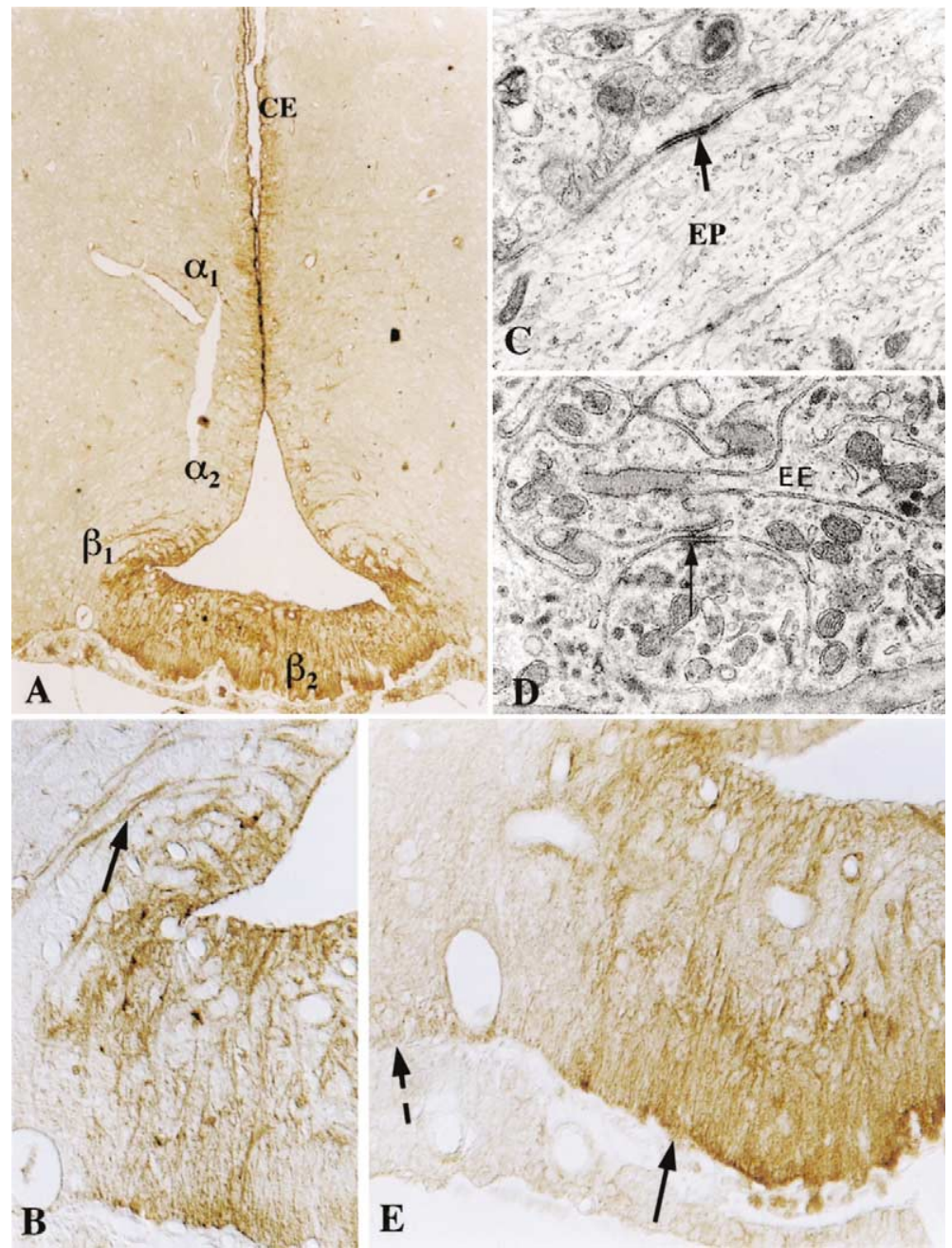

FIG. 4 Zonula adherens in tanycytes. (A) Immunocytochemistry for $\alpha$ catenin; $\beta_{1,2}$ tanycytes are strongly reactive throughout the cell processes and their endings. $\mathrm{CE}$, ciliated ependyma. Original magnification: $\times 85$. (B) Detailed magnification of (A), showing bundles of immunoreactive ependymal processes (arrow). Original magnification: $\times 300$. (C) Transmission electron microscopy of a bundle of ependymal processes (EP) of $\beta_{1}$ tanycytes displaying zonula (macula) adherens (arrow). Original magnification: $\times 16,000$. (D) Transmission electron microscopy showing zonula adherens (arrow) between ependymal endings (EE). Original magnification: $\times 20,000$. (E) Immunocytochemistry for $\mathrm{N}$-cadherin. The processes and endings of only $\beta_{2}$ tanycytes are reactive. Original magnification: $\times 370$. 
apparently specific to tanycytes (Blázquez et al., 2002) (Fig. 1A) immunostain tanycytes, revealing some differences between the tanycyte subtypes (see later discussion).

Early enzyme histochemical studies had shown that $\alpha$ tanycytes differ from $\beta$ tanycytes and react differently to adrenalectomy (Bock and Goslar, 1969; Goslar and Bock, 1970). A light and electron microscopic analysis of the distribution of adenosine triphosphatase has shown that this enzyme is abundant in the tanycytes facing the ventromedial nucleus ( $\alpha_{1}$ tanycytes) and is not detectable in the tanycytes facing the arcuate nucleus $\left(\alpha_{2}\right.$ tanycytes $)$ or those of the median eminence ( $\beta_{1,2}$ tanycytes) (Firth and Bock, 1976). By use of semiquantitative histochemical methods, Akmayev and coworkers have investigated the presence of several metabolic enzymes in the tanycytes of the rat under normal and experimental conditions. They found that in $\beta$ tanycytes the activity of glycerophosphate dehydrogenase, lactic dehydrogenase, and glucose-6-phosphate dehydrogenase is 1.5 to 3 times higher than that in $\alpha$ tanycytes (Akmayev et al., 1973). By using a similar technical approach, Akmayev and Fidelina (1976) reported that during the critical period of sexual differentiation of the rat hypothalamus (first postnatal week) $\beta_{1}$ tanycytes but not the other subtypes of tanycytes display sexual differences, with the metabolic activity higher in females than in males. Under conditions of reduced corticotrophic function (long-term administration of dexamethasone) the metabolic activity of both $\beta_{1}$ and $\beta_{2}$ tanycytes increases markedly, whereas under conditions of increased adrenocorticotropic hormone (ACTH) secretion (adrenalectomy) such metabolic activity is reduced (Akmayev and Fidelina, 1974).

Immunocytochemistry is contributing to a further characterization of the four types of tanycytes. Thus, $\alpha_{1,2}$ and $\beta_{1}$ tanycytes express the glucose transporter-1, whereas $\beta_{2}$ tanycytes do not (Peruzzo et al., 2000) (Fig. 1E). $\beta_{1}$, but not $\beta_{2}$, tanycytes express insulin-like growth factor-binding protein (Cardona-Gómez et al., 2000). Glutamate transporters GLT-1 and GLAST are differentially expressed by tanycytes (Fig. 1D); GLT-1 is expressed by $\alpha$ tanycytes and GLAST is preferentially expressed by $\beta$ tanycytes (Berger and Hediger, 2001). An antibody against the somatostatin sst 2 (a) receptor gives a strong immunoreaction in $\alpha$ tanycytes and a moderate reaction in $\beta$ tanycytes (Hashemi et al., 2001). Antibodies against molecular markers of the endocytotic and transcytotic pathways have revealed key differences between tanycyte subtypes (Peruzzo et al., 2004). Thus, $\beta_{2}$ tanycytes express caveolin-1 at the ventricular cell pole and at their terminals contacting the portal capillaries, $\beta_{1}$ tanycytes express this protein only at the terminals, and $\alpha_{1,2}$ tanycytes do not contain this protein. The antibody against Rab4 produces a strong reaction in the basal processes of $\beta_{2}$ tanycytes. Anti-Rab4 also reacted with the ependymal cells of the choroid plexus, but it did not react with $\alpha_{1,2}$ and $\beta_{1}$ tanycytes or the ciliated ependyma. 
Immunocytochemistry for junction proteins also reveals differences between tanycyte subtypes. $\beta_{1,2}$ tanycytes are strongly reactive for $\alpha$-catenin throughout the cell processes and their endings, $\alpha_{2}$ tanycytes are weakly or nonreactive, and $\alpha_{1}$ tanycytes are only reactive at the ventricular cell pole (Fig. 4A, B). Immunocytochemistry for $\mathrm{N}$-cadherin reveals that only the processes and endings of $\beta_{1}$ tanycytes are reactive (Fig. 4E).

\section{Ultrastructure}

There are numerous studies on the ultrastructure of the median eminence that include a description of tanycytes (Flament-Durand, 1978; Kobayashi et al., 1970; Leonhardt, 1966, 1980; Mestres, 1981; Rodríguez, 1969, 1972; Wittkowski, 1968, 1969). However, there are only two publications describing the ultrastructural characteristics of $\alpha$ and $\beta$ tanycytes (Akmayev and Popov, 1977; Rodríguez et al., 1979). Furthermore, whereas the fine structure of $\beta$ tanycytes has been described in detail (Akmayev and Popov, 1977; Rodríguez et al., 1979), that of $\alpha$ tanycytes is less well known and the only article dealing with them does not distinguish between $\alpha_{1}$ and $\alpha_{2}$ tanycytes (Akmayev and Popov, 1977).

\section{1. $\alpha$ Tanycytes}

The cell body of $\alpha$ tanycytes has a cylindrical shape with an ovoid nucleus displaying abundant euchromatin. The perikaryon and the supranuclear region contain the Golgi complex, poorly developed rough and smooth endoplasmic reticula, several mitochondria, numerous polyribosomes, and all the components of the endocytic machinery, namely, coated vesicles, early and late (multivesicular bodies) endosomes, and lysosomes. A few lipid inclusions may be found in the perikaryon and basal process (E. M. Rodríguez, J. L. Blázquez, F. E. Pastor, B. Peláez, P. Peña, B. Peruzzo, and P. Amat, unpublished observations). $\alpha$ tanycytes project to the ventricle microvilli and small bulbous protrusions containing a multivesicular body that, because of its structure, could correspond to late or recycling endosomes. They apparently lack cilia. Laterally they are joined together by zonula adherens, and tight junctions are missing (Akmayev and Popov, 1977; and E. M. Rodríguez, J. L. Blázquez, F. E. Pastor, B. Peláez, P. Peña, B. Peruzzo, and P. Amat, unpublished observations). The terminal regions of neighboring basal processes are joined together by tight junctions (Krisch et al., 1978). The proximal segment of the basal process presents lateral swellings (corresponding to the spines seen in the Golgi preparations) filled with polyribosomes. The process proper contains numerous mitochondria, microtubules, intermediate filaments, and tubular 
formations of the smooth endoplasmic reticulum. The terminal embracing blood capillaries is occupied by tubular structures of moderate electron density and electron-lucent and electron-dense vesicles (Brawer, 1972; and E. M. Rodríguez, J. L. Blázquez, F. E. Pastor, B. Peláez, P. Peña, B. Peruzzo, and P. Amat, unpublished observations).

\section{2. $\beta_{1}$ Tanycytes}

$\beta_{1}$ tanycytes line the lateral evaginations of the infundibular recess (Amat et al., 1998); they are cylindrical cells that have elongated nuclei lying at various levels, giving this region a stratified appearance. The apical cytoplasm and the perikaryon contain a well-developed Golgi apparatus, a few cisternae of the rough endoplasmic reticulum, abundant polyribosomes, numerous mitochondria, and the subcellular compartments of the endocytic pathway, namely, smooth and coated vesicles and early, late, and recycling endosomes, some of which are seen in apical protrusions lying in the ventricle (Akmayev and Popov, 1977; Rodríguez et al., 1979; Wittkowski, 1998). A distinct feature of $\beta_{1}$ tanycytes is the presence in the perikaryon of numerous and large lipid inclusions that are associated with a highly developed smooth endoplasmic reticulum (Rodríguez et al., 1979). Such an arrangement is found in cells involved in steroid or lipid synthesis or in lipid metabolism. Interestingly, enzymes involved in lipid metabolism have been histochemically demonstrated in these tanycytes (Akmayev et al., 1973; Bock and Goslar, 1969). $\beta_{1}$ tanycytes project to the ventricle numerous microvilli, small spherical protrusions containing endosomes, and large protrusions filled with polyribosomes (Rinne, 1966; Rodríguez et al., 1979; Wittkowski, 1967a,b) (Fig. 3A). The latter appear to undergo physiological variations (see Section VI.A). Laterally, $\beta_{1}$ tanycytes interdigitate extensively. The proximal segment of the basal process has an irregular outline due to several irregular spinelike protrusions that are filled with polyribosomes and that correspond to the spines seen in Golgi preparations (Fig. 3A). The possibility that this large accumulation of polyribosomes in the apical protrusions and in the spines could be related to the synthesis of cytosolic/nuclear receptors, such as estrogen receptors, is worth considering (see Section VI.B.1). The core of the proximal segment of the basal process is occupied by the Golgi apparatus, the smooth endoplasmic reticulum, microtubules, and filaments (Fig. 3A). The distal segment of the basal process has a rather uniform diameter and contains abundant polyribosomes, microtubules, intermediate filaments, and tubular structures with a content of low and moderate electron density (Fig. 3C).

Apically, $\beta_{1}$ tanycytes are joined by zonula adherens but tight junction are missing (Rodríguez et al., 1979). An amazing feature of $\beta_{1}$ tanycytes is that they are joined together by zonula and macula adherens localized throughout 
the lateral surface of the cell body, basal processes, and terminals, as it is revealed by transmission electron microscopy and immunocytochemistry for $\alpha$-catenin and $\alpha$-cadherin (Fig. 4A-D; and E. M. Rodríguez, J. L. Blázquez, F. E. Pastor, B. Peláez, P. Peña, B. Peruzzo, and P. Amat, unpublished observations). This unique feature, sheared by $\beta_{1}$ and $\beta_{2}$ tanycytes, may explain the formation of bundles of tanycyte processes (Fig. 4B, C) and suggests that the compartments of the median eminence delimited by these tanycytes have a high degree of stability. Still, the functional significance of this arrangement must be clarified.

According to the ultrastructure, three types of terminals of the basal process of $\beta_{1}$ tanycytes have been described. Type $I$ terminals (Fig. 3B) contains the elements known to be involved in endocytosis/transcytosis (Peruzzo et al., 2004; Rodríguez et al., 1979), namely, (1) tubular structures about $70-100 \mathrm{~nm}$ in diameter, with an electron-dense content (elongated region of recycling endosomes?); (2) tubular structures with an irregular outline, about $70-100 \mathrm{~nm}$ in diameter, with an electron-lucent content (smooth endoplasmic reticulum?); (3) multivesicular bodies connected to tubular structures (recycling endosomes); (4) smooth-surfaced vesicles, 130 $\mathrm{nm}$ in diameter; and (5) 130-nm vesicles with an external coat. The content of all types of vesicles and tubular structures bound concanavalin A (Con-A) and wheat germ agglutinin (WGA) (Peruzzo et al., 2004). In addition, these endings contain a few electron-dense granules of $100-130 \mathrm{~nm}$ in diameter and 170-nm vesicles with a coat on the lumenal side of the vesicle membrane that might correspond to secretory vesicles, numerous mitochondria, microtubules, filaments, and a few lipid droplets and glycogen particles (Fig. 3B). Type II endings are characterized by the presence of numerous electron-dense granules of 100-130 $\mathrm{nm}$ in diameter and short tubular formations of 100-130 $\mathrm{nm}$ in diameter with an electron-dense content (Rodríguez et al., 1979; Scott and Knigge, 1970) (Fig. 3B, C). Smooth-surfaced cisternae, filaments, mitochondria, and microtubules are abundant in the preterminal region (Fig. 3C). Type III terminals contain (1) several smooth-surfaced cisternae that are frequently arranged concentrically (Brawer, 1972; Rodríguez et al., 1979) (Fig. 3B); a similar structure present in the ependymal cells of the bovine subcommissural organ has been shown to correspond to the rough endoplasmic reticulum (Pérez et al., 1995); (2) granules of different sizes filled with a filamentous material; and (3) glycogen particles (Fig. 3B). All types of terminals are joined together by macula adherens (E. M. Rodríguez, J. L. Blázquez, F. E. Pastor, B. Peláez, P. Peña, B. Peruzzo, and P. Amat, unpublished observation) and to the external limiting membrane of the brain by hemidesmosomes (Rodríguez et al., 1979).

The terminals of $\beta_{1}$ tanycytes, in particular types II and III, localize in the lateral region of the median eminence where they form a continuous cuff that separates the nerve terminals (GnRH fibers; see Section VI.B.1) from 
the external limiting membrane of the brain. In turn, the latter separates the ependymal cuff from the perivascular space of the portal capillaries (Rodríguez et al., 1979). This ependymal cuff is present in all regions of the median eminence with the exception of the medial region of the preinfundibular median eminence (Rodríguez et al., 1979; Figs. 3A, C and 8C), matching exactly the distribution of the GnRH fibers and terminals (Baker et al., 1975; Krisch, 1978; Sétáló et al., 1975). The GnRH fibers may contact the basal process of $\beta_{1}$ tanycytes throughout its trajectory (Fig. 8A), but they appear to terminate only on the preterminal portion of these processes (Figs. 3C and 8B, C), establishing synaptoid contacts (Fig. 8C). No other regions of these basal processes display synaptoid contacts; this may explain their lack of immunoreactivity to an antibody against synaptic vesicles (Fig. 5A).

\section{3. $\beta_{2}$ Tanycytes}

Elongated $\beta_{2}$ tanycyte perikarya line the floor of the infundibular recess. The apical cytoplasm projects microvilli and contains coated pits, coated vesicles $100 \mathrm{~nm}$ in diameter, smooth-surfaced vesicles about $130 \mathrm{~nm}$ in diameter, vacuoles of about $250 \mathrm{~nm}$ (early endosomes?), multivesicular bodies (late endosomes), and numerous electron-lucent tubular formations with an irregular outline and oriented parallel to the free cell surface (recycling endosomes?). Several cisternae of the rough endoplasmic reticulum are present in the apical region and perikaryon. The Golgi complex is formed by several elongated cisternae located in the proximal segment of the basal process and oriented parallel to the axis of the process. Coated vesicles and smoothsurfaced vesicles, structures most likely corresponding to late and common endosomes, several smooth-surfaced tubular structures, filaments, microtubules, and numerous lipid droplets and glycogen particles are present throughout the process (Akmayev and Popov, 1977; Peruzzo et al., 2004; Rinne, 1966; Rodríguez et al., 1979). The terminals of $\beta_{2}$ tanycytes have an ultrastructure similar to that of the type I terminal of $\beta_{1}$ tanycytes; these terminals localize in the medial region of the preinfundibular region of the median eminence; here, groups formed by a few terminals are joined together by macula adherens and establish contact with the external limiting membrane of the brain; in between these groups of terminals, peptidergic and aminergic nerve terminals also contact the external limiting membrane of the brain, which separates the tanycyte and axon terminals from the portal capillaries lying in this region of the median eminence.

Two distinct ultrastructural characteristics of $\beta_{2}$ tanycytes are (1) apically, they are joined together by zonula adherens and tight junctions (Fig. 7B) (Brightman and Reese, 1969; Rinne, 1966); and (2) the basal process receives numerous synaptoid contacts throughout its length (Fig. 5A, D) 

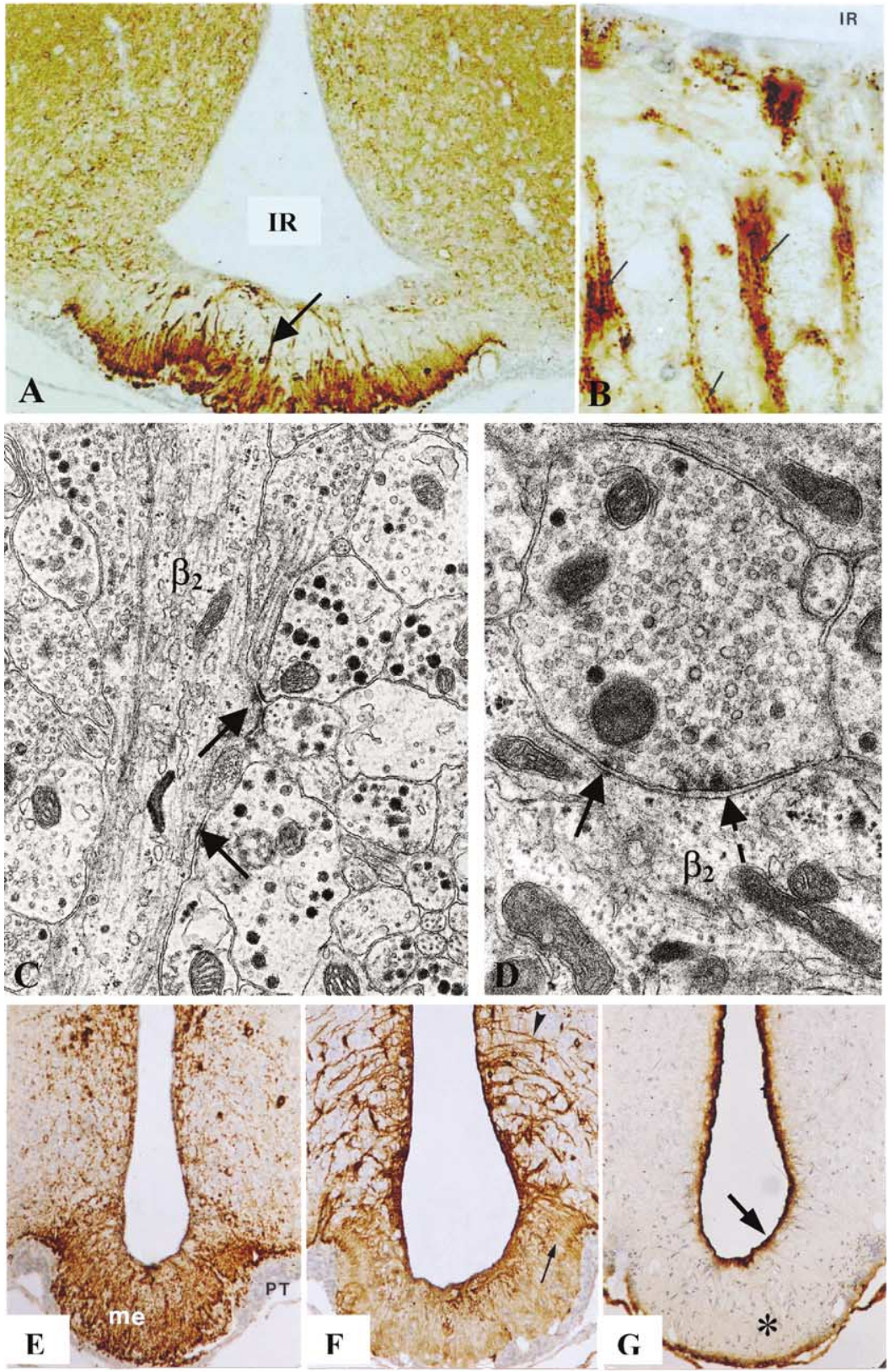

FIG. 5 (A) Immunocytochemistry to reveal synaptic vesicles. The basal process of $\beta_{2}$ tanycytes displays reactive terminals on their surfaces, but $\alpha_{1,2}$ and $\beta_{1}$ tanycytes do not. Original magnification: $\times 100$. (B) Detailed magnification of (A), showing the immunoreactive terminals on the surface of the ependymal processes (arrows). IR, infundibular recess. Original 
(Akmayev and Popov, 1977; Kobayashi et al., 1970; Rodríguez et al., 1979; Wittkowski, 1972).

\section{Functional Differences Between Tanycyte Subtypes}

Although the functions of tanycytes have been clarified only partially, some relevant functional differences between the four subtypes of tanycytes have been found. Thus, $\alpha_{1,2}$ tanycytes do not have barrier properties, whereas $\beta_{1}$ tanycytes establish a barrier between the arcuate nucleus and the median eminence (Réthelyi, 1984), and $\beta_{2}$ tanycytes form a barrier between the CSF and the neuropil of the median eminence (Brightman et al., 1975; Rodríguez et al., 1982; Weindl and Joynt, 1972; see Section IV.B). The intercellular space of $\alpha_{1,2}$ and $\beta_{1}$ tanycytes is permeable to horseradish peroxidase injected into the ventricle, whereas $\beta_{2}$ tanycytes prevent the diffusion of this tracer into the neuropil of the median eminence (Brightman et al., 1975; Rodríguez et al., 1982). Similarly, $\alpha_{1,2}$ and $\beta_{1}$ tanycytes express the glucose transporter-1 whereas $\beta_{2}$ tanycytes do not (Peruzzo et al., 2000). $\beta_{1}$ but not $\beta_{2}$ tanycytes express insulin-like growth factor-binding protein (Cardona-Gómez et al., 2000). $\beta_{1,2}$ tanycytes express caveolin-1 at the ventricular cell pole and at their terminals contacting the portal capillaries, but $\alpha_{1,2}$ tanycytes do not contain this protein, suggesting that caveola-dependent endocytosis does not occur in the latter (Peruzzo et al., 2004). Although all tanycyte subtypes internalize wheat germ agglutinin injected into the CSF, $\alpha_{1}$ and $\beta_{1,2}$ tanycytes transport the tracer along their basal processes, whereas $\alpha_{2}$ tanycytes do not (Peruzzo et al., 2004).

Apparently, only $\alpha_{2}$ tanycytes retain the property to serve as neuron progenitors (see Section VII). The basal processes of $\beta_{1}$ tanycytes, but not that of the other tanycyte subtypes, have the property to generate large cisterns that localize preferentially at their terminals (Akmayev et al., 1973; Blázquez et al., 2002; Brion et al., 1982; Peruzzo et al., 2000); consequently, these cisterns concentrate at the lateral regions of the median eminence (Bodoky et al., 1979; see Section VI.B.5).

magnification: $\times 500$. (C) Synaptoid contacts between neurosecretory endings and the basal process of $\beta_{2}$ tanycytes (arrows). Original magnification: $\times 20,000$. (D) Fine structure of a synaptoid contact. Broken arrow, dilatation of the synaptic space; full arrow, electron densities in the presynaptic and postsynaptic cytoplasm. Original magnification: $\times 40,000$. (E-G) Organ culture of the rat median eminence for $4 \mathrm{~h}$ in the presence of wheat germ agglutinin. Although the dopamine neurons of the arcuate nucleus and their endings in the median eminence (ME) (E) and GLUT-1-immunoreactive tanycytes (F) are well preserved, tanycytes do not transport the lectin along their processes. Original magnification: $\times 60$. 
There are also important differences in the neuron-tanycyte relationships. $\beta_{1,2}$ tanycytes are innervated by peptidergic and aminergic neurons; at variance, $\alpha_{1,2}$ tanycytes appear to lack innervation (Akmayev et al., 1973; Rodríguez et al., 1979; see Section III.E). A solid body of evidence (see Section VI.B) associates $\beta_{1}$ tanycytes with the mechanism of release of $\mathrm{GnRH}$ from the terminals of the GnRH neurons to the portal blood (Blázquez et al., 2002; Hökfelt, 1973; King and Rubin, 1994; Ojeda and Ma, 1998; Ojeda et al., 1990, 1992, 1997; Prevot et al., 1999, 2003; Rodríguez et al., 1982, 1985; Wittkowski, 1998).

\section{E. Nervous Control of Tanycytes}

Specialized contacts between nerve fibers and tanycytes have been described as synaptoid contacts (Güldner and Wolff, 1973). These contacts are characterized by an accumulation in the presynaptic cytoplasm of small clear and electron-dense vesicles embedded in an electron-dense matrix and a wide synaptic cleft filled with a fine electron-dense material. The lack of postsynaptic densities has also been described as a characteristic of these contacts (Güldner and Wolff, 1973; Rodríguez et al., 1979; Wittkowski, 1998); however, they may be found in some of these neuron-tanycyte contacts (Fig. 5C, D). Although several authors have described synaptoid contacts on tanycytes (Amat et al., 1985; Güldner and Wolff, 1973; Knigge and Scott, 1970; Kobayashi and Matsui, 1967; Scott and Knigge, 1970; Scott and Paull, 1979; Wittkowski, 1967b), none of them have distinguished the type of tanycyte receiving the neural input. Rodríguez et al. (1979) have reported that whereas the basal process of $\beta_{2}$ tanycytes displays synaptoid contacts throughout its length, $\beta_{1}$ tanycytes receive synaptoid contacts only at the preterminal portion of the basal process. The use of an antibody specific for synaptic vesicles demonstrates the dense innervation of $\beta_{2}$ tanycytes and the apparent lack of terminals on the processes of the other types of tanycytes (Fig. 5A, B; E. M. Rodríguez, J. L. Blázquez, F. E. Pastor, B. Peláez, P. Peña, B. Peruzzo, and P. Amat, unpublished observation). No synaptoid contacts on $\alpha$ tanycytes have been described in any of the publications dealing with tanycytes. Thus, a rich neural input may be regarded as a distinct characteristic of $\beta_{2}$ tanycytes.

The functional significance of the synaptoid contacts between GnRH neurons and the processes of $\beta_{1}$ tanycytes are discussed extensively in Section VI.B. However, the significance of the rich neural input to $\beta_{2}$ tanycytes is puzzling. The nature of the neurotransmitter and/or peptide present in the terminals contacting $\beta_{2}$ tanycytes is not known. There is some evidence that some of the terminals innervating $\beta_{2}$ tanycytes are monoaminergic 
(Calas, 1975; Kobayashi et al., 1970). Evidence obtained from experiments of deafferentation of the medial basal hypothalamus indicates that such a monoaminergic input participates in the regulation of the absorptive function of $\beta$ tanycytes (Kobayashi et al., 1975; Nozaki, 1975; Nozaki et al., 1975). This is in agreement with results obtained with organ culture of the medial basal hypothalamus; under these conditions the arcuate neurons and all tanycytes remain intact (Fig. 5E, F; and E. M. Rodríguez, J. L. Blázquez, F. E. Pastor, B. Peláez, P. Peña, B. Peruzzo, and P. Amat, unpublished observation), thus resembling the hypothalamic islands obtained by deafferentation (Scott and Knigge, 1970). If the lectin wheat germ agglutinin is added to the culture medium for $4 \mathrm{~h}$ all tanycytes internalize the lectin into the apical cytoplasm but they do not transport it along their basal process (Fig. 5G), as they do in the living rat (see Section V.C). Several days after transplantation of the rat median eminence into the anterior chamber of the eye, tanycytes display an accumulation of "pleomorphic vesicles" in their terminals that was interpreted as increased secretory activity or altered transport (Dellmann, 1977).

Certainly, in light of all the information about neuron-glia crosstalk (Bezzi and Voltera, 2001; Carmignoto, 2000), the neuron-tanycyte relationship deserves to be revisited.

\section{Barrier Properties of Tanycytes}

In the CNS there are discrete periventricular areas, known as circumventricular organs (Hofer, 1958), in most of which the blood-brain barrier (BBB) is missing. These brain windows serve two purposes, namely, to allow brain hormones to reach the blood stream and to allow neural tissue to censor the plasma. The median eminence of the hypothalamus is one of these brain windows through which peptides and monoamines secreted by hypothalamic neurons reach the portal circulation (Leonhardt, 1980). The amazing design is that the perikaryon and a long segment of the axon of these neurons are localized in areas under the protection of the BBB, whereas the terminal segment and the terminal proper of the axon are localized in an area lacking a $\mathrm{BBB}$. This results in a compartmentalization of the intercellular space of the median eminence, allowing it to behave as a canal lock, with inlet and outlet gates. Thus, neurohormones can reach the intercellular and perivascular space by axonal transport but are prevented from traveling back either to the ventricular CSF or to the intercellular space of the neighboring arcuate nucleus. This design allows neurons of the CNS to secrete into the blood stream without making the BBB leaky. Tanycytes, in particular $\beta_{1}$ and $\beta_{2}$ types, play a key role in the formation of these barrier systems. 

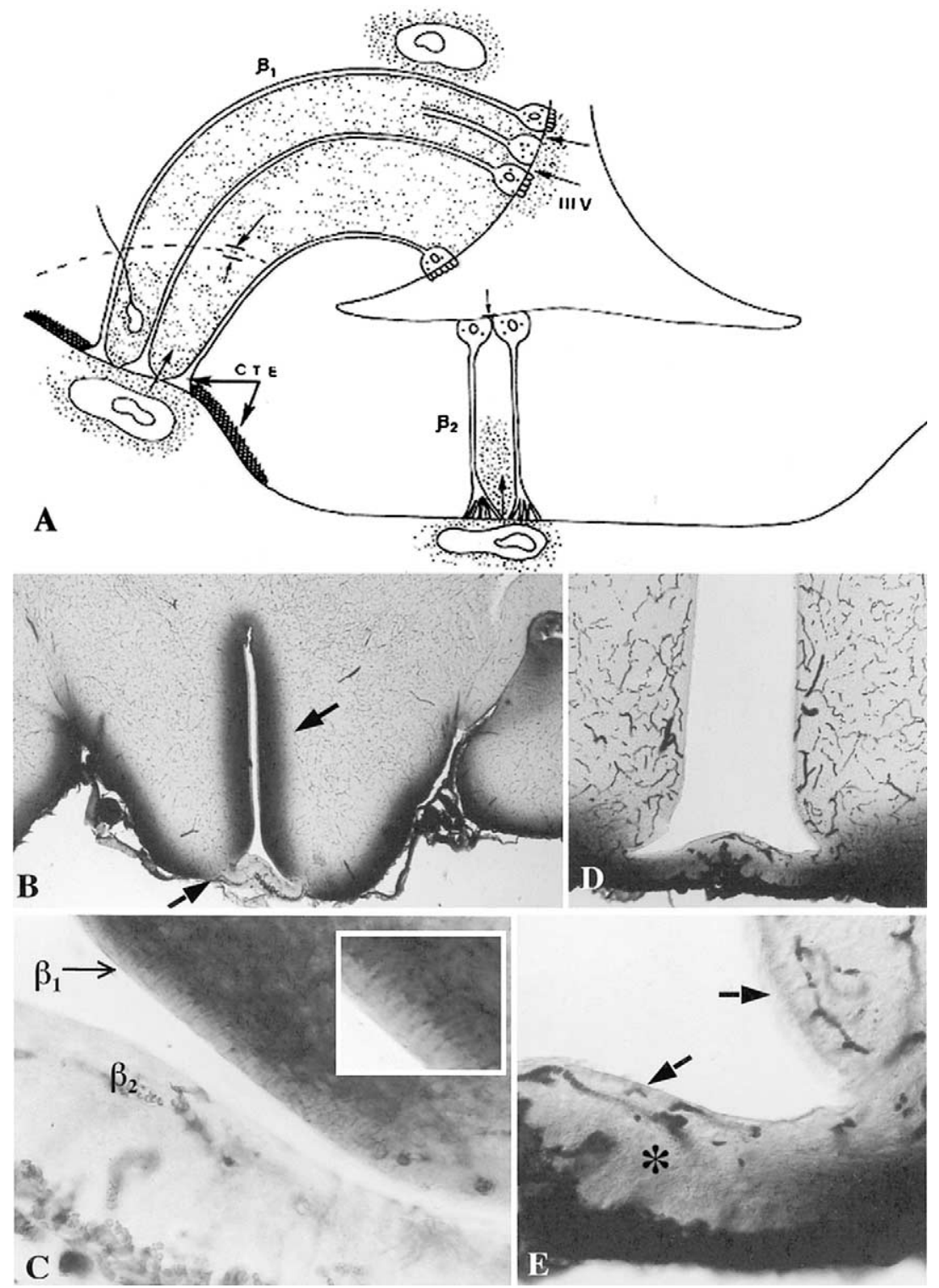

FIG. 6 Distribution of horseradish peroxidase (HRP) injected into a lateral ventricle (B and C) or into the cisterna magna (D and E). (A) Schematic representation of the routes followed by HRP. When injected into the ventricle, the tracer does not penetrate through the layer of $\beta_{1}$ tanycytes (small arrow) but it does penetrate through the intercellular space of $\alpha_{1,2}$ and $\beta_{1}$ tanycytes (long arrows) to reach the neuropil of the arcuate nucleus up to a region close to the median eminence, at which point it does not progress any further (two facing arrows). When injected into the subarachnoid space, HRP reaches the lateral region of the median eminence 
The median eminence is a compartment with a dorsal aspect bathed by the ventricular CSF, a ventral aspect exposed to the perivascular space of the portal capillaries and to the subarachnoidal CSF, and two lateral aspects establishing a border with the hypothalamus.

\section{A. Exposure of the Median Eminence Milieu to the Perivascular Space of the Portal Vessels and Subarachnoid CSF}

Tracers administered intravenously escape from the portal capillaries into the perivascular space and readily reach the intercellular space of the median eminence (Brightman et al., 1975; Broadwell et al., 1987). This indicates that plasma compounds can escape from the fenestrated portal capillaries, reach the intercellular space of the median eminence, and be confined there because of the CSF-median eminence and arcuate nucleus-median eminence barriers (see later discussion).

Tracers injected into the subarachnoidal CSF reach the perivascular space of the portal capillaries and the intercellular space of the median eminence, indicating that the median eminence milieu is also in open communication with the subarachnoidal CSF (Peruzzo et al., 2000) (Fig. 6A, D, and E). However, Krisch et al. (1983) have proposed that such communication does not exist. This discrepancy and the evidence presented by several authors supporting the existence of such a communication have been discussed extensively by Peruzzo et al. (2000). To elucidate this point is important, because such a communication has some relevant implications: (1) neurotransmitters and neuropeptides released at the perivascular space of the portal vessels by hypothalamic neurons (and tanycytes?) could reach the local subarachnoidal CSF; (2) compounds present in the subarachnoidal CSF could enter the portal circulation; and (3) blood-borne substances would

through the ependymal cuff (CTE) formed by $\beta_{1}$ tanycytes, and into the medial region of the median eminence through the layer of nerve and ependymal endings of $\beta_{2}$ tanycytes. (B) HRP injected into the lateral ventricle penetrates the walls of the third ventricle (full large arrow) but not the floor (median eminence) (broken large arrow); it also reaches the brain tissue from the subarachnoid space. Original magnification: $\times 30$. (From Rodríguez et al., 1982.) (C) Detailed magnification of (B). HRP penetrates through the intercellular space of $\alpha_{1,2}$ and $\beta_{1}$ tanycytes but not between $\beta_{2}$ tanycytes. Original magnification: $\times 225$. Inset: HRP localized in the intercellular space of tanycytes is visible. Original magnification: $\times 500$. (D) When injected into the cisterna magna, HRP reaches the subarachnoid space but not the ventricles; it penetrates the brain tissue from the subarachnoid space. Original magnification: $\times 30$. (E) Some HRP present in the subarachnoid space reaches the neuropil of the median eminence where a ventrodorsal gradient can be seen (asterisk), but it does not reach the layer of $\beta_{1,2}$ tanycytes (arrows). Original magnification: $\times 100$. (See also color insert.) 
reach not only the median eminence milieu but also the local subarachnoidal CSF.

The tracers present in the perivascular space of the portal capillaries enter not only the medial region of the median eminence, where ependymal and nerve endings are intermingled, but also the neuropil of the lateral regions through the cuff formed by the terminals of $\beta_{1}$ tanycytes (Peruzzo et al., 2000). This leads to an important conclusion, namely, the ependymal cuff does not function as a barrier between the GnRH fibers and the portal capillaries, allowing the free movement of compounds between the space around the nerve terminals and the space around the portal vessels. This supports the view that $\beta_{1}$ tanycytes participate actively in the mechanism of GnRH release rather than behaving as a plastic barrier (see Sections VI.B.3 and VI.B.4).

\section{B. $\beta_{2}$ Tanycytes Establishing a Barrier Between Median Eminence Milieu and Ventricular CSF}

Horseradish peroxidase (HRP) injected into the ventricular CSF enters the hypothalamus, but it does not enter the median eminence because of the tightness of the tanycyte layer (Brightman et al., 1975; Peruzzo et al., 2000; Reese and Brightman, 1968; Rodríguez et al., 1982; Weindl and Joynt, 1972) (Fig. 6A-C). The possibility that the tight junctions between $\beta_{2}$ tanycytes may be leaky has been considered by Pilgrim (1978) and by Broadwell et al. (1987). Ultrastructural immunocytochemistry using an antibody against a tight junction-associated protein has shown that the median eminence tanycytes are joined by continuous, unbroken junctions (Petrov et al., 1994). In an investigation involving the use of HRP under various experimental designs, Peruzzo et al. (2000) have reported that intraventricularly injected HRP, regardless of the postinjection interval, does not traverse the tight junctions of $\beta_{2}$ tanycytes, but is visualized in the median eminence as a ventrodorsal gradient of peroxidase reaction product, similar to that found after intracisternal injection of the tracer. This indicates that HRP injected intraventricularly can rapidly and readily reach the median eminence milieu through the subarachnoidal CSF. An alternative route for compounds present in the ventricular CSF to reach the intercellular space of the median eminence is through transependymal transport. This is especially evident when cationic ferritin is administered into the ventricular CSF; in the apical cytoplasm of $\beta_{2}$ tanycytes ferritin is seen within pinocytic vesicles connected to the apical plasma membrane and to the lateral plasma membrane, and clusters of ferritin particles are seen below the tight junction (Fig. 7B).

The ventrodorsal gradient of peroxidase reaction product in the intercellular space of the median eminence, which is patent even 15 min after HRP 
injection, as well as after the intracisternal administration of HRP (Fig. 6D and E), could be an indication that there is a dorsoventral bulk flow of intercellular fluid toward the perivascular space of the portal vessels. If this were the case, blood-borne and subarachnoidal CSF-borne molecules gaining access to the median eminence milieu would be pushed back to the perivascular space.

\section{C. $\beta_{1}$ Tanycytes Establishing a Lateral Barrier Separating the Median Eminence and Arcuate Nucleus Neuropils}

When used at certain doses and postinjection intervals, HRP injected into the ventricle readily gains access to the intercellular space of the arcuate nucleus without reaching the median eminence (Brightman et al., 1975; Rodríguez et al., 1982; Weindl and Joynt, 1972) (Fig. 6A-C). At variance, HRP injected intravenously strongly labels the median eminence but does not pass to the arcuate nucleus (Brightman et al., 1975; Broadwell et al., 1987; Krisch et al., 1983). These findings strongly suggested that a barrier between the arcuate nucleus and the median eminence should exist. This assumption was further substantiated by the finding that HRP injected directly into the arcuate nucleus does not enter the median eminence (Réthelyi, 1984). In all cases, labeling of the intercellular space suddenly stopped at both sides of the median eminence, exactly at the site of location of $\beta_{1}$ tanycytes and their basal processes. Thus, $\beta_{1}$ tanycytes became a good candidate to be involved in the barrier mechanism between the median eminence and the arcuate nucleus. Indeed, tight junctions between tanycyte processes located in the lateral region of the median eminence have been reported by freeze-etching studies (Krisch et al., 1978).

Findings have further supported these barrier properties of $\beta_{1}$ tanycytes. The glucose transporter-1 (GLUT-1) is a good marker of the BBB (Pardridge et al., 1990). In the median eminence GLUT-1 is missing from the portal capillaries but is present throughout the whole plasma membrane of $\beta_{1}$ tanycytes, further indicating that these cells contribute to the lateral barrier of the median eminence (García et al., 2001; Peruzzo et al., 2000) (Fig. 1E). Furthermore, the postnatal development of GLUT-1 immunoreactivity of tanycytes parallels that of the lability of arcuate neurons to monosodium glutamate treatment (Peruzzo et al., 2000). Indeed, maximal damage of the arcuate neurons occurs when monosodium glutamate is administered during the first postnatal week (Olney, 1971; Perez and Olney, 1972; Peruzzo et al., 2000), a period when GLUT-1 immunoreactivity of $\beta_{1}$ tanycytes is barely detectable. The possibility must be considered that, at this time, the median eminence-arcuate nucleus barrier is not yet developed, thus allowing monosodium glutamate borne from portal vessels to gain access to the arcuate 

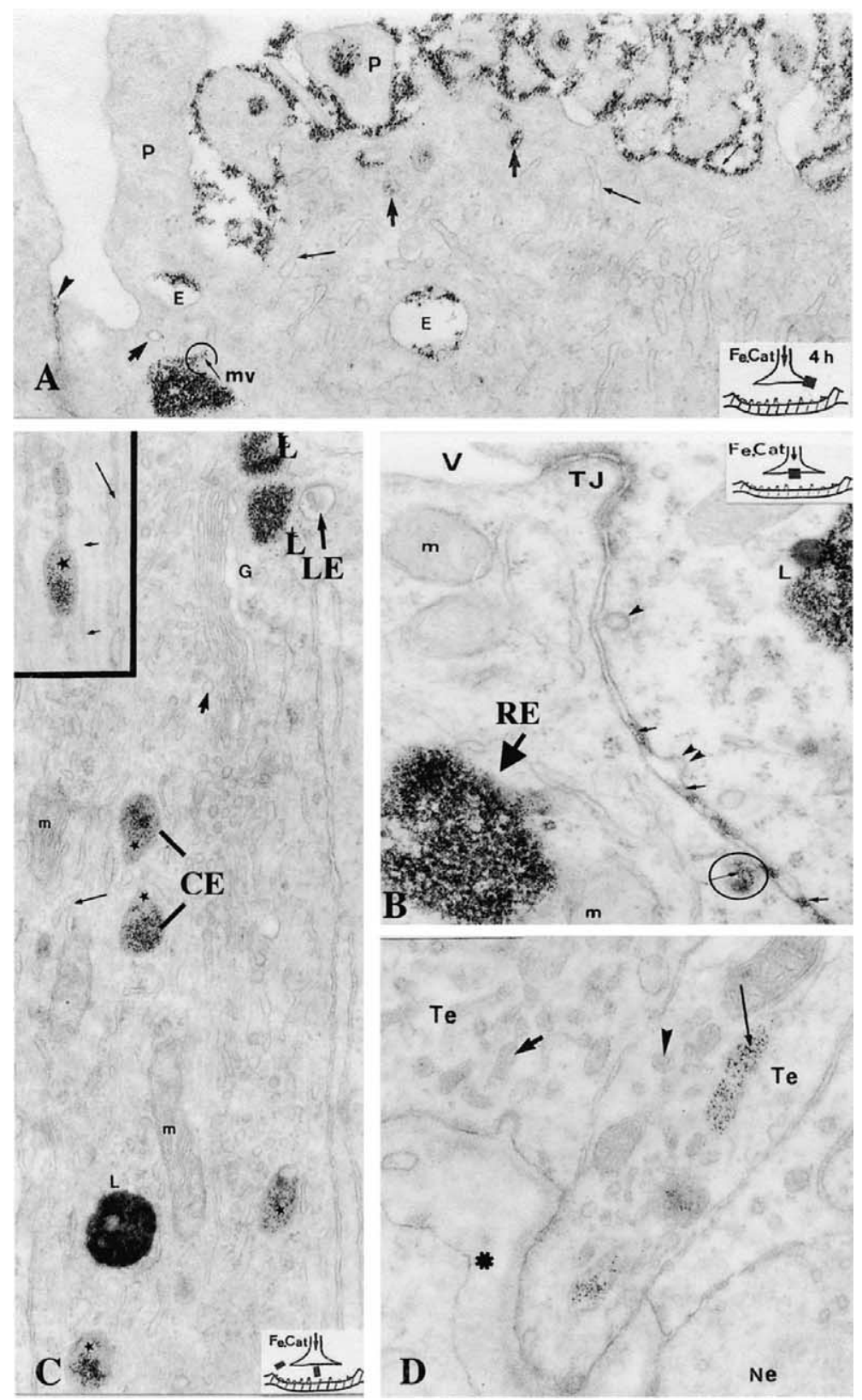

FIG. 7 Polarized transcytosis in tanycytes. Internalization and transport of cationic ferritin $4 \mathrm{~h}$ after its administration in a lateral ventricle. (A) Ferritin is bound to most but not all regions of the apical plasma membrane, and it is incorporated into apical vesicles (short arrows) and early (E) and late (mv) endosomes. P, protrusions into the ventricle; arrowhead, some ferritin in the 
nucleus. Once the tanycytic median eminence-arcuate nucleus barrier is fully developed, around the fourth postnatal week, the systemic administration of monosodium glutamate does not affect the arcuate nucleus (Peruzzo et al., 2000). Thus, all the evidence indicates that, in rats older than 1 month, a median eminence-arcuate nucleus barrier does occur. This raises the question of how axons penetrate this barrier without making it leaky.

Another important aspect of the median eminence-arcuate nucleus barrier concerns the vasculature. According to Duvernoy (1972), vessels of the arcuate nucleus communicate with the portal capillaries. If this were the case, the communicating vessels should, at a given point, have a sealed perivascular space protecting the arcuate nucleus from the median eminence milieu that is exposed to the blood stream (Krisch et al., 1978). Peruzzo et al. (2000) have found that capillaries endowed with an endothelium expressing GLUT-1 extend between the arcuate nucleus and the subependymal layer of the lateral region of the median eminence (territory of $\beta_{1}$ tanycytes), and that they do not seem to communicate with portal vessels. Consequently, there would not be communication between the wide perivascular space of the portal capillaries and the intercellular space around the arcuate nucleus vessels.

\section{Polarized Endocytosis and Transcytosis}

As discussed in Section III, $\beta$ tanycytes connect two functionally separated compartments, namely, the ventricular CSF and the perivascular space of the portal capillaries. $\beta$ tanycytes, thus, appear as distinctly polarized cells. Such cell polarity is strongly supported by the ultrastructural organization of these

apical region of the intercellular space; thin arrows, rough endoplasmic reticulum. Original magnification: $\times 35,000$. Inset: Drawing indicating with a black rectangle the area from which this picture was obtained. (B) Apical region of two $\beta_{2}$ tanycytes, showing the presence of tight (TJ) and adherent junctions and the presence of ferritin in the intercellular space below these junctions (small arrows) in areas where coated vesicles (arrowheads) are connected to the lateral plasma membrane. $\mathrm{RE}$, recycling endosome; $\mathrm{m}$, mitochondrion; $\mathrm{V}$, ventricle. Original magnification: $\times 37,000$. Inset: Drawing indicating with a black rectangle the area from which this picture was obtained. (C) Proximal segment of a cell process of a $\beta_{2}$ tanycyte. Ferritin is concentrated into late endosomes (LE) and common endosomes (CE, stars) and in lysosomes (L) located in the vicinity of the Golgi apparatus $(G)$. Original magnification: $\times 20,000$ Inset: Detailed magnification of a common endosome (star) loaded with ferritin. Small arrows, microtubules; long arrow, smooth-surfaced tubular formation (recycling endosome?). Original magnification: $\times 30,000$. (D) Fine structure of $\beta$ tanycyte terminals (Te); in one terminal ferritin is located within endosomes (recycling endosomes?) (long arrow); other structures, such as vesicles, do not contain ferritin (arrowhead). The other terminal contains electron-dense tubular structures (short arrow) and is devoid of ferritin. Asterisk, perivascular space; $\mathrm{Ne}$, nerve ending. Original magnification: $\times 20,000$. 
cells (Section III.C). The use of tracer molecules and of labeled biologically active substances administered into the ventricle indicates that $\beta$ tanycytes have the capacity to absorb substances present in the CSF (Bjelke and Fuxe, 1993; Brightman et al., 1975; Broadwell et al., 1987; Kendall et al., 1972; Knigge and Silverman, 1972; Kobayashi et al., 1972; Peruzzo et al., 2000, 2004; Rodríguez, 1972). This absorptive capacity of tanycytes develops early during perinatal life (Ugrumov and Mitskavich, 1980). Whether the substances absorbed through the apical pole of $\beta$ tanycytes are actually transported along their basal processes to reach the terminals, and if so, whether they are released to the perivascular space, have been the subject of debate and controversy (Broadwell et al., 1987; Flament-Durand and Brion, 1985; Pilgrim, 1978; Rodríguez, 1976).

The availability of molecular markers of the endocytic and transcytotic pathways and of tracer molecules that follow specific endocytic mechanisms has made it possible to reinvestigate the controversial problem of the transport capacity of tanycytes (Peruzzo et al., 2004).

\section{A. Differential Expression of Proteins Involved in Endocytosis and Transcytosis}

The absorption of molecules from the cell exterior may be mediated by clathrin-dependent or caveolin-dependent endocytosis (Miaczynska and Zerial, 2002; Nichols and Lippincott-Schwartz, 2001). After endocytosis, cargoes reach early endosomes from where they may either sequentially reach the late endosomes (multivesicular bodies) lysosomes and be degraded, or may be sorted to common endosomes. From the latter, cargo molecules may be sorted (1) back to the plasma membrane, (2) to the trans-Golgi network, or (3) to the apical or basal recycling endosome, from where they are released to the cell exterior (transcytosis) (Miaczynska and Zerial, 2002; Mostov et al., 2000; Rojas and Apodaca, 2002; Tuma and Hubbard, 2003; Van der Goot and Gruenberg, 2002). Clathrin and caveolin are distinct molecular markers of the two best known endocytotic and transcytotic pathways.

The following evidence indicates that the different types of tanycytes appear to use different mechanisms to internalize cargo molecules: (1) Clathrin is detected in the four types of tanycytes; however, its subcellular distribution in $\alpha_{1,2}$ and $\beta_{1}$ tanycytes is different with respect to that of $\beta_{2}$ tanycytes; (2) caveolin-1 is abundant in the ciliated ependyma of the ventricular walls, the choroid plexus, and in $\beta_{2}$ tanycytes, but it is missing from $\alpha_{1,2}$ tanycytes (Peruzzo et al., 2004); (3) there is differential expression of other proteins involved in the endocytotic pathways, such as ARF6 and Rab4; of particular interest is the high expression of the latter in $\beta_{2}$ tanycytes; 
and (4) although the four types of tanycytes internalize (endocytosis) the lectin WGA injected into the ventricular CSF, $\alpha_{1}$ and $\beta_{1,2}$ tanycytes transport this cargo molecule along their basal process, whereas $\alpha_{2}$ tanycytes do not (Peruzzo et al., 2004). Thus, transport along the basal processes and accumulation at their terminals of the WGA internalized at the apical cell pole constitute a specialized mechanism (transcytosis?) of only $\alpha_{1}$ and $\beta_{1,2}$ tanycytes.

\section{B. Caveola- and Clathrin-Mediated Endocytosis/Transcytosis in $\beta$ Tanycytes}

Caveolin-1 is distinctly present in the apical and basal (terminal) cell poles of $\beta_{2}$ tanycytes, but in $\beta_{1}$ tanycytes it is localized in the terminals only. This suggests that $\beta_{1,2}$ tanycytes perform caveola-mediated endocytosis at their terminals contacting the portal capillaries, and that only $\beta_{2}$ tanycytes, in addition, carry out caveola-mediated endocytosis at their ventricular cell pole. The possibility that endocytosis occurs in the terminals of $\beta_{1,2}$ tanycytes is further supported by the presence in these terminals of (1) multivesicular bodies with and without connection to tubular structures, now known as early and late endosomes, respectively (Van der Goot and Gruenberg, 2002; Miaczynska and Zerial, 2002); (2) tubular structures with an electrondense content that binds Con-A and WGA, that could correspond to recycling endosomes (Mostov et al., 2000), and (3) the strong immunoreaction with anti-Rab4. Rabs are GTP-binding proteins that act as membrane domain organizers of the endocytotic pathway (Miaczynska and Zerial, 2002). Early and recycling endosomes are rich in Rab4 (Miaczynska and Zerial, 2002).

What is the nature of the compound(s) being internalized through caveolamediated endocytosis from the portal perivascular space into the terminals of $\beta_{1,2}$ tanycytes or from the CSF into the apical cytoplasm? Although most endocytosed cargo via caveolae is fluid, certain compounds enter caveolae via specific receptors (Tuma and Hubbard, 2003). Indeed, several membrane receptors and membrane transporters have been localized in caveolae (Nichols and Lippincott-Schwartz, 2001). Potential candidates to be internalized by tanycytes via caveolae are those compounds known to be endocytosed by other cells through a nonclathrin mechanism, such adenosine, angiotensin, and dopamine (Nichols and Lippincott-Schwartz, 2001). There is evidence that tanycytes internalize dopamine by a receptor-mediated mechanism. Scott et al. (1974) have shown that $\left[{ }^{3} \mathrm{H}\right]$ dopamine infused into the ventricular CSF is selectively absorbed by tanycytes and transported along the basal processes. A dopamine- and cyclic AMP-regulated phosphoprotein of $32 \mathrm{kDa}$ (DARPP-32) is present both in neurons bearing dopamine 
D-1 receptors (Hökfelt et al., 1988) and in tanycytes (Everitt et al., 1986; Fekete et al., 2000; Hökfelt et al., 1988; Meister et al., 1988). Further evidence of the presence of dopamine D-1 receptor in tanycytes has been provided by Bjelke and Fuxe (1993).

Clathrin-coated membranes and pits are negatively charged whereas caveolae are not; this allows cationic molecules to be preferentially bound and internalized through the former, whereas anionic molecules are included in the fluid internalized by caveolae (Tuma and Hubbard, 2003). Thus, the internalization by $\beta_{1,2}$ tanycytes of cationic ferritin injected into the ventricle should occur through clathrin-mediated endocytosis (Fig. 7A, B; and E. M. Rodríguez, J. L. Blázquez, F. E. Pastor, B. Peláez, P. Peña, B. Peruzzo, and P. Amat, unpublished observation). The presence of ferritin within coated vesicles located in the vicinity of the apical plasma membrane strongly supports this possibility. There is also a good body of evidence indicating that the lectin WGA administered into the ventricular CSF is internalized by tanycytes through clathrin-mediated and not through caveolin-mediated endocytosis (Peruzzo et al., 2004).

\section{Functional Polarity of $\beta$ Tanycytes}

Compounds that are internalized via clathrin-dependent endocytosis would enter $\beta$ tanycytes only through the ventricular cell pole. Indeed, clathrin is present in the ventricular cell pole and is virtually absent in the basal (terminal) cell pole. The strong evidence for the polarity of $\beta$ tanycytes results from the administration of WGA into the ventricle and into the subarachnoid space; $\beta$ tanycytes incorporate WGA through their ventricular cell pole but not through their terminals, although the lectin was indeed available to the tanycyte terminals as shown by the fact that the neighboring nerve terminals of the median eminence did incorporate WGA (Peruzzo et al., 2004).

Clathrin-mediated endocytosis is regarded as receptor-mediated endocytosis (Nichols and Lippincott-Schwartz, 2001; Rojas and Apodaca, 2002; Tuma and Hubbard, 2003). Several plasma membrane receptors have been detected in tanycytes. Interestingly, the ligands of most of these receptors have been immunocytochemically detected in the hypothalamic tanycytes (Table I; see Section II.B).

The case of IGF-I deserves special consideration; tanycytes display IGF-I receptors (Cardona-Gómez et al., 2000), contain immunoreactive IGF-I (Dueñas et al., 1994; García-Segura et al., 1991, 1996) (Fig. 1B), but do not have IGF-I mRNA (Fernández-Galaz et al., 1997), thus indicating that the peptide is absorbed but not synthesized by tanycytes. At the ultrastructural level IGF-I receptors have been localized at the apical (ventricular) 
plasma membrane of tanycytes (Cardona-Gómez et al., 2000); when IGF-I is administered into the CSF it is internalized by tanycytes (Fernández-Galaz et al., 1996). Because the IGF-I levels in tanycytes undergo variations with the estrous cycle in normal female rats, and in castrated rats they are dose dependent on estrogens (Dueñas et al., 1994), the authors have concluded that tanycytes incorporate IGF-I either from blood or CSF, under the influence of estrogens. The functional polarity of tanycytes (see previous discussion) suggests that they incorporate IGF-I from the ventricular CSF and not from blood, via clathrin-mediated endocytosis. Whether tanycytes internalize those ligands for which they display membrane receptors, such as fibroblast growth factor, transforming growth factor- $\alpha$, prolactin, and glutamate (see Section II.B), must be investigated. Conversely, it would be interesting to investigate in tanycytes the presence of receptors for those compounds shown to be internalized by tanycytes after their administration into the CSF, such as GnRH (Goldgefter, 1976; Knigge et al., 1976) and $\beta$-endorphin (Bjelke and Fuxe, 1993).

\section{Fate of Molecules Endocytosed by $\beta$ Tanycytes}

Both the ultrastructural characteristics of the cytoplasm of $\beta_{1,2}$ tanycytes and the subcellular localization within these tanycytes of WGA and cationic ferritin incorporated from the ventricular CSF indicate that both tracers are internalized by coated vesicles, and are then found in smooth-surfaced vesicles, most likely corresponding to coated vesicles denuded of clathrin, and in early endosomes (Fig. 7A, B). Considering (1) the distribution of WGA and cationic ferritin throughout the tanycyte, and (2) all the information concerning endocytosis and transcytosis (Rojas and Apodaca, 2002; Tuma and Hubbard, 2003), it may be suggested that from the early endosome both tracers are sorted through two endocytotic pathways, one leading to degradation and the other to transcytosis. A third possible pathway through the trans-Golgi network would operate for WGA (Peruzzo et al., 2004) but not for cationic ferritin (E. M. Rodríguez, J. L. Blázquez, F. E. Pastor, B. Peláez, P. Peña, B. Peruzzo, and P. Amat, unpublished observation). In the degradative pathway WGA and ferritin are sorted from early to late endosomes (multivesicular body) and then to lysosomes.

In the transcytosis pathway part of the WGA and ferritin present in the apical early endosome would be routed toward the basal process into vacuoles connected to tubular structures that, according to Mostov et al. (2000) and Rojas and Apodaca (2002), correspond to common endosomes (Fig. 7C). The fate of cargoes after exit from the common endosome is controversial, but recycling endosomes are the best candidate (Rojas and Apodaca, 2002). In the tanycyte terminals, WGA and ferritin are found 
in tubules with an electron-dense content and within smooth-surfaced vesicles; both structures might correspond to recycling endosomes (Fig. 7D). This is further supported by the strong immunoreaction of the tanycyte terminals with anti-Rab4; indeed, recycling endosomes are enriched in Rab4 (Miaczynska and Zerial 2002). In the CNS the strong immunoreactivity of $\beta$ tanycytes to anti-Rab4 is matched only by the choroid plexus (Peruzzo et al., 2004), whose specialized ependyma is actively involved in transcytosis.

In brief, WGA and ferritin injected into the ventricle are internalized by tanycytes, and after being sorted through various membranous compartments, part of them is transported along the basal processes and stored at their terminals. We do not know whether these molecules are finally released to the perivascular space. However, as an exogenous tracer, WGA is most likely revealing a transcytotic pathway followed by endogenous compounds present in the CSF under physiological conditions. An alternative is that WGA, because of its affinity for sialoglycoproteins, is actually depicting the route followed by CSF molecules that, through receptor-mediated endocytosis, are specifically internalized by tanycytes, transported along the basal process, and stored at the terminal where they would perform their physiological activity, that is, to facilitate release of neuropeptides into the portal system. This seems to be the case for IGF-I that is absorbed and accumulated by tanycytes (see previous discussion) and when administered it releases GnRH from the axon terminals of the median eminence (Hiney et al., 1996).

It is well established that cells discriminate between cargo destined to degradation in lysosomes from that undergoing transcytosis (Tuma and Hubbard, 2003). How to explain that a single compound such as WGA follows both pathways? A likely explanation is that WGA, as a lectin, binds to several sialoglycoconjugates corresponding to receptors, transporters, or other compounds located in the clathrin pits, some of which will follow the degradative pathway while others are sorted to the transcytotic pathway.

Transcytosis would occur not only along the basal process of tanycytes but through a small portion of the apical cytoplasm. Indeed, cationic ferritin injected into the ventricle may be seen within vesicles that are close to or opening into the intercellular space located below the junctional complexes (Fig. 7B). A similar route had been described for HRP injected into the ventricle (Nakai and Naito, 1975). This "short" transcytosis pathway resembles that operating in the choroid plexus.

An important observation from the transport experiments is that most but not all $\beta$ tanycytes transport WGA and ferritin along their basal processes. Tanycyte terminals containing membrane-bound structures carrying the tracers coexist with tanycyte terminals devoid of tracer but displaying 
tubules and vesicles with an electron-dense content (Fig. 7D). Do the latter correspond to secretory tanycytes?

\section{Synthetic Activities of Tanycytes}

\section{A. Secretion of Biologically Active Compounds}

The projection by tanycytes of bulbous protrusions into the ventricle, and variations in the number and size of such protrusions under various endocrine states, have led several authors to regard this as an evidence of a secretory activity of tanycytes (Flament-Durand and Brion, 1985). However, substantial evidence that tanycytes do secrete into the CSF is missing.

There are tanycyte terminals, in particular type II and III terminals of $\beta_{1}$ tanycytes, that contain rough endoplasmic reticulum and numerous tubular structures and vesicles with an electron-dense content (Fig. 3C; Section III.C). These ultrastructural characteristics might reflect a secretory activity of peptides/proteins at this level (Peruzzo et al., 2004; Rodríguez, 1969; Rodríguez et al., 1979; Scott and Knigge, 1970). Dellmann (1977) has reported an increase in the granulated vesicles of the tanycyte terminals after median eminence grafting and suggested that this might be the expression of increased secretory activity or of decreased release.

Worth mentioning is the fact that many of the tanycytes displaying ultrastructural secretory features do not transport WGA or cationic ferritin (Fig. 7D; see Section V), suggesting a division of labor among tanycytes, with only some of them being secretory.

Findings point to certain compounds as secretory products of tanycytes. Ojeda and colleagues have shown that estrogen stimulates tanycytes to sequentially synthesize and secrete transforming growth factor- $\alpha$ and then prostaglandin $\mathrm{E}_{2}$, which in turn stimulates $\mathrm{GnRH}$ release (Ojeda and $\mathrm{Ma}$, 1998; Ojeda et al., 1990, 1992, 1997). Furthermore, the use of conditioned medium of cultured hypothalamic astrocytes-tanycytes has shown that these cells secrete a still-enigmatic compound that potentiates the stimulatory effect of prostaglandin $\mathrm{E}_{2}$ on GnRH release (Ma et al., 1997). The exceptionally high number of large lipid inclusions present only in $\beta$ tanycytes and their close association with a well-developed smooth endoplasmic reticulum (Rodríguez et al., 1979; see Section III) could be a reflection of the property of these cells to secrete prostaglandin $E_{2}$. The functional significance of estrogens on the secretory activity of tanycytes is further supported by the presence in these cells of estrogen receptors (Langub and Watson, 1992). Tanycytes express the transforming growth factor- $\beta$, type I (Prevot et al., 
2000), the release of which is, in turn, stimulated by prostaglandin $E_{2}$ (Prevot et al., 2003).

Blázquez et al. (2002) have detected in tanycytes two compounds of 85 and $60 \mathrm{kDa}$ and have concluded they correspond to two novel proteins selectively synthesized by tanycytes. The reduction in the amount of immunoreactive $85-$ and $60-\mathrm{kDa}$ compounds in median eminence extracts of castrated rats suggests that synthesis and/or release of these tanycyte proteins may be under the influence of ovarian hormones (Blázquez et al., 2002). Some evidence points to the possibility that the $85-$ and $60-\mathrm{kDa}$ compounds are involved in the tanycyte-GnRH neuron communication (Blázquez et al., 2002; see Section VI.B).

\section{B. Tanycytes and the Release of Gonadotropic Hormone-Releasing Hormone}

The location and spatial relationships of tanycytes, their ultrastructural organization, their transport capacity, and their changes under different endocrine states, in particular those related to sexual activity (estrous and menstrual cycles, castration, estrogen treatment, etc.), led early authors to advance the possibility that hypothalamic tanycytes play a role in the control of pituitary function (Akmayev et al., 1973; Brawer et al., 1974; FlamentDurand and Brion, 1985; Kendall et al., 1972; Knigge and Scott, 1970; Knigge and Silverman, 1972; Knowles and Kumar, 1969; Kobayashi et al., 1972; Kumar, 1968; Leveque and Hofkin, 1961; Löfgren, 1959, 1960; Mestres and Jaeschke, 1977; Rodríguez, 1969a,b; Scott and Knigge, 1970; Scott et al., 1974; Vaala and Knigge, 1974). The presence of GnRH in the CSF of various species (Matsubara et al., 1988; Skinner et al., 1995; Uemura et al., 1981), its fluctuations with the estrous cycle (Skinner et al., 1995), and the observations that GnRH administered into the CSF is incorporated by tanycytes (Goldgefter, 1976; Knigge et al., 1976), reaches the portal circulation and adenohypophysis (Ben-Jonathan et al., 1974; Porter et al., 1975), and stimulates luteinizing hormone (LH) release (Ondo et al., 1973) led several authors to postulate that under physiological conditions tanycytes may transport GnRH from CSF to portal blood. This early hypothesis has not been further substantiated and has remained as a proposition that deserves to be revisited. However, a possibility that is being thoroughly investigated is the probable involvement of tanycytes in the release of GnRH from the axon terminals to the portal blood (Flament-Durand and Brion, 1985; García-Segura et al., 1999; Rodríguez et al., 1982, 1985; Wittkowski, 1998).

Tanycytes appear to participate in the release of GnRH through two different mechanisms. One of them implies the transient and cyclic remodeling of the spatial relationship between the GnRH terminals, the tanycyte 
processes, and the perivascular space. The second manner of tanycyteGnRH neuron communication would be through cell-cell signaling mechanisms mediated by specific compounds. The most recent evidence not only supports the existence of both mechanisms, but also the possibility that they are part of a single mechanism (Prevot, 2002).

\section{Tanycyte-GnRH Neuron-Portal Capillary Relationship}

In all vertebrates reproductive functions are regulated by $\mathrm{GnRH}$, a decapeptide synthesized and released by a group of neurons located in the rostral hypothalamus. In mammals these neurons project principally to the median eminence, where their axon terminals contact the pericapillary space of the portal capillaries. GnRH neurons are under the influence of multiple neuronal systems that regulate their secretory activity via the synaptic release of neurotransmitters and neuropeptides (Gore and Roberts, 1997).

It was early established that hypothalamic GnRH nerve fibers and their endings are concentrated mainly in the lateral regions of the median eminence, and in the medial region of the postinfundibular median eminence (Baker et al., 1975; Barry and Dubois, 1976; Barry et al., 1973; King et al., 1974) (Figs. 8A and 12A), exactly matching the distribution of $\beta_{1}$ tanycytes (Rodríguez et al., 1979). Indeed, these fibers and their endings are in close association with the basal processes of $\beta_{1}$ tanycytes rather than contacting directly the perivascular space (Kozlowski and Coates, 1985; Meister et al., 1988) (Fig. 8B, C). Thus, although the fate of GnRH is the portal blood, most GnRH endings are separated from the perivascular space by a continuous cuff formed by the tanycyte terminals (Rodríguez et al., 1979) (Figs. 3A, C and 8C). This peculiar arrangement, which is missing in other neurohemal regions of the median eminence, led Rodríguez et al. (1979) to wonder whether this ependymal cuff actually behaves as a barrier or as a cellto-cell arrangement facilitating GnRH release. These findings and the existence of synaptoid contacts between GnRH fibers and tanycytes (Kozlowski and Coates, 1985) (Fig. 8C) led some authors to postulate that the ependymal cuff is a dynamic structure that, under certain physiological conditions, changes its spatial organization to allow GnRH terminals to establish direct contact with the limiting membrane of the brain (Rodríguez et al., 1979; Kozlowski and Coates, 1985).

The close spatial GnRH fiber-tanycyte relationship is further shown in the experiment performed by Silverman et al. (1991). These authors studied the outgrowth of GnRH axons from fetal preoptic tissue transplanted into host mutant hypogonadal mouse median eminence, and found that glial processes (possibly tanycytic) provide a permissive substrate for axonal guidance to their termination on the portal vasculature. Amazingly, in this experimental model, the axon terminals were surrounded by tanycyte 


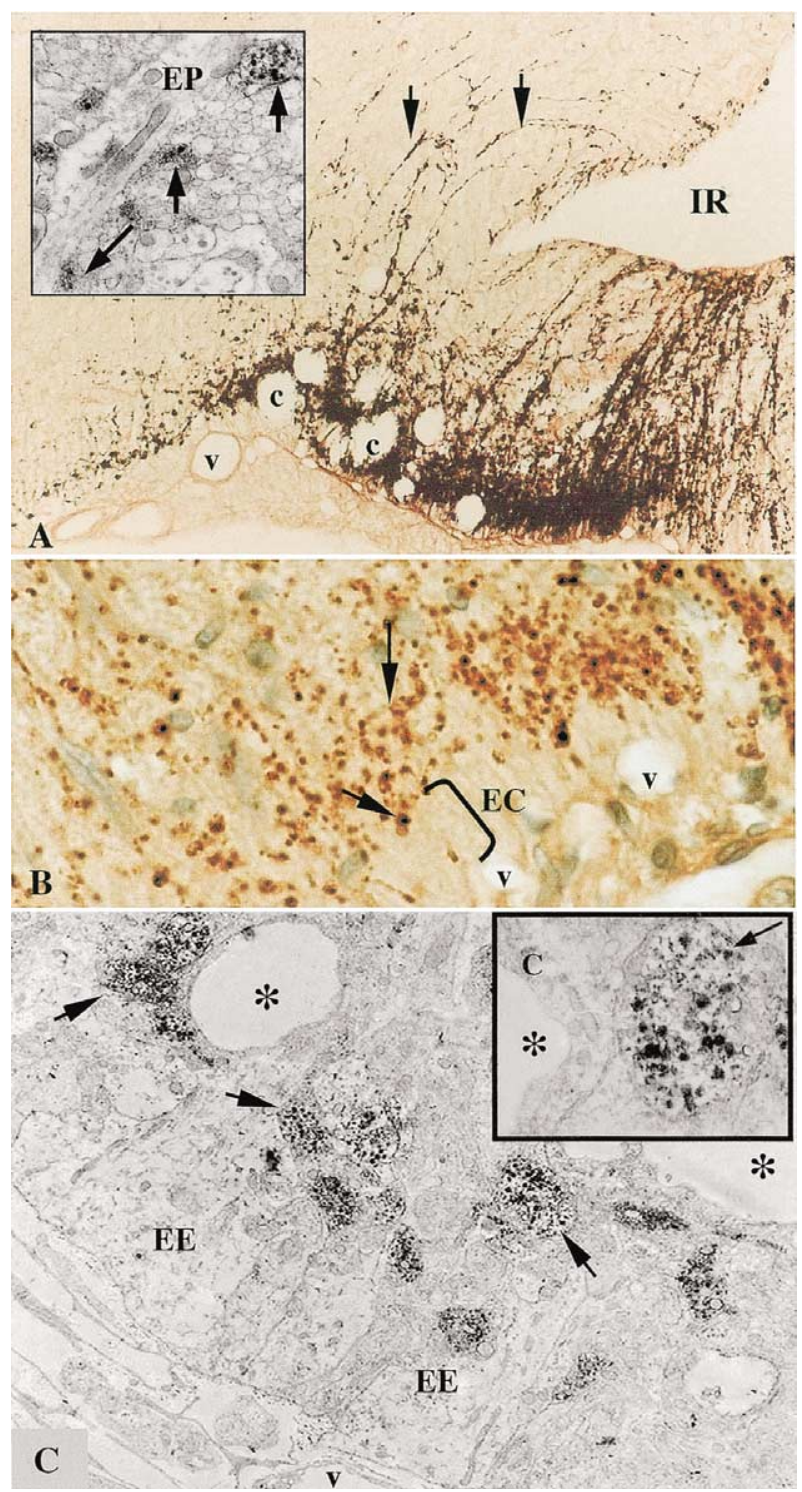

FIG. 8 (A) Immunocytochemistry for GnRH. The reactive nerve fibers (arrows) codistribute with $\beta_{1}$ tanycytes, establishing a close spatial relationship, as shown by ultrastructural immunocytochemistry (inset). IR, infundibular recess; c, cisterns; v, portal vessel. Original magnification: $\times 170$. Inset: Ultrastructural immunocytochemistry for GnRH. Labeled axon profiles (arrows) contact a basal process of a tanycyte (EP). Original magnification: $\times 8000$. (B) The GnRH fibers (arrows) terminate on the ependymal cuff of $\beta_{1}$ tanycytes (EC) and do not contact the perivascular space of the portal capillaries (v). Original magnification: $\times 1200$. 
end feet that prevented them from making contact with the perivascular space.

\section{Remodeling Theory}

$\mathrm{GnRH}$ is released into the portal blood in a pulsatile fashion; this pattern requires the simultaneous activation of most or all $\mathrm{GnRH}$ terminals to release their neuropeptide. The cellular and molecular mechanism responsible for the pulsatile release of GnRH is not known. GnRH neurons could be coordinated at the level of the cell bodies or at the level of the axon terminals (Moenter et al., 2003). Median eminence explants, lacking GnRH cell bodies, display some features of $\mathrm{GnRH}$ episodic release (Rasmussen, 1993). This and other findings indicate that the synchronization mechanism operates at the median eminence level (Moenter et al., 2003; Rasmussen, 1993).

The remodeling theory postulates that the transient and cyclic changes in the spatial relationship between the GnRH terminals and the tanycyte processes leads to a retrieval of the tanycyte terminals during proestrus or after castration, thus facilitating the release of this hormone into the portal blood (Hökfelt, 1973; King and Rubin, 1994, 1995; Prevot et al., 1999; Wittkowski, 1998). Which changes are actually occurring in the spatial relationship between GnRH terminals and $\beta_{1}$ tanycytes is a matter of controversy. Schiebler et al. (1978) have reported that after castration, glial surface area in the external zone increased by $23 \%$, and Rodríguez et al. (1979) reported that 7 and 30 days after ovariectomy the ependymal cuff remains an "efficient anatomical barrier." More recently, King and Letourneau (1994) have investigated, in intact males and females and after gonadectomy, the distance between the GnRH-immunopositive terminals and the perivascular basal lamina; they found that this distance was almost twice as large in intact males as compared with that in diestrous females. In castrated males, the shortest distance was observed on day 1 after the operation, whereas in females the shortest distance between GnRH terminals and basal lamina was observed 6 days after ovariectomy. These authors concluded that the architecture of the median eminence could result from the local concentration of factors produced by neuronal or nonneuronal elements. Studies of the plastic changes occurring in the external zone of the median eminence throughout the rat estrous cycle have shown that in proestrus $12 \%$ of

(C) Ultrastructural immunocytochemistry for GnRH, showing the termination of the GnRH fibers (arrows) on the ependymal cuff (EE) and the presence in this area of the large cisterns (asterisks). V, portal capillary. Original magnification: $\times 5000$. Inset: Synaptoid contact between a GnRH fiber (arrow) and the preterminal region of a tanycyte process containing a large cistern (asterisk). C, cytoplasm surrounding the cistern. Original magnification: $\times 12,000$. 
GnRH nerve terminals make physical contact with the parenchymatous basal lamina (i.e., the pericapillary space) whereas in diestrus II no contacts were observed (Prevot, 2002; Prevot et al., 1999). The authors suggested that these changes might involve both GnRH axon growth and tanycytic process withdrawal, but could also imply endothelium outgrowth. These findings and the presence of estrogen receptors in tanycytes (Langub and Watson, 1992) give support to the view of King and Rubin $(1994,1995)$ that gonadal steroids, by acting on glial elements (tanycytes), may regulate access of GnRH terminals to the basal lamina and influence the amount of peptide reaching the portal blood.

In a search for the molecules responsible for the plastic changes occurring in the lateral region of the median eminence, Prevot et al. (2003) have found that transforming growth factor (TGF) $-\alpha$ and TGF- $\beta_{1}$ display opposite effects on tanycyte plasticity in vitro. TGF- $\alpha$ promotes tanycytic outgrowth whereas TGF- $\beta_{1}$ elicits retraction of tanycytic processes. Although prolonged exposure of tanycytes to TGF- $\alpha$ results in tanycytic retraction, this effect is abolished by immunoneutralization of TGF- $\beta_{1}$, indicating that the retraction may be due to induction of TGF- $\beta_{1}$ formation by TGF- $\alpha$.

The capacity of tanycytes to incorporate and accumulate insulin growth factor-I (Fernández-Galaz et al., 1996) and the fact that this capacity is under the influence of ovarian hormones (see later discussion) have led to the suggestion that this compound is involved in the cyclic plastic changes of tanycytes (García-Segura et al., 1999).

Although a certain degree of functional plasticity in the spatial arrangement of GnRH terminals and tanycyte terminals may be taken as a fact, more substantial evidence is needed to accept that retrieval of tanycyte terminals is indeed a requirement for the GnRH released from the nerve terminals to gain access to the portal blood. This rather mechanistic view is challenged by findings showing that tanycytes generate molecular signals promoting GnRH release both in vivo and in vitro (see later discussion), and by the fact that large molecules can freely move between the intercellular space around the GnRH fibers and the perivascular space, through the intercellular space of the ependymal cuff (Peruzzo et al., 2000; see Section IV.A) (Fig. 6A).

\section{Tanycyte-GnRH Neuron Signaling Theory}

Several observations indicate that hypothalamic glial cells, in particular tanycytes, may modulate the activity of GnRH neurons through the release of signaling molecules. The most important principles released by these cells, and that appear to be responsible for such effects, are TGF- $\alpha$, TGF- $\beta_{1}$, TGF- $\beta_{2}$, basic fibroblast growth factor (bFGF), and IGF-I. These compounds represent a complementary mode of control of GnRH secretion, 
which is also regulated by steroid hormones and by neuronal inputs to the cell body (Galbiati et al., 2003; Marchetti, 1997; Melcangi et al., 2001, 2002).

TGF- $\alpha$ is a member of a family of growth factors that also includes epidermal growth factor (EGF) and neuregulins (NRGs). The proteins of this family have the ability to activate membrane-associated tyrosine kinases linked to the EGF receptor (EGFR), also known as ErbB-1 (Melcangi et al., 2002). However, whereas TGF- $\alpha$ binds directly to ErbB-1, NRG binds preferentially to ErbB-3 and ErbB-4 (Buonnano and Fischbach, 2001). Tanycytes express TGF- $\alpha$ and EGF receptors (Ma et al., 1994a,b; Ojeda and Ma, 1999). The tanycyte-GnRH neuron communication, via a cell-cell signaling mechanism, is strongly supported by the finding that estrogen stimulates tanycytes to sequentially synthesize and secrete TGF- $\alpha$ and then prostaglandin $\mathrm{E}_{2}$, which in turn stimulates $\mathrm{GnRH}$ release (Ma et al., 1997; Melcangi et al., 2001, 2002; Ojeda and Ma, 1998; Ojeda et al., 1990, 1992, 1997). On the other hand, ErbB-1, ErbB-2, and ErbB-3 are expressed by tanycytes (Prevot et al., 2003; Steiner et al., 1999), and the activation of these receptors by neuregulins triggers the release of prostaglandin $\mathrm{E}_{2}$ and then the secretion of GnRH (Ma et al., 1999). The effects of neuregulins and TGF- $\alpha$ on GnRH release appear to be synergistic. Worth mentioning is the observation that cultured hypothalamic astrocytes-tanycytes secrete into the conditioned medium a compound, not yet identified, that potentiates the stimulatory effect of prostaglandin $\mathrm{E}_{2}$ on GnRH release (Ma et al., 1997).

TGF- $\beta$ belongs to a family of potent cytokines involved in many biological processes. TGF- $\beta$ signaling is based on three cell surface receptors that bind with high-affinity TGF- $\beta$ ligands; they are named type I-III receptors (Bottner et al., 2000). The participation of TGF- $\beta_{1}$ and TGF- $\beta_{2}$ in the mechanism controlling the release of $\mathrm{GnRH}$ has been demonstrated in vitro. The release of GnRH from GT1 cells, a neuron cell line secreting $\mathrm{GnRH}$, is increased when they are cocultured with rat astrocytes or after their exposure to the conditioned medium of this kind of glial cell. The treatment of GT1 cells with TGF- $\beta_{1}$ (Melcangi et al., 1995) or TGF- $\beta_{2}$ (Messi et al., 1999) stimulates GnRH release. Furthermore, cultured tanycytes respond to TGF- $\alpha$ releasing prostaglandin $\mathrm{E}_{2}$ and the latter, in turn, increases the release of TGF- $\beta_{1}$ (Prevot et al., 2003).

It has also been established that IGF-I is involved in the regulation of GnRH neurons (Hiney et al., 1996; Zhen et al., 1997). In the mediobasal hypothalamus, IGF-I is localized in tanycytes (Dueñas et al., 1994); however, tanycytes do not synthesize this factor but incorporate it, most likely, from the CSF (see Section V.C). Tanycytes express IGF-I receptor (García-Segura et al., 1997) and IGF-I-binding protein-2 (Cardona-Gómez et al., 2000). The tanycyte content of IGF-I shows sex differences; in females, it fluctuates in parallel with the plasma levels of ovarian steroids. In particular, a peak in IGF-I immunoreactivity levels is observed in tanycytes on the day of the 

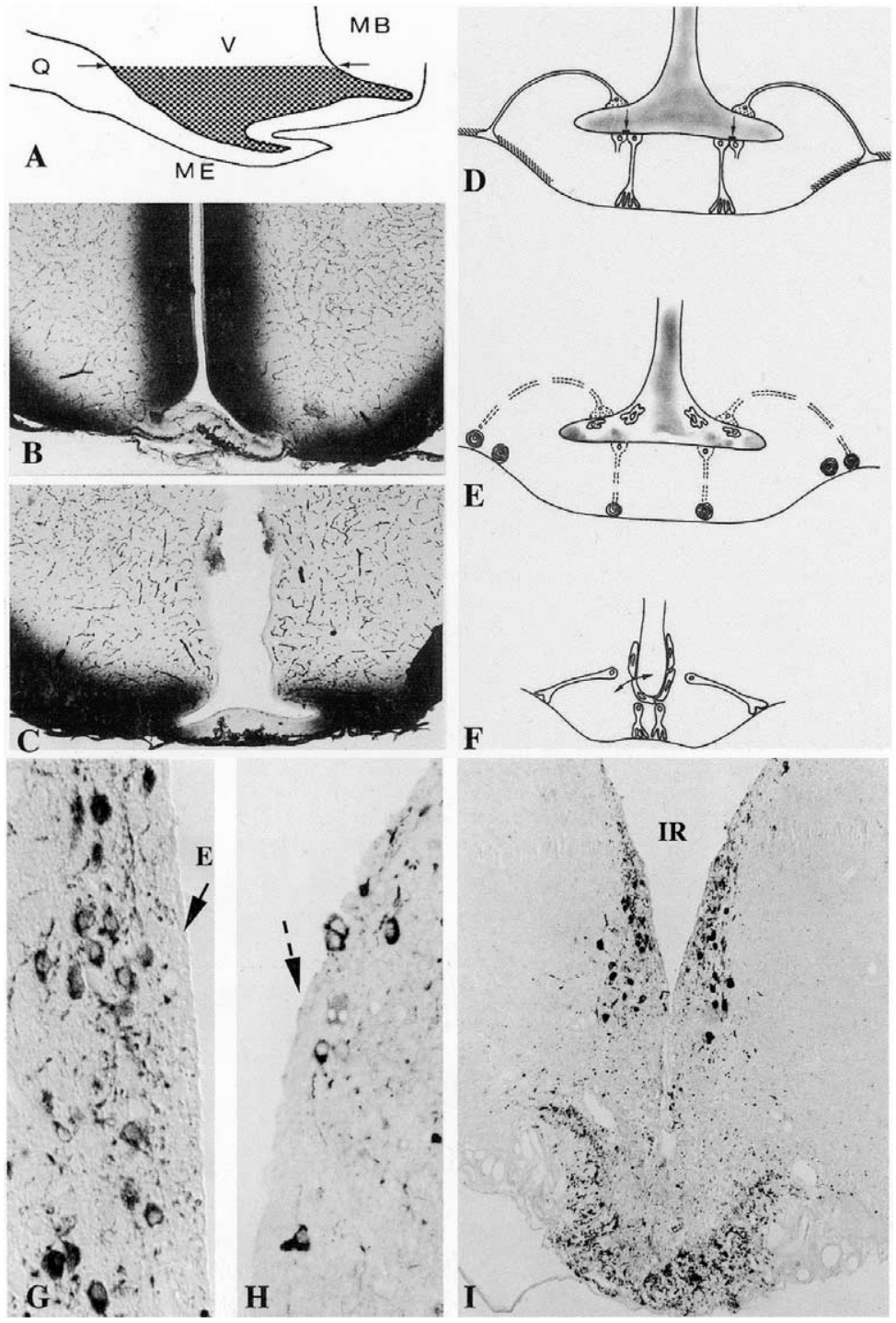

FIG. 9 (A) The injection of $1 \mu$ of epoxy resin into the third ventricle (V) fills the infundibular recess (dotted area). Q, optic chiasm; ME, median eminence; MB, mamillary body. (B) Horseradish peroxidase (HRP) injected into a lateral ventricle of a normal rat reaches the infundibular recess. Original magnification: $\times 40$. (C) HRP, injected into a lateral ventricle of a rat that had been previously injected with resin into the third ventricle, does not reach the infundibular recess. Original magnification: $\times 40$. (From Rodríguez et al., 1982.) (D-F) Drawings depicting the three stages after injecting $1 \mu \mathrm{l}$ of resin into the infundibular recess. (D) Shortly after the injection the resin fills the infundibular recess and the median eminence remains intact. (E) Three to 4 days after the injection macrophages reach the infundibular recess 
first proestrus (Fernández-Galaz et al., 1997; García-Segura et al., 1999). In addition, ovarian hormones may affect IGF-I accumulation in the hypothalamus via regulation of the IGF-I receptor and of IGF-I-binding protein-2 in the membrane of tanycytes (Cardona-Gómez et al., 2000). However, the mechanism by which IGF-I incorporated by tanycytes under the influence of estrogen participates in GnRH release is not known.

The active involvement of tanycytes in the release of GnRH, which has been investigated largely by in vitro investigations, is supported by findings obtained in living rats whose tanycytes have been experimentally removed.

\section{Experimental Tanycytectomy and GnRH Release}

With the aim to exclude the infundibular recess of the rat third brain ventricle from the circulation of CSF, Rodríguez et al. $(1982,1985)$ filled this discrete ventricular region with an epoxy resin (Fig. 9A, D). Three phases were distinguished in the evolution of these experimental rats (Rodríguez et al., 1985; Fig. 9D-F). Phase 1 (3-4 days postinjection) is characterized by the presence of the still-intact layer of tanycytes and the lack of circulation of CSF in the infundibular recess, as shown by the lack of penetration in this recess of HRP injected into the lateral ventricle (Fig. 9B, C). In phase 2, by the end of the first postinjection week the resin mixture polymerizes, forming a cast in which the cell bodies of tanycytes become embedded; the basal processes of tanycytes degenerate (Figs. 9E and 10B). During the following weeks macrophages progressively degrade the resin cast. Phase 3 started about 1 month after the injection and lasted throughout the 13-month observation period. It is characterized by the absence of the resin, the free circulation of CSF in the reorganized infundibular recess, and the complete absence of $\alpha$ and $\beta$ tanycytes (Fig. 9E-I). At the ultrastructural level no damaged is observed either in the fiber tracts running through the median eminence, such as the hypothalamo-hypophysial tract, or in the neuropil of the medial basal hypothalamus (Fig. 10A) or the neurons of the arcuate nucleus. The denuded surface of the infundibular recess is covered by a thin layer of cytoplasm most likely corresponding to astrocytes (Fig. 10A). During the 13-month observation period there was no regeneration of tanycytes.

and tanycytes degenerate. (F) One month after the injection the median eminence without tanycytes reorganizes and shrinks and the infundibular recess is clean, with the CSF freely circulating. (G) In a normal rat, immunocytochemistry for tyrosine hydroxylase reveals the dopamine-secreting neurons of the arcuate nucleus lying under the ependyma (E) of the infundibular recess. Original magnification: $\times 240$. (H and I) In a rat without tanycytes (broken arrow) the median eminence shrinks, the lateral recesses of the infundibular recess disappear, and the dopamine-median eminence neuronal system remains undamaged (I), although neurons are close the ventricular cavity $(\mathrm{H})$. Original magnification: $(\mathrm{H}) \times 240$; $(\mathrm{I}) \times 80$. 


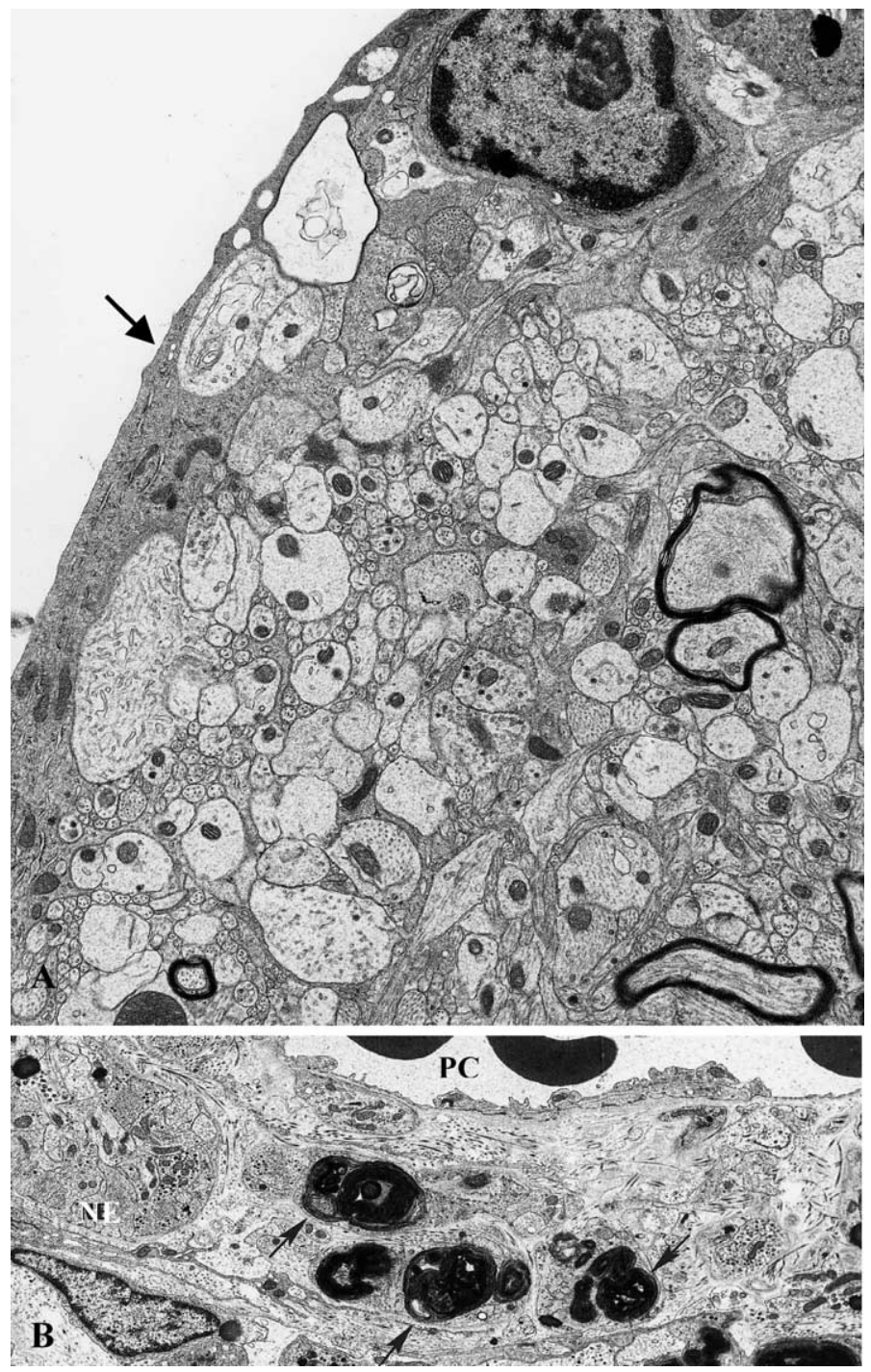

FIG. 10 (A) Transmission electron microscopy of the medial basal hypothalamus. One month after the injection of epoxy resin into the infundibular recess, the ependyma has been replaced by a monolayer of thin glial cells (arrow) and the underlying neuropil remains undamaged. Original magnification: $\times 12,000$. (B) A few days after the injection of epoxy resin into the ventricle, degenerated ependymal processes and endings are seen in the external region of the median eminence (arrows) whereas the nerve endings (NE) remain intact. PC, portal capillaries. Original magnification: $\times 12,000$. (From Rodríguez et al., 1985.) 
In rats devoid of tanycytes for more than 1 month, the neurosecretory fibers ending in the middle third of the median eminence do not display apparent ultrastructural changes. Furthermore, the immunocytochemical study shows that the spatial distribution and density of somatostatin, corticotrophin-releasing hormone, vasopressin, and dopamine (Fig. 9H, I) immunoreactive fibers do not differ from those of normal rats.

At variance, GnRH neurons ending in the lateral regions of the median eminence of tanycytectomized rats do show some relevant changes. In all experimental rats, the GnRH fibers continued to be present and were distributed in the lateral regions of the median eminence (Fig. 11C, inset). After tanycytes have disappeared, and consequently the ependymal cuff that normally separates the GnRH fibers from the portal capillaries is also missing (Fig. 11D), the GnRH fibers/endings continue to be densely packed in the lateral regions of the median eminence and lie very close to the portal capillaries (Fig. 11D). About 1 month after the resin injection, and thereafter, the GnRH fibers/endings are randomly distributed in the lateral regions of the median eminence.

LH and follicle-stimulating hormone (FSH) plasma levels of tanycytectomized rats were not different from those of control and sham-operated rats at diestrus (Fig. 11B). One month after ovariectomy, normal, sham-operated, and tanycytectomized rats all show increased levels of plasma LH and FSH (Fig. 11B). Although the experimental rats were able to maintain the tonic secretion of LH and FSH at levels similar to young control rats (Wise and Ratner, 1980) and were able to respond to stimulation such as castration (Brann and Mahesh, 1991; Wise and Ratner, 1980), they were not apparently able to produce the peak of LH normally seen in the afternoon of the proestrus day, as indicated by the facts that these rats fail to ovulate and remain in persistent diestrus (Rodríguez et al., 1985). The following findings further indicate that the lack of an LH peak is due to the lack of a GnRH peak: (1) sham-operated rats do show a peak of LH in the afternoon of the proestrus day (Fig. 11C); and (2) both sham-operated and tanycytectomized rats show high plasma LH levels after the administration of GnRH (Fig. 11C), indicating that the pars distalis of the experimental rats retains the capacity to produce a peak of LH under the influence of a peak of GnRH (Grattan et al., 1995; Kalra and Kalra, 1981).

In brief, tanycytectomized rats are able to maintain basal tonic release of $\mathrm{LH}$ and $\mathrm{FSH}$, and to hypersecrete $\mathrm{LH}$ in response to castration and GnRH administration, but are unable to produce an LH peak under conditions known to produce an endogenous peak of GnRH release. Because GnRH neurons reaching the lateral regions of the median eminence appear to be undamaged and continue to be in contact with the portal capillaries, it may be postulated that the absence of tanycytes prevents the pulse of $\mathrm{GnRH}$ release into the portal blood, as depicted in Fig. 11F. This supports the view 

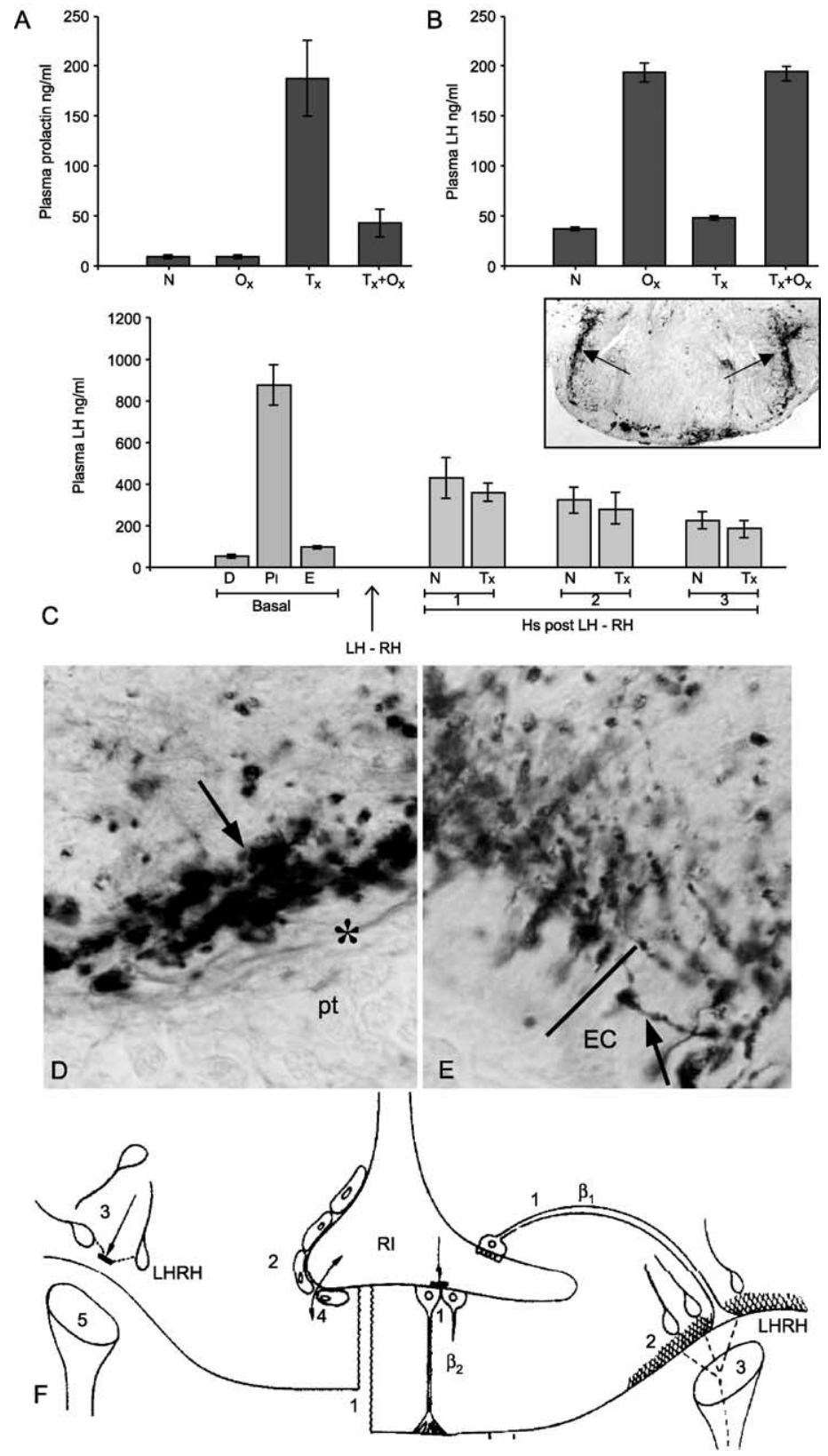

FIG. 11 (A) Plasma prolactin levels of normal young (3-month-old) female rats at diestrus (N, $n=18$ ), young female rats 1 month after castration (Ox, $n=12)$, and young female rats 1 month after tanycytectomy ( $\mathrm{Tx}, n=9$ ) and 1 month after castration and tanycytectomy (Tx + Ox, $n=8)$. Vertical bars represent the standard deviation. (B) Luteinizing hormone 
that $\beta_{1}$ tanycytes participate in GnRH release by providing essential signal(s) to the GnRH neuron rather than by behaving as a plastic barrier. This is in apparent disagreement with Nozaki et al. (1980), who lesioned the rat tanycytes by electrocoagulation, without apparently affecting the underlying neuropil, and did not find changes in the plasma LH levels as compared with control rats, suggesting that tanycytes are not involved in pituitary control.

In the normal rat, dopamine neurons represent a subpopulation of arcuate nucleus neurons, mostly localized close the third ventricle lumen (Zoli et al., 1993) (Figs. 9G and 14A); they project axons to the external zone of the median eminence, where many of them terminate in the middle region and others in the lateral regions (Fig. 14A). In rats without tanycytes the spatial distribution and density of the dopamine perikarya and their axons and terminals in the median eminence do not show apparent changes (Fig. 9H, I). However, tanycytectomized rats display plasma prolactin levels that are about 10 times higher than those of sham-operated rats; such

plasma levels of normal young female rats at diestrus $(\mathrm{N}, n=21)$, young female rats 1 month after castration (Ox, $n=11)$, and young female rats 1 month after tanycytectomy (Tx, $n=10)$ and after 1 month of castration and tanycytectomy $(\mathrm{Tx}+\mathrm{Ox}, n=8)$. Vertical bars represent the standard deviation. (C) Luteinizing hormone plasma levels. Left: Sham-operated female rats at diestrus $(\mathrm{D}, n=12)$, in the afternoon of the proestrus day $(\mathrm{Pl}, n=10)$, and at estrus $(\mathrm{E}, n=10)$. Right: One month after the operation tanycytectomized rats $(\mathrm{Tx}, n=5)$ and sham-operated rats (at proestrus) ( $\mathrm{N}, n=7$ ) received, at 10 A.M., a subcutaneous injection of $1 \mathrm{mg}$ of chlorpromazine per $100 \mathrm{~g}$ body weight. At 2 P.M. of the same day, all rats were infused intravascularly with $\mathrm{GnRH}(\mathrm{LH}-\mathrm{RH})$ at $40 \mathrm{ng} / 100 \mathrm{~g}$ body weight. Blood samples from the retroocular sinus were collected 1, 2, and $3 \mathrm{~h}$ after GnRH administration. The levels of LH were analyzed by radioimmunoassay. Vertical bars represent the standard deviation. (Some of these data are from Rodríguez et al., 1982, 1985; and E. M. Rodríguez, J. L. Blázquez, F. E. Pastor, B. Peláez, P. Peña, B. Peruzzo, and P. Amat, unpublished results.) Inset: One month after the injection of epoxy resin into the infundibular recess, the immunoreactive GnRH tract appears intact and keeps its specific localization in the lateral regions of the median eminence (arrows). Immunostaining, using intensification with silver methenamine. Original magnification: $\times 45$. (D) In a tanycytectomized rat the ependymal cuff is missing (asterisk) and the GnRH fibers lose their palisade organization and lie close to the external basal lamina of the brain and the portal capillaries (arrow). Pt, pars tuberalis. Original magnification: $\times 1200$. (From Rodríguez et al., 1985.) (E) In a control rat the ependymal cuff (EC) separates the GnRH fibers (arrow) from the external basal lamina of the brain and the portal capillaries. Original magnification: $\times 1200$. $(\mathrm{F})$ Schematic representation of the events occurring in a normal rat (right) and in a tanycytectomized rat (left). Normal rat: $1, \beta_{1,2}$ tanycytes are present; 2 , the GnRH fibers terminate on the ependymal cuff; $3, \mathrm{GnRH}$ is released into the portal capillaries. Tanycytectomized rat: 1 , the median eminence is reduced to about half its normal size; 2 , the lateral recesses of the infundibular recess disappear; 3, the GnRH fibers lose its palisade organization, lie close to the external basal lamina of the brain and the portal capillaries, but $\mathrm{GnRH}$ is not released into the portal capillaries (5); 4, the CSF-median eminence barrier, which in the normal rat is formed by $\beta_{2}$ tanycytes, is missing. 

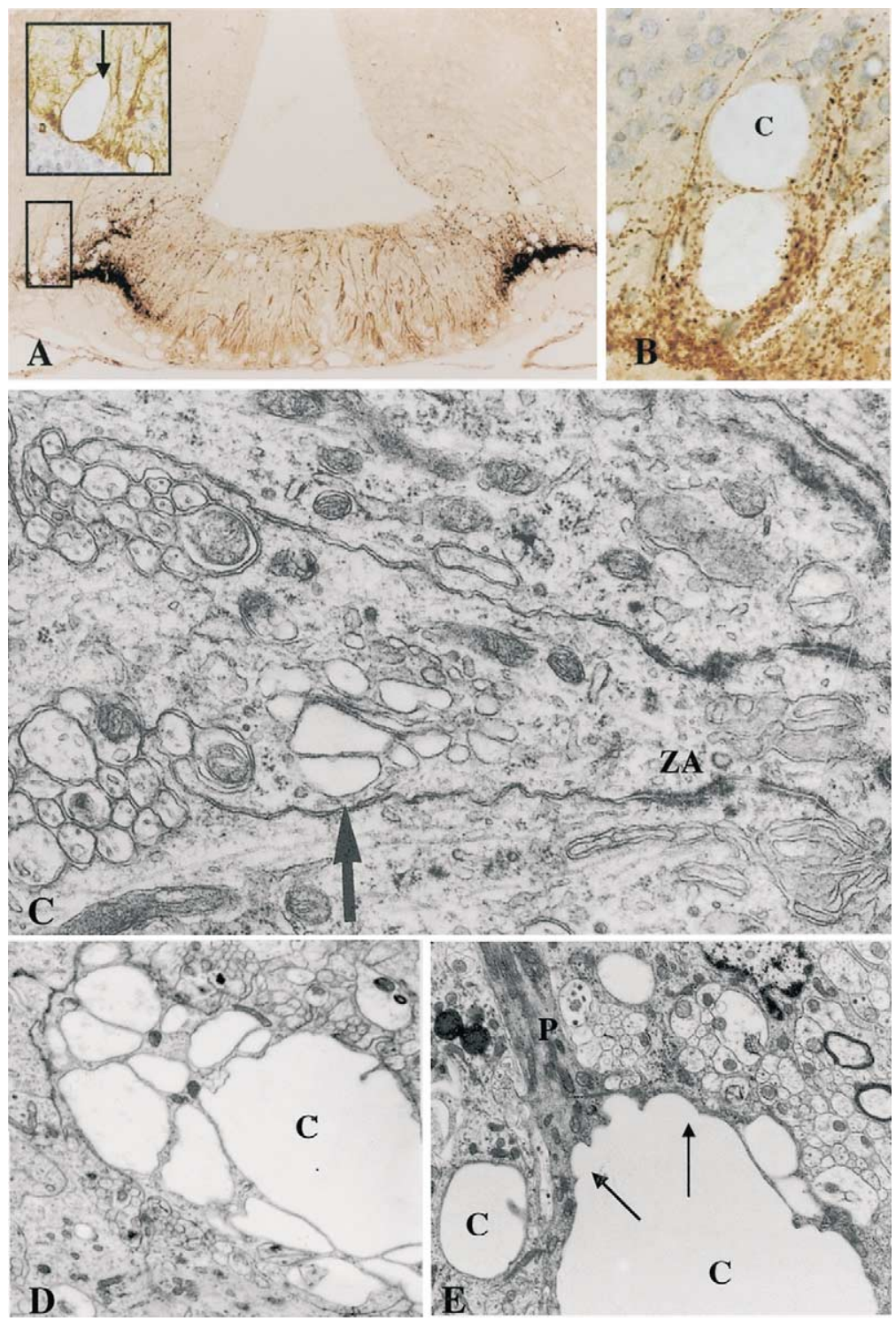

FIG. 12 (A) Rat medial basal hypothalamus. Double immunostaining for GnRH and vimentin, showing colocalization of the GnRH fibers and the large cisterns. The area framed in rectangle is shown in (B). Original magnification: $\times 120$. Inset: GLUT-1 immunoreactivity in the processes of $\beta_{1}$ tanycytes and in the wall of a large cistern. Original magnification: $\times 270$. (B) Detailed magnification of (A), showing the close spatial relationship between the GnRH fibers and the large cisterns (C). Original magnification: $\times 700$. (C) Transmission electron microscopy of $\beta_{2}$ tanycytes. Vacuoles of various sizes appear to originate in the Golgi apparatus (arrow). ZA, zonula adherens. Original magnification: $\times 30,000$. (D) A tanycyte process with cisterns (C) 
hyperprolactinemia was sustained and lasted throughout the 13-month observation period (Fig. 11A; Rodríguez et al., 1982). The hyperprolactinemia displayed by these rats could be ascribed either to the absence of $\beta_{2}$ tanycytes, which would prevent the release of dopamine into the portal blood, or to a dysfunction of the pars distalis-ovary axis triggered by the lack of the GnRH peak. This latter possibility is supported by the drastic reduction of the hyperprolactinemia of tanycytectomized rats that are subjected to ovariectomy (Fig. 11A).

\section{Intriguing Story of the Large Cisterns of $\beta_{1}$ Tanycytes}

In the midline of the rostral end of the median eminence and all along its lateral borders at the medial and caudal regions, there are large cisternae ranging in size between 1 and $60 \mu \mathrm{m}$ (Bodoky et al., 1979). This spatial distribution fully matches that of the processes and terminals of $\beta_{1}$ tanycytes (Rodríguez et al., 1979) (Fig. 12A). These cisternae, first described by Löfgren (1961) and Legait et al. (1973) at the light microscope level, were later investigated by transmission electron microscopy (Matsui, 1966; Scott and Knigge, 1970) and by scanning electron microscopy (Kaur et al., 1989). Transmission electron microscopy studies (Amat et al., 1999; Bodoky et al., 1979; Brion et al., 1982; Peruzzo et al., 2000; Scott and Knigge, 1970) indicate that these large cisternae are localized within tanycytes (Fig. 12C-E).

The availability of a specific immunological marker for tanycytes (antiP85; see Section II.B) has allowed the demonstration that many of these cisternae are, indeed, within the basal process of tanycytes (Blázquez et al., 2002). Similarly, an antibody against GLUT-1, which labels $\beta_{1}$ tanycytes, also labels the walls of some cisternae (Peruzzo et al., 2000) (Fig. 12A). Furthermore, after intraventricular injection of WGA, the lectin is endocytosed by tanycytes and it labels the thin ring of cytoplasm lining the large cisternae (Peruzzo et al., 2004). However, there is a small population of cisternae whose wall is not labeled with anti-P85, anti-GLUT-1, or intraventricularly injected WGA (Blázquez et al., 2002; Peruzzo et al., 2004). Furthermore, after tanycytectomy most but not all cisternae disappear from the lateral regions of the median eminence (Fig. 9I). All this evidence indicates that there are two populations of cisternae, the largest one located within tanycytes and a small one probably located in subependymal cells (subependymal tanycytes?).

of various sizes probably undergoing a confluence process. Original magnification: $\times 18,000$. (E) Tanycyte processes $(\mathrm{P})$ displaying cisterns $(\mathrm{C})$. One of them has a large cistern lined by a thin cytoplasmic ring. Arrows point to caveolar structures, suggesting fusion of small vacuoles to form the large cistern. (From Blázquez et al., 2002.) 
At the ultrastructural level, these cisternae appear to arise from the progressive coalescence of smaller vacuoles originated in the Golgi apparatus (Fig. 12C-E). After intraventricular injection of horseradish peroxidase the tracer reaches the subarachnoid space and then the intercellular space of the median eminence (see Section IV.A); under these circumstances the tanycyte cisternae do not incorporate the tracer, further demonstrating that they are intracellular structures that are not functionally connected with the intercellular space (Brion et al., 1982).

In the rat, the tanycyte cisternae appear between PN-15 and PN-17 in the form of small blebs in the lateral walls of the infundibular recess. They then increase in number and appear closer to the external surface of the median eminence; by PN-30 they reach the spatial distribution, number, and size found in the adult rat (Bodoky et al., 1979).

The tanycytes containing large cisternae in their basal process establish large surface contact areas with the external limiting membrane of the brain neighboring the portal capillaries located in the lateral regions of the median eminence.

There is a remarkably topographical correlation between the distribution of the basal processes of $\beta_{1}$ tanycytes and, consequently, of the large vacuoles they contain, and that of the GnRH axons and their terminals (Bodoky et al., 1979; Rodríguez et al., 1979) (Figs. 8A-C and 12A). Light and electron microscopy-immunocytochemistry for $\mathrm{GnRH}$ clearly shows that the GnRH terminals establish close contact with the preterminal region of the basal process of $\beta_{1}$ tanycytes (Fig. 8C) and that GnRH axons establish large surface contacts with the walls of the large cisternae (Figs. 8A, C and 12B). The facts that (1) the content of the large vacuoles is electron lucent, (2) it lacks immunoreactivity with a long series of antibodies against neuronal and glial markers and neuropeptides (E. M. Rodríguez, J. L. Blázquez, F. E. Pastor, B. Peláez, P. Peña, B. Peruzzo, and P. Amat, unpublished observation), and (3) the processes of $\beta_{1}$ tanycytes are part of the bloodbrain barrier of the median eminence (Peruzzo et al., 2000; see Section IV) support the possibility advanced early by Scott and Knigge (1970) that they may be filled with a plasma-like fluid.

Because the tanycyte processes containing the large cisterns are the ones undergoing spatial plastic changes during the estrous cycle (King and Rubin, 1994, 1995; Prevot et al., 1999; Wittkowski, 1998), the possibility that these vacuoles play a role in such plasticity must be considered and investigated. The following are unpublished results obtained in our laboratories. In a first experiment, the number and surface area of the cisternae of mature rats were determined at estrus, diestrus, 9:00 A.M. of proestrus, and 6:00 P.M. of the proestrus day. In these phases of the estrous cycle the number of cisternae does not vary but the surface area of such cisternae does (Fig. 13A, B). Indeed, during late afternoon of the proestrus day there is a significant 
decrease in surface area of the cisternae as compared with that of the rats killed in the morning of the proestrus day (Fig. 13A). This implies that some time between 9:00 A.M. and 6:00 P.M. of the proestrus day there is a decrease in the volume of most or all of the cisternae. Whether this shrinkage of the cisterna occurs before, simultaneously, or immediately after the peak of LH release that, in our rat colony, occurs between 4:00 P.M. and 6:00 P.M., must be established. The large dispersion of the volume size of the cisternae detected on the diestrus day (Fig. 13A) could be an indication that the population of cisternae is in the process of increasing its size and that in the morning of proestrus, with a small dispersion, all of them have reached their maximum size. A decrease in the immunoreactive GnRH of the median eminence on the afternoon of the proestrus day parallels that of the surface area of the tanycyte cisterns (Fig. 13A, B; Rubin and King, 1995). In a second experiment, the tanycyte cisternae were investigated in female castrated rats. One and 6 days after castration there is a significant increase in the surface area of the cisternae as compared with that of control rats killed at diestrus (Fig. 13D). It is known that castration stimulates GnRH (Grattan et al., 1995) and LH (Brann and Mahesh, 1991; King et al., 1987; Wise and Ratner, 1980) release. Both experiments indicate that under conditions of enhanced release of GnRH into the portal blood, the volume of the $\beta_{1}$ tanycyte cisternae undergoes significant changes; peak release of GnRH (late proestrus) would be associated with shrinkage of the cisternae, whereas sustained increase in the release of GnRH (castration) would correlate with dilatation of the cisternae. The mechanism(s) and functional significance of this plasticity of the tanycyte cisternae deserve to be further investigated.

\section{Production of Enzymes Involved in Neuroendocrine Mechanisms}

Expression in the CNS of several enzymes involved in steroid biosynthesis has been investigated by immunocytochemistry and through the detection of the actual enzyme activity. Immunoreactive $5 \alpha$-reductase has been shown to be present in rat tanycytes, suggesting that these cells play a role in the conversion of testosterone to dihydrotestosterone and of progesterone to dihydroprogesterone (Pelletier et al., 1994).

Thyroxine deiodinase types I and II generate $\mathrm{T}_{3}$ from $\mathrm{T}_{4}$, thus activating thyroid hormone. Deiodinase type I predominates in peripheral tissues and deiodinase type II predominates in the CNS, in particular in the arcuate nucleus-median eminence region (Riskind et al., 1987). Within this discrete hypothalamic region, deiodinase type II appears to be localized exclusively in tanycytes (all subtypes), as shown by in situ hybridization by Tu et al. (1997). These authors also have shown that the deiodinase type II messenger is 

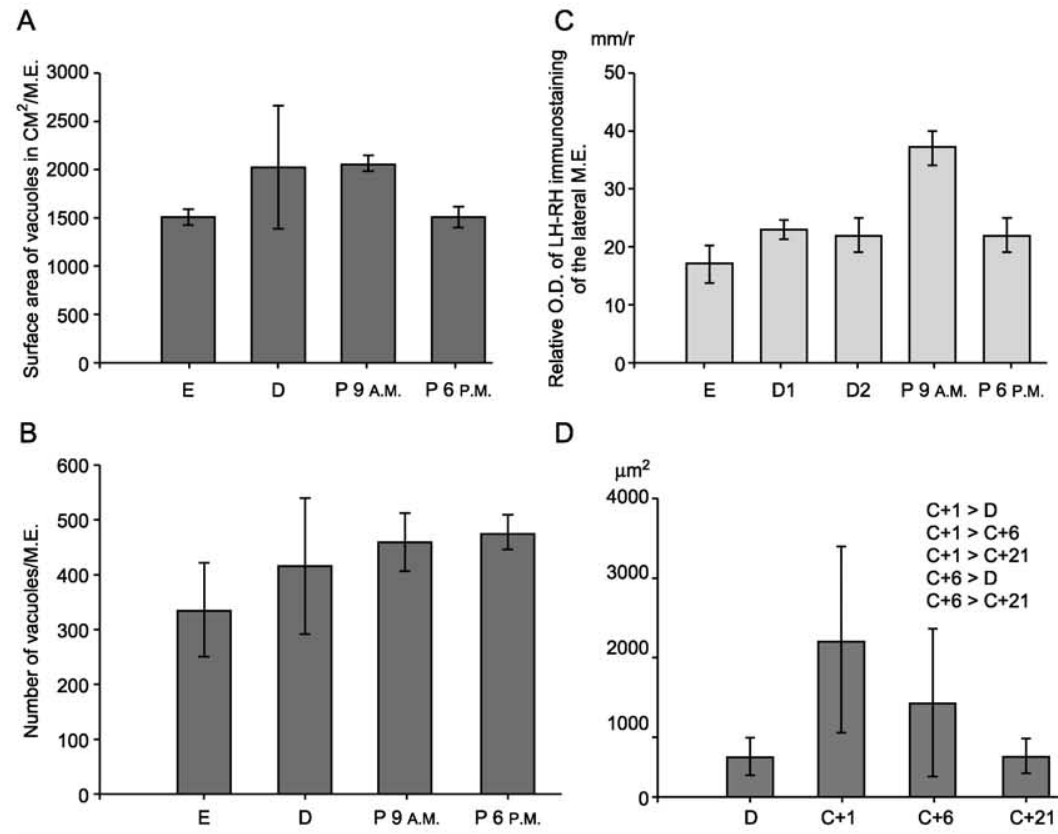

$\mathrm{D}$
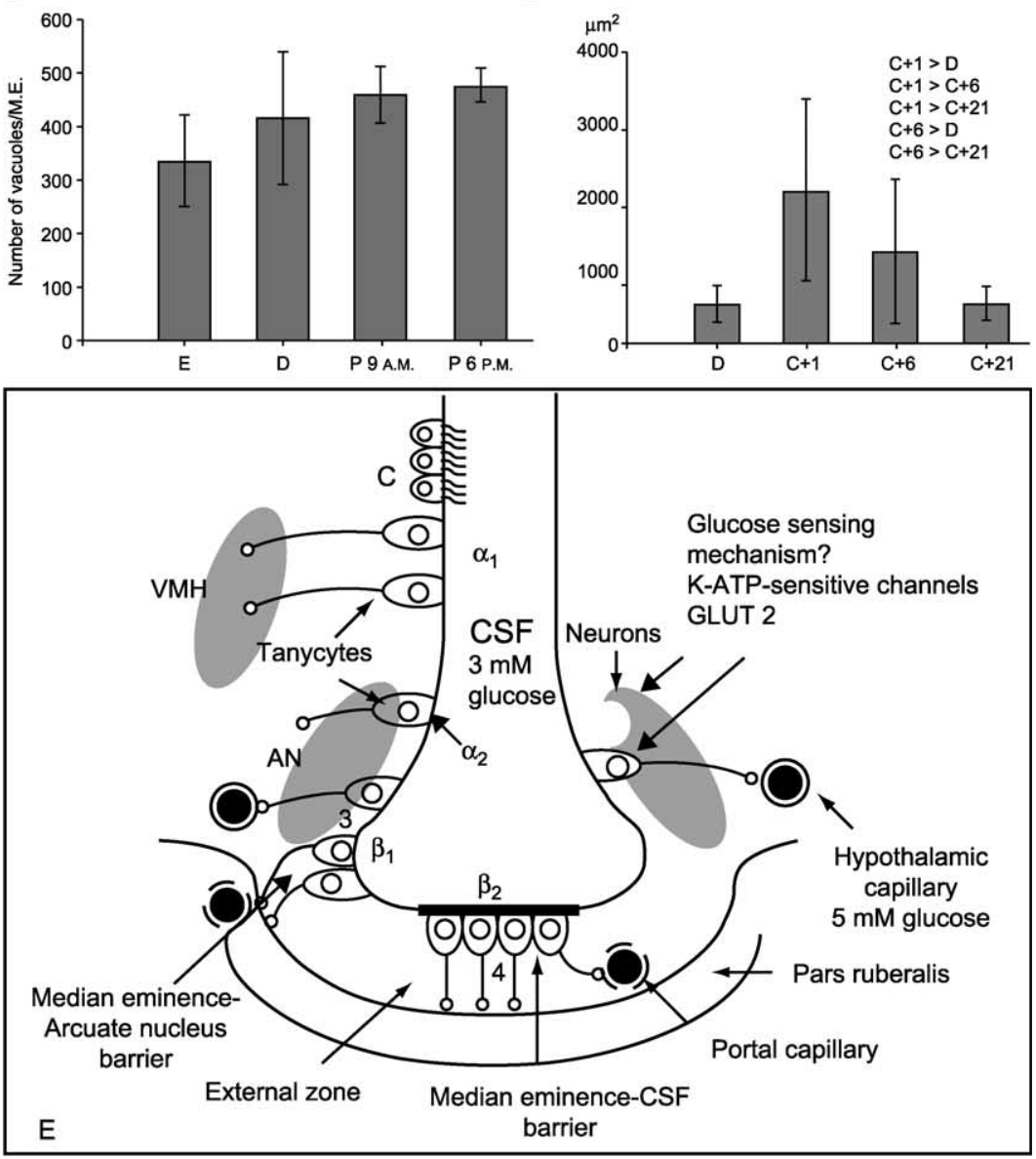

FIG. 13 (A and B) Number and surface area of the tanycyte cisternae of 3-month-old female Sprague-Dawley rats, determined by image analysis of serial paraffin sections of Bouin-fixed median eminence. Rats were killed at 9:00 A.M. of estrus $(\mathrm{E}, n=5)$ and diestrus $(\mathrm{D}, n=5)$, and at 9:00 A.M. $\left(\mathrm{P}_{\mathrm{e}}, n=5\right)$ and 6:00 P.M. $\left(\mathrm{P}_{1}, n=5\right)$ of the proestrus day. (A) A significant reduction 
present throughout the tanycyte cytoplasm and suggested that this enzyme would be synthesized in the cell body bathed by the ventricular CSF and the basal processes contacting the local blood vessels (Fekete et al., 2000; Tu et al., 1997). Tu et al. (1997) have proposed that the high concentrations of deiodinase type II in tanycytes play a relevant function by providing $\mathrm{T}_{3}$ locally to the hypothalamus, and to other regions of the CNS via the CSF.

\section{Tanycytes and Glucose Metabolism}

The electrophoretic application of insulin and glucose to discrete regions of the hypothalamus led Oomura and Kita (1981) to describe two types of neurons. One of them, regarded as a glucose receptor neuron, was located in the ventromedial hypothalamus and responded to applied glucose with an increased frequency of discharge; this effect was enhanced when glucose and insulin were applied simultaneously. Several molecules involved in the glucose-sensing mechanism have been identified in the insulin-secreting cells of the pancreas (Schuit et al., 2001). Interestingly, evidence indicates that in the hypothalamus there are nonneuronal cell elements expressing similar glucose-sensing molecules, such as glucose transporter-2 (GLUT-2; Leloup et al., 1996), glucokinase (Roncero et al., 2000), glucagon-like peptide-1 receptors (Alvarez et al., 1996), and the ATP-sensitive $\mathrm{K}^{+}$channels (Thomzig et al., 2001). Studies have shown that the hypothalamic cells expressing two of these molecules, namely, GLUT-2 and ATP-sensitive $\mathrm{K}^{+}$channels, correspond to tanycytes (García et al., 2003; Thomzig et al., 2001).

$(p<0.001)$ in the surface area of cisterns occurs in the afternoon of the proestrus day as compared with the morning of this day. (B) The same groups of animals showed no significant changes in the number of cisterns. (C) Relative amount of immunoreactive GnRH in the median eminence at different stages of the estrous cycle (for each group, $n=5$ ), as estimated by microdensitometry. A significant increase $(p<0.001)$ is seen in the morning of the proestrus day. (D) Surface area of the tanycyte cisternae of 3-month-old female Sprague-Dawley rats $(n=$ 48). $\mathrm{D}$, control rats killed at diestrus; $\mathrm{C}+1, \mathrm{C}+6$, and $\mathrm{C}+21$, female rats castrated at diestrus and killed 1, 6, and 21 days after surgery, respectively. The surface area of 100 randomly selected cisternae of the median eminence of each of the four groups of rats was determined by the image analysis IBAS I system (Kontron, Eching, Germany), and the data were processed by the StatView $512+$ program (SAS Institute, Cary, NC). A significant increase $(p<0.01)$ in the cistern surface area occurs 1 and 6 days after castration. The groups of pairs shown are significantly different $(p<0.01)$. Vertical bars standard error. (E) Line drawing of the mouse medial basal hypothalamus, depicting the location and distribution of $\alpha$ and $\beta$ tanycytes and the neurons of the ventromedial (VMH) and arcuate (AN) nuclei. The evidence that cells of the walls of the infundibular recess (ependyma and neurons) express ATP-sensitive $\mathrm{K}^{+}$channels and GLUT-2 is indicated; these molecules are associated with the glucose-sensing mechanism. (Modified after García et al., 2003.) 
GLUT-2 is a low-affinity transporter of glucose and fructose. García et al. (2003) have shown by immunocytochemistry and in situ hybridization that whereas the ciliated ependyma of the third ventricle does not express GLUT$2, \alpha$ and $\beta$ tanycytes do; in these latter cells the transporter is localized mostly in the ventricular cell pole. Unfortunately, the authors do not indicate whether both types of $\beta$ tanycytes express the transporter. Transport studies performed in primary cultures of tanycytes indicate that the two glucose transporters present in tanycytes, namely GLUT-1 (see Section IV.C) and GLUT-2, are functional (García et al., 2003). These findings have led García et al. (2003) to postulate that tanycytes are involved in the detection of glucose concentrations in the CSF (Fig. 13E). Worth mentioning is the striking linear correlation between plasma and CSF glucose levels, with a fixed ratio that is species dependent (3:1 for rats, 3:2 for rabbits, and 5:4 for humans) (Davson and Segal, 1996). This implies that if tanycytes sense the CSF glucose concentrations, they are, indirectly, sensing the glucose plasma levels. If the CSF glucose levels actually are an input signal to tanycytes, what is the nature and target of the output signal? Would the glucose receptor neurons located in the ventromedial hypothalamus (Oomura and Kita, 1981; Oomura et al., 1969) be a target? Because these latter neurons are involved in the complex mechanism controlling insulin secretion (Oomura and Kita (1981), it is tempting to speculate that tanycytes, by monitoring CSF glucose, would be part of such a mechanism.

\section{Tanycytes as Neural Stem Cells}

In the mammalian embryonic brain, radial glia serve as neuronal progenitors and may be regarded as embryonic stem cells (Alvarez-Buylla et al., 2001, 2002; Malatesta et al., 2000; Noctor et al., 2001). In the neonatal rodent brain, radial glial persisting in the lateral wall of the lateral ventricle have the ability to generate neurons, astrocytes, ependymal cells, and oligodendrocytes (Merkle et al., 2004; Tramontin et al., 2003). Of special interest is that neonatal radial glia gives rise to the neural stem cells of the adult subventricular zone (SVZ) (Merkle et al., 2004).

In the brain of mammals there are radial glia descendants, different from astroglia, that retain certain characteristics of radial glia and that persist throughout the life span. Radial glia descendants that persist in the adult neural tissue are Bergmann glia in the cerebellum and Muller cells in the retina (Li et al., 2004). In the brain proper, apparently the only radial glia descendants remaining in adulthood are the hypothalamic tanycytes (see Section II.C). It has been shown that one of these three radial glia descendants, the Muller cells of the retina, can be induced to become neurogenic (Fischer and Reh, 2001). 
There is some evidence suggesting that transient radial glia of the embryonic and neonatal brain and the tanycytes of the adult brain share the ability to serve as neuronal progenitors. There are important phenotypic and functional differences between the four subtypes of tanycytes (see Section III and Table II). Would all tanycytes retain the capacity to generate neurons? There is evidence pointing to $\alpha_{2}$ tanycytes as the cell group able to display neurogenic properties under certain conditions (see later discussion). Would all $\alpha_{2}$ tanycytes keep such potency? Electron microscopy of the wall of the infundibular recess of adult rats provides some clues. Scanning electron microscopy has shown that although most tanycytes lack cilia, a few of them are endowed with a single centrally located cilium (Scott and Paull, 1983). Unfortunately, this technique does not allow determination of whether this single cilium presents $9+0$ or $9+1$ pairs of microtubules. This point is relevant because the neural stem cells present in the subventricular zone of the lateral ventricle project a ventricular process bearing a single $9+0$ cilium (Doetsch et al., 1997; Tramontin et al., 2003). Interestingly, a few cells of the arcuate nucleus located in the vicinity of the ependyma posses a single $9+0$ cilium projecting to the intercellular space (Rodríguez, 1976). The area lined by the hypothalamic tanycytes lacks a subventricular zone proper, as that present in the lateral wall of the lateral ventricles (Alvarez-Buylla et al., 2002; Doetsch et al., 1997). Indeed, the subependymal zone of the medial basal hypothalamus is occupied by the neurons and the neuropil of the arcuate and ventromedial nuclei. Thus, if neurogenesis does occur in this discrete brain region, the tanycyte layer appears to be the best candidate source of neural precursors. This situation resembles that of the embryonic brain.

The following findings support the neurogenic potency of tanycytes. In amphibians the median eminence is devoid of neuronal perikarya and is separated from the infundibular nucleus of the hypothalamus (homologous to the mammalian arcuate nucleus) by a thin stalk. This anatomical arrangement allows a clean surgical separation of the median eminence from the hypothalamus. Two days after disconnection of the median eminence clear cells are observed among tanycytes; these cells progressively develop all the ultrastructural characteristics of the neurosecretory neurons of the infundibular nucleus and extend processes contacting the portal capillaries (Dellmann and Rodríguez, 1970).

In the rat, hypophysectomy is followed by the generation, migration into the infundibular recess of the third ventricle, and differentiation of neurons that remain as clusters of supraependymal neurons that, after a few days, receive numerous synaptic contacts. These neurons appear to originate from local stem cells (Scott, 1999, 2002; Scott and Hansen, 1997; Wu et al., 1989). The migration of neurons to the surface of the third ventricle also occurs after experimental lesion of the endocrine hypothalamus of the adult rat; 

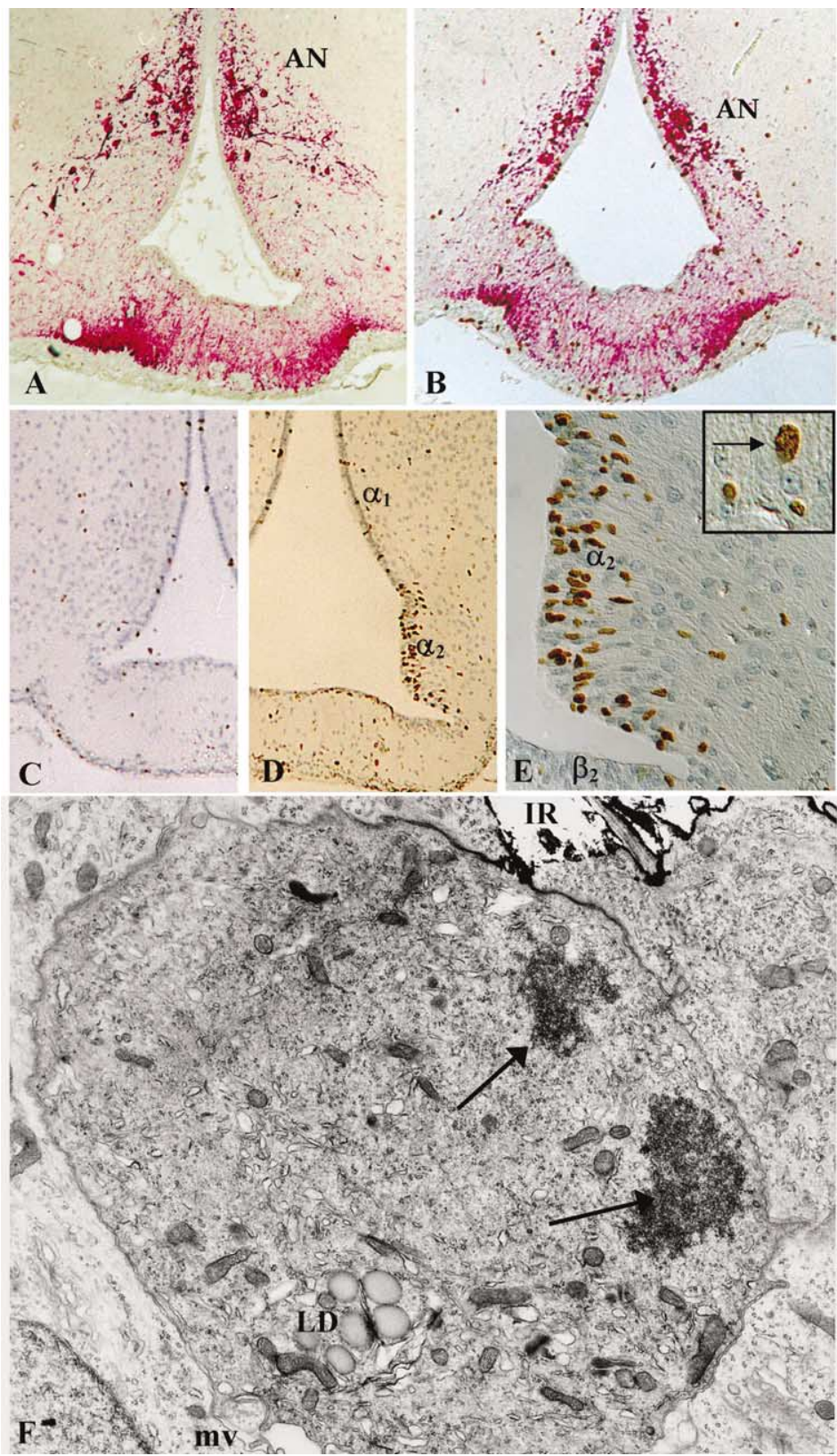

FIG. 14 (A and B) Medial basal hypothalamus of 30-day-old rats. (A) Normal rat. (B) Rat treated with monosodium glutamate $(4 \mathrm{mg} / \mathrm{g}$ body weight) on PN-4. Immunostaining for tyrosine hydroxylase. The number of dopamine neurons and fibers is reduced in the treated rat. Original magnification: $\times 85$. (C and D) Medial basal hypothalamus of 30-day-old rats. $(\mathrm{C})$ 
these migratory neuroblasts express PSA-NCAM and b-50/GAP-43 (Alonso et al., 1997).

It is well established that the subcutaneous administration of monosodium glutamate (MSG) to newborn rats leads to a severe and selective destruction of most neurons of the arcuate nucleus (Hu et al., 1998; Olney, 1971). However, a few days after the massive neuronal death, new neurosecretory neurons start to appear in the arcuate nucleus. Thus, by PN-30 the dopaminergic neurons, although reduced in number compared with the normal rat, project a dense axonal plexus to the median eminence resembling that of the normal rat (Fig. 14A, B; and E. M. Rodríguez, J. L. Blázquez, F. E. Pastor, B. Peláez, P. Peña, B. Peruzzo, and P. Amat, unpublished observation). What is the source of these neurons partially regenerating the arcuate nucleus? Some evidence is being collected in our laboratory that these neurons generate from tanycytes, in particular of the $\alpha$ type (C. Dimey Galindo and J. L. Blázquez, unpublished observations). Rats that had been treated with monosodium glutamate $(4 \mathrm{mg} / \mathrm{g}$ body weight) on $\mathrm{PN}-4$ received three subcutaneous injections of bromodeoxyuridine (BrdU) per day, for the three consecutive days after administration of monosodium glutamate. They were killed on PN-15 and PN-30 and serial sections of the hypothalamus were processed for immunostaining of BrdU, GFAP, and tyrosine hydroxylase. The hypothalamus of the 30-day-old control rats display a few cells reactive with anti-BrdU; these cells were localized mostly in the tanycyte layer (Fig. 14C). The 15- and 30-day-old rats that had been treated with monosodium glutamate displayed a strikingly large number of labeled cells, localized mostly in the region occupied by $\alpha_{2}$ tanycytes (Fig. 14D and E). The ultrastructural study of this region indicates that at least some of these proliferating cells are indeed tanycytes (Fig. 14F). Large and smaller labeled nuclei are also seen in the regenerating arcuate nucleus (Fig. 14E). Double immunostaining for GFAP and BrdU reveals

\footnotetext{
Normal rat. (B) Rat treated with monosodium glutamate at PN-4. Both rats received three subcutaneous injections of $\mathrm{BrdU}(100 \mathrm{mg} / \mathrm{kg}$ body weight) per day, for the three consecutive days after the administration of monosodium glutamate. Immunostaining for BrdU. At variance with the normal rat (C), the treated rat (D) displays a large number of labeled cells, mostly corresponding to $\alpha_{2}$ tanycytes. Original magnification: $\times 85$. (E) Detailed magnification of (D), showing the large number of proliferating cells located in the area corresponding to $\alpha_{2}$ tanycytes and the large variation in size, shape, and intensity of immunoreaction of the labeled nuclei. Original magnification: $\times 330$. (Courtesy of C. Dimey Galindo and J. L. Blázquez.) Inset: Large labeled nucleus localized in the arcuate nucleus (neuron?) (arrow). Original magnification: $\times 450$. (F) Transmission electron microscopy of the medial basal hypothalamus of a 6-day-old rat treated with monosodium glutamate on PN-4. A dividing cell contacting the ventricular lumen (IR) and displaying in the cytoplasm two chromosome patches (arrows) and lipid droplets (LD) most likely corresponds to a tanycyte. To the right of the dividing cell there is a tanycyte displaying a single cilium. Mv, microvilli. Original magnification: $\times 15,000$.
} 
that some astrocytes display a labeled nucleus. The double immunostaining for BrdU and tyrosine hydroxylase has not yet provided convincing evidence of double labeling of the same cell. However, the size of the large labeled nuclei is matched only by the size of the nucleus of the arcuate neurons (Fig. 14E). Using a similar experimental design, G. Rivera (personal communication) has shown that cells of the arcuate nucleus display neuronal markers and a BrdU-labeled nucleus. Cells with cytoplasm showing many of the ultrastructural features of the arcuate neurons and displaying a nucleus with packed chromosomes (late telophase?) may be found underneath the tanycyte layer.

The long-lasting labeling of tanycytes in monosodium glutamate-treated rats, that is, 26 days after the last injection of BrdU, could be an indication that after the lesion, numerous tanycytes undergo asymmetric division giving rise to a new stem cell and to a progenitor cell. The former would remain in situ until a new stimulus triggers its proliferation and the BrdU becomes redistributed and consequently the labeling decreases. This possibility is supported by the fact that both the degree of the immunoreaction and the size of the labeled nuclei localized in the $\alpha_{2}$ tanycyte layer vary considerably (Fig. 14E). These ongoing findings obtained through this promising experimental model support the possibility that tanycytes have the ability to generate neurons and astrocytes. Xu et al. (2005) have presented convincing evidence that a subpopulation of tanycytes of adult normal rats behaves as neural progenitor cells that differentiate into hypothalamic neurons.

The neurogenic capacity of tanycytes deserves to be further investigated in an effort to answer some important questions. To what extent does the potential of radial glia change after they transform into tanycytes? Is this change reversible so that under certain conditions tanycytes regain neurogenic capacity? What is the actual potency of $\alpha$ tanycytes as neural generators? What distinguishes $\alpha$ tanycytes from the other tanycyte subtypes that apparently do not retain the neurogenic potency?

\section{Concluding Remarks}

After having been the subject of numerous investigations during the 1970s and early 1980s, tanycyte research was virtually abandoned until recently. During that period most of the morphological features of tanycytes had been recorded. Such features, together with certain experimental studies, pointed mainly to the probable transport capacity of tanycytes. This led numerous investigators to postulate tanycytes as a functional link between the ventricular CSF and the portal blood. However, none of the early hypotheses concerning the function of tanycytes had been supported by substantial 
evidence, and that research period rendered important questions that have remained without answers. More recently. new input into tanycyte research has occurred. Some early views have been substantiated with results obtained by new experimental designs and modern technical protocols. Thus, the remarkable identification of four types of tanycytes made 30 years ago by Akmayev and coworkers has been now fully confirmed. Similarly, relevant evidence supporting the notion that tanycytes may transport compounds from the CSF to the tanycyte terminals has been obtained. Nevertheless, identification of the compounds being transported by tanycytes needs to be thoroughly investigated. Worth mentioning are the findings by GarcíaSegura and coworkers, who have provided strong evidence that tanycytes absorb insulin growth factor from the CSF and transport it along their basal processes, and that such a capacity is under the influence of ovarian hormones.

The participation of tanycytes, in particular $\beta_{1}$ tanycytes, in the release of $\mathrm{GnRH}$ to the portal blood represents the aspect that has gained the most important input. Several research groups have obtained rather definitive evidence about the role tanycytes play in the complex mechanism of release of $\mathrm{GnRH}$ from the axon terminal to the portal blood. At variance, neither the nature of the neurotransmitter and/or peptide nor the functional significance of the rich neural input to $\beta_{2}$ tanycytes is known. Certainly, in light of all the information about neuron-glia cross-talk, the neuron-tanycyte relationship deserves to be revisited.

Reliable evidence is being collected about the secretory activity of tanycytes, and some of the secretory compounds have been identified. However, this is an aspect that deserves to be further investigated.

Emerging new evidence on functional aspects of tanycytes not previously envisaged is opening new and promising avenues. The possibility that tanycytes have the potency to generate neurons and astrocytes, retaining the potency of their ancestor cells, the radial glia, raises important questions that deserve to be investigated. To what extent does the potential of radial glia change after they transform into tanycytes? Is this change reversible so that under certain conditions tanycytes regain neurogenic capacity? What is the actual potency of $\alpha$ tanycytes as neural generators?

The fact that tanycytes are the main brain site of expression of thyroxine deiodinase type II and, consequently, the main source of brain $T_{3}$ is a puzzling finding that most likely will stimulate new investigations.

GLUT-2, a low-affinity transporter of glucose and fructose, and ATPsensitive $\mathrm{K}^{+}$channels are expressed by tanycytes, suggesting that they may sense CSF glucose concentrations; because there is a linear correlation between plasma and CSF glucose levels, tanycytes might be sensitive to glucose plasma levels. If CSF glucose levels actually are an input signal to tanycytes, what is the nature and target of the output signal? Would 
the glucose receptor neurons located in the ventromedial hypothalamus be a target? Because these latter neurons are involved in the complex mechanism controlling insulin secretion, the possibility that tanycytes, by monitoring the CSF glucose, participate in such a mechanism should be investigated.

Although some key questions concerning tanycytes have been clarified, several new and relevant questions have arisen.

\section{Acknowledgments}

We are most grateful to Drs. Gaspar Amat Peral, Feliciano Sánchez Domínguez, Rosa López Morales, Montserrat Matilla Barba, Carmen María Simón Salvador, and Carolina Dimey Galindo (Departamento de Anatomía e Histología Humanas, Facultad de Medicina, Universidad de Salamanca, Spain) for having allowed us to use in the present review some of the results included in their Ph.D. theses. The valuable help of Cesar González, M.Sc., is acknowledged. Our recent investigations on tanycytes have been supported by grant 1030265 (Fondecyt, Chile) to E.M.R. and by grant 01/1050 (FIS, Spain) to J.L.B.

\section{References}

Akmayev, I. G., and Fidelina, O. V. (1974). Morphological aspects of the hypothalamichypophyseal system. V. The tanycytes: Their relation to the hypophyseal adrenocorticotrophic function. An enzyme-histochemical study. Cell Tissue Res. 152, 403-410.

Akmayev, I. G., and Fidelina, O. V. (1976). Morphological aspects of the hypothalamichypophyseal system. VI. The tanycytes: Their relation to the sexual differentiation of the hypothalamus. An enzyme histochemical study. Cell Tissue Res. 173, 407-416.

Akmayev, I. G., and Popov, A. P. (1977). Morphological aspects of the hypothalamichypophyseal system. VII. The tanycytes: Their relation to the hypophyseal adrenocorticotrophic function. An ultrastructural study. Cell Tissue Res. 180, 263-282.

Akmayev, I. G., Fidelina, O. V., Kabolova, Z. A., Popov, A. P., and Schitkova, T. A. (1973). Morphological aspects of the hypothalamic-hypophyseal system. IV. Medial basal hypothalamus. An experimental morphological study. Z. Zellforsch. 137, 493-512.

Alonso, G., Prieto, M., Legrand, A., and Chauvet, N. (1997). PSA-NCAM and B-50/GAP43 are co-expressed by specific neuronal systems of the adult rat mediobasal hypothalamus that exhibit remarkable capacity for morphological plasticity. J. Comp. Neurol. 384, 181-199.

Altman, J., and Bayer, S. A. (1978). Development of the diencephalon in the rat. III. Ontogeny of the specialized ventricular linings of the hypothalamic third ventricle. J. Comp. Neurol. 182, 995-1016.

Altman, J., and Bayer, S. A. (1986). The development of the rat hypothalamus. Adv. Anat. Embryol. Cell Biol. 100, 1-173.

Alvarez, E., Roncero, I., Chowen, J. A., Thorens, B., and Blázquez, E. (1996). Expression of the glucagon-like peptide-1 receptor gene in rat brain. J. Neurochem. 66, 920-927.

Alvarez-Buylla, A., García-Verdugo, J. M., and Tramontin, A. D. (2001). A unified hypothesis on the lineage of neural stem cells. Nat. Rev. Neurosci. 2, 287-293.

Alvarez-Buylla, A., Seri, B., and Doetsch, F. (2002). Identification of neural stem cells in the adult vertebrate brain. Brain Res. Bull. 57, 751-758. 
Amat, P., Pastor, F. E., Blázquez, J. L., Toranzo, D., and Muñoz Barragan, L. (1985). Ultrastructural study of the nerve endings of the hypothalamic neurosecretory systems. Acta Microsc. 8, 367-378.

Amat, P., Pastor, F. E., Blázquez, J. L., Peláez, B., Sánchez, A., Alvarez-Morujo, A. J., Toranzo, D., and Amat-Peral, G. (1999). Lateral evaginations from the third ventricle into the rat mediobasal hypothalamus: An amplification of the ventricular route. Neuroscience $\mathbf{8 8 ,}$ 673-677.

Anthony, T. E., Klein, C., Fishell, G., and Heintz, N. (2004). Radial glia serve as neuronal progenitors in all regions of the central nervous system. Neuron 41, 881-890.

Baker, B. L., Dermody, W. C., and Reel, J. R. (1975). Distribution of gonadotropinreleasing hormone in the rat brain as observed with immunocytochemistry. Endocrinology 97, 125-135.

Barry, L., and Dubois, M. P. (1976). Immunoreactive LRF neurosecretory pathways in mammals. Acta Anat. 94, 497-503.

Barry, J., Dubois, M. P., and Poulain, P. (1973). LRF producing cells of the mammalian hypothalamus: A fluorescent antibody study. Z. Zellforsch. 146, 351-366.

Beauvillain, J. C., Moyse, E., Dutriez, I., Mitchell, V., Poulain, P., and Mazzuca, M. (1992). Localization of opioid receptors on the membranes of nerve endings and tanycytes in the guinea-pig median eminence by electron microscopic radioautography. Neuroscience 49, 925-936.

Ben-Jonathan, N., Mical, R. S., and Porter, J. C. (1974). Transport of LRF from CSF to hypohysial portal and systemic blood and release of LH. Endocrinology 95, 18-25.

Berger, U. V., and Hediger, M. A. (2001). Differential distribution of the glutamate transporters GLT-1 and GLAST in tanycytes of the third ventricle. J. Comp. Neurol. 433, 101-114.

Bezzi, P., and Volterra, A. (2001). A neuron-glia signaling network in the active brain. Curr. Opin. Neurobiol. 11, 387-394.

Bjelke, B., and Fuxe, K. (1993). Intraventricular $\beta$-endorphin accumulates in DARPD-32 immunoreactive tanycytes. Neuroreport 5, 265-268.

Blázquez, J. L., Guerra, M., Pastor, F., Peruzzo, B., Amat, P., and Rodríguez, E. M. (2002). Antibodies obtained by xenotransplantation of organ-cultured median eminence specifically recognize hypothalamic tanycytes. Cell Tissue Res. 308, 241-253.

Bleier, R. (1971). The relations of ependyma to neurons and capillaries in the hypothalamus: A Golgi-Cox study. J. Comp. Neurol. 142, 439-463.

Bleier, R. (1972). Structural relationship of ependymal cells and their processes within the hypothalamus. In "Brain-Endocrine Interaction" (K. M. Knigge, D. E. Scott, and A. Weindl, Eds.), Vol. I, pp. 306-318. Karger, Basel, Switzerland.

Bock, R., and Goslar, H. G. (1969). Enzymhistochemische Untersuchungen an Infundibulum und Hypophysenhinterlappen der normalen und beidseitig adrenalektomierten Ratte. $Z$. Zellforsch. 95, 415-428.

Bodoky, M., Koritsánszky, S., and Réthelyi, M. (1979). A system of intraependymal cisternae along the margins of the median eminence in the rat: Structure, three-dimensional arrangement and ontogeny. Cell Tissue Res. 196, 163-173.

Bottner, M., Krieglstein, K., and Unsicker, K. (2000). The transforming growth factor- $\beta$ s: Structure, signalling, and roles in nervous system development and functions. J. Neurochem. 75, 2227-2240.

Brann, D. W., and Mahesh, V. B. (1991). Regulation of gonadotropin secretion by steroid hormones. Front. Neuroendocrinol. 12, 165-207.

Brawer, J. R. (1972). The fine structure of the ependymal tanycytes at the level of the arcuate nucleus. J. Comp. Neurol. 145, 25-42.

Brawer, J. R., and Walsh, R. J. (1982). Response of tanycytes to aging in the median eminence of the rat. Am. J. Anat. 163, 247-256. 
Brawer, J. R., Lin, P. S., and Sonnenschein, C. (1974). Morphological plasticity in the wall of the third ventricle during the estrous cycle in the rat: A SEM study. Anat. Rec. 179, 481-489.

Brightman, M. W., and Reese, T. S. (1969). Junctions between intimately apposed cell membranes in the vertebrate brain. J. Cell Biol. 40, 648-677.

Brightman, M. W., Prescott, L., and Reese, T. S. (1975). Intercellular junctions of special ependyma. In "Brain-Endocrine Interaction" (K. M. Knigge, D. E. Scott, H. Kobayashi, and S. Ishii, Eds.), Vol. II, pp. 146-165. Karger, Basel, Switzerland.

Brion, J. P., Depierreux, M., Couck, A. M., and Flament-Durand, J. (1982). Transmission and scanning electron-microscopic observations on tanycytes in the mediobasal hypothalamus and the median eminence of adrenalectomized rats. Cell Tissue Res. 221, 643-655.

Broadwell, R. D., Balin, B. J., and Cataldo, A. M. (1987). Fine structure and cytochemistry of the mammalian median eminence. In "Circumventricular Organs and Body Fluids" (P. M. Gross, Ed.), Vol. II, pp. 61-85. CRC Press, Boca Raton, FL.

Bruni, J. E. (1998). Ependymal development, proliferation and functions: A review. Microsc. Res. Tech. 41, 2-13.

Bruni, J. E., Clattenburg, R. E., and Millar, E. (1983). Tanycyte ependymal cells in the third ventricle of young and adult rats: A Golgi study. Anat. Anz. 153, 53-68.

Bruni, J. E., Del Bigio, M. R., and Clattenburg, R. E. (1985). Ependyma: Normal and pathological. A review of the literature. Brain Res. Rev. 9, 1-19.

Calas, A. (1975). The avian median eminence as a model for diversified neuroendocrine routes. In "Brain-Endocrine Interaction" (K. M. Knigge, D. E. Scott, H. Kobayashi, and S. Ishii, Eds.), Vol. II, pp. 54-69. Karger, Basel, Switzerland.

Campbell, K. (2003). Signaling to and from radial glia. Glia 43, 44-46.

Card, J. P., and Rafols, J. A. (1978). Tanycytes of the third ventricle of the neonatal rat: A Golgi study. Am. J. Anat. 151, 173-190.

Cardona-Gómez, G. P., Doncarlos, L., and García-Segura, L. M. (2000). Insulin-like growth factor I receptors and estrogen receptors colocalize in female rat brain. Neuroscience 99, $751-760$.

Carmignoto, G. (2000). Reciprocal communication systems between astrocytes and neurones. Prog. Neurobiol. 62, 561-581.

Carretero, J., Burks, D., Rubio, M., Blanco, E., Herrero, J. J., Bodego, P., Juanes, J. A., Hernández, E., and Riesco, J. M. (2002). Immunocytochemical evidence for growth hormone-releasing hormone in the tanycytes of the median eminence of the rat. Folia Morphol. 61, 209-216.

Chanas-Sacré, G., Rogister, B., Moonen, G., and Leprince, P. (2000). Radial glia phenotype: Origin, regulation, and transdifferentiation. J. Neurosci. Res. 61, 357-363.

Chauvet, N., Privat, A., and Alonso, G. (1996). Aged median eminence glial cell cultures promote survival and neurite outgrowth of cocultured neurons. Glia 18, 211-223.

Chauvet, N., Apert, C., Dumoulin, A., Epelbaum, J, and Alonso, G. (1997). Mab22C11 antibody to amyloid precursor protein recognizes a protein associated with specific astroglial cells of the rat central nervous system characterized by their capacity to support axonal outgrowth. J. Comp. Neurol. 377, 550-564.

Chiba, A. (2001). Marked distributional difference of $\alpha$-melanocyte-stimulating hormone $(\alpha-$ MSH)-like immunoreactivity in the brain between two elasmobranchs (Scyliorhinus torazame and Etmopterus brachyurus): An immunohistochemical study. Gen. Comp. Endocrinol. 122, 287-295.

Coggeshall, R. E. (1964). A study of diencephalic development in the albino rat. J. Comp. Neurol. 122, 241-270. 
Das, G. D. (1979). Gliogenesis and ependymogenesis during embryonic development of the rat. J. Neurol. Sci. 43, 193-204.

Davson, H., and Segal, M. B. (1996). "Physiology of the CSF and Blood-Brain Barriers." CRC Press, Boca Raton, FL.

Dellmann, H. D. (1977). Ultrastructure of homografts of the rat median eminence into the anterior chamber of the eye. Neuroendocrinology 23, 99-112.

Dellmann, H. D., and Rodríguez, E. M. (1970). Neuronal transformation of ependymal cells in the median eminence of the grass frog (Rana pipiens) after transection of the proximal neurohypophysis. J. Endocrinol. 47, 399-401.

Diano, S., Naftolin, F., and Horvath, T. L. (1998). Kainate glutamate receptors (GluR5-7) in the rat arcuate nucleus: Relationship to tanycytes, astrocytes, neurons and gonadal steroid receptors. J. Neuroendocrinol. 10, 239-247.

Dueñas, M., Luquín, S., Chowen, J. A., Torres-Alemán, I., Naftolin, F., and García Segura, L. M. (1994). Gonadal hormone regulation of insulin-like growth factor-I-like immunoreactivity in hypothalamic astroglia of developing and adult rats. Neuroendocrinology 59, 528-538.

Duvernoy (1972). The vascular architecture of the median eminence. In "Brain-Endocrine Interaction" (K. M. Knigge, D. E. Scott, and A. Weindl, Eds.), Vol. I, pp. 79-108. Karger, Basel, Switzerland.

Edwards, M. A., Yamamoto, M., and Caviness, V. S.Jr. (1990). Organization of radial glia and related cells in the developing murine CNS: An analysis based upon a new monoclonal antibody marker. Neuroscience 36, 121-144.

Elkjaer, M., Vajda, Z., Nejsum, L. N., Kwon, T., Jensen, U. B., Amiry-Moghaddam, M., Frokiaer, J., and Nielsen, S. (2000). Immunolocalization of AQP9 in liver, epididymis, testis, spleen and brain. Biochem. Biophys. Res. Commun. 276, 1118-1128.

Errante, L. D., Wiche, G., and Shaw, G. (1994). Distribution of plectin, an intermediate filament-associated protein, in the rat central nervous system. J. Neurosci. Res. 37, 515-528.

Everitt, B. J., Meister, B., Hökfelt, T., Melander, T., Terenius, L., Rökaeus, A., TheodorssonNorheim, E., Dockray, G., Edwardson, J., Cuello, C., Elde, R., Goldstein, M., Hemmings, H., Ouimet, C., Walaas, I., Greengard, P., Vale, W., Weber, E., Wu, J.-Y., and Chang, K.-J. (1986). The hypothalamic arcuate nucleus-median eminence complex: Immunohistochemistry of transmitters, peptides and DARPP-32 with special reference to coexistence in dopamine neurons. Brain Res. Rev. 11, 97-155.

Eyigor, O., and Jennes, L. (1998). Identification of kainate-preferring glutamate receptor subunit GluR7 mRNA and protein in the rat median eminence. Brain Res. 814, 231-235.

Fekete, C., Mihaly, E., Herscovici, S., Salas, J., Tu, H., Larsen, P. R., and Lechan, R. M. (2000). DARPP-32 and CREB are present in type 2 iodothyronine deiodinase-producing tanycytes: Implications for the regulation of type 2 deiodinase activity. Brain Res. 862, 154-161.

Fernández-Galaz, M. C., Torres Alemán, I., and García-Segura, L. M. (1996). Endocrinedependent accumulation of IGF-I by hypothalamic glia. Neuroreport 8, 373-377.

Fernández-Galaz, M. C., Morschl, E., Chowen, J. A., Torres Alemán, I., Naftolin, F., and García-Segura, L. M. (1997). Role of astroglia and insulin-like growth factor-I in gonadal hormone-dependent synaptic plasticity. Brain Res. Bull. 44, 525-531.

Firth, J. A., and Bock, R. (1976). Distribution and properties of an adenosine triphosphatase in the tanycyte ependyma of the IIIrd ventricle of the rat. Histochemistry 47, 145-157.

Fischer, A. J., and Reh, T. A. (2001). Muller glia are potential source of neural regeneration in the postnatal chicken retina. Natl. Neurosc. 4, 247-252.

Flament-Durand, J. (1978). Transmission and scanning electron microscopy study of the ependymal lining of the third ventricle in man and in the rat. Bull. Mem. Acad. R. Med. Belg. 133, 88-102. 
Flament-Durand, J., and Brion, J. P. (1985). Tanycytes: Morphology and function. A review. Int. Rev. Cytol. 96, 121-155.

Galbiati, M., Saredi, S., and Melcangi, R. C. (2003). Steroid hormones and growth factors act in an integrated manner at the levels of hypothalamic astrocytes: A role in the neuroendocrine control of reproduction. Ann. N.Y. Acad. Sci. 1007, 162-168.

Garcia, M. A., Carrasco, M., Godoy, A., Reinicke, K., Montecinos, V. P., Aguayo, L. G., Tapia, J. C., Vera, J. C., and Nualart, F. (2001). Elevated expression of glucose transporter-1 in hypothalamic ependymal cells not involved in the formation of the brain-cerebrospinal fluid barrier. J. Cell. Biochem. 80, 491-503.

García, M. A., Millán, C., Balmaceda-Aguilera, C., Castro, T., Pastor, P., Montecinos, H., Reinicke, K., Zúñiga, F., Vera, J. C., Oñate, S. A., and Nualart, F. (2003). Hypothalamic ependymal-glial cells express the glucose transporter GLUT-2, a protein involved in glucose sensing. J. Neurochem. 86, 709-724.

García-Segura, L. M., Pérez, J., Pons, S., Rejas, M. T., and Torres-Alemán, I. (1991). Localization of insulin-like growth factor I (IGF-I)-like immunoreactivity in the developing and adult rat brain. Brain Res. 500, 167-174.

García-Segura, L. M., Luquín, S., Párducz, A., and Naftolin, F. (1994). Gonadal hormone regulation of glial fibrillary acidic protein immunoreactivity and glial ultrastructure in the rat neuroendocrine hypothalamus. Glia 10, 59-69.

García-Segura, L. M., Chowen, J. A., and Naftolin, F. (1996). Endocrine glia: Roles of glial cells in the brain actions of steroid and thyroid hormones and in the regulation of hormone secretion. Front. Neuroendocrinol. 17, 180-211.

Garcia-Segura, L. M., Rodriguez, J. R., and Torres-Alemán, I. (1997). Localization of the insulin-like growth factor I receptor in the cerebellum and hypothalamus of adult rats: An electron microscopic study. J. Neurocytol. 26, 479-490.

García-Segura, L. M., Naftolin, F., Hutchinson, J. B., Azcoitia, I., and Chowen, J. A. (1999). Role of astroglia in estrogen regulation of synaptic plasticity and brain repair. J. Neurobiol. 40, 574-584.

Gibson, M. J., Ingraham, L., and Dobrjansky, A. (2000). Soluble factors guide gonadotropinreleasing hormone axonal targeting to the median eminence. Endocrinology 141, 3065-3071.

Goldgefter, L. (1976). Non-difffusional distribution of radioactivity in the rat median eminence after intraventricular injection of $\left[{ }^{3} \mathrm{H}\right] \mathrm{LH}-\mathrm{RH}$. Cell Tissue Res. 168, 411-418.

Goldman, S. (2003). Glia as neural progenitor cells. Trends Neurosci. 26, 590-596.

Gore, A. C., and Roberts, J. L. (1997). Regulation of gonadotropin-releasing hormone gene expression in vivo and in vitro. Front. Neuroendocrinol. 18, 209-245.

Goslar, H. G., and Bock, R. (1970). Zur Spaltbarkeit verschiedener Naphthol-Carbonsäureester durch Esterasen im tanycytenependym des III.Ventrikels der Wistarratte. Histochemie 21, 353-365.

Götz, M., Hartfuss, E., and Malatesta, P. (2002). Radial glial cells as neuronal precursors: A new perspective on the correlation of morphology and lineage restriction in the developing cerebral cortex of mice. Brain Res. Bull. 57, 777-788.

Grattan, D. R., Park, S.-K., and Selmanoff, M. (1995). Orchidectomy and NMDA increase GnRH secretion as measured by push-pull perfusion of rat anterior pituitary. Am. J. Physiol. 268, E685-E692.

Gudiño-Cabrera, G., and Nieto-Sampedro, M. (2000). Schwann-like macroglia in adult rat brain. Glia 30, 49-63.

Guldner, F. H., and Wolff, J. R. (1973). Neurono-glial synaptoid contacts in the median eminence of the rat: Ultrastructure, staining properties and distribution on tanycytes. Brain Res. 61, 217-234.

Hashemi, S. H., Li, J. Y., Schindler, M., and Dahlstrom, A. (2001). Presence of sst 2 (a) receptor $^{2}$ immunoreactivity in rat ependyma and tanycytes. Neuroreport 12, 1793-1797. 
Hiney, J. K., Srivastava, V., Nyberg, C. L., Ojeda, S. R., and Les Dees, W. (1996). Insulin-like growth factor I of peripheral origin acts centrally to accelerate the initiation of female puberty. Endocrinology 137, 3717-3728.

Hofer, H. (1958). Zur Morphologie der Circumventrikulären Organe der Zwischenhirns der Säugetiere. Verh. Dtsch. Zool. Ges. 22, 202-261.

Hökfelt, T. (1973). Possible site of action of dopamine in the hypothalamic pituitary control. Acta Physiol. Scand. 89, 606-608.

Hökfelt, T., Foster, G., Schultzberg, M., Meister, B., Schalling, M., Goldstein, M., Hemmings, H. C.Jr., Ouimet, C., and Greengard, P. (1988). DARPP-32 as a marker for D-1 dopaminoceptive cells in the rat brain: Prenatal development and presence in glial elements (tanycytes) in the basal hypothalamus. Adv. Exp. Med. Biol. 235, 65-82.

Horstmann, E. (1954). Die Faserglia des Selachiergehirns. Z. Zellforsch. 39, 588-617.

Hu, L., Ferstrom, J. D., and Goldsmith, P. C. (1998). Exogenous glutamate enhances glutamate receptor subunit expression during selective neuronal injury in the ventral arcuate nucleus of postnatal mice. Neuroendocrinology 68, 77-88.

Joy, K. P., and Sathyanesan, A. G. (1981). A Golgi-Cox study of tanycytes in the hypothalamic region of the third ventricle in the wild rat, Rattus rattus (L.). Acta Anat. 111, 296-304.

Kalra, P. S., and Kalra, S. P. (1981). Differential effects of low serum levels of estradiol-17ß on hypothalamic LHRH levels and LH secretion in castrated male rats. Neuroendocrinology 33, 340-346.

Kaur, C., Ling, E. A., and Wong, W. C. (1989). Scanning electron microscope of transitory subependymal cysts in the developing midbrain of postnatal rats. Arch. Histol. Cytol. 52, 311-317.

Kawakami, S. (2000). Glial and neuronal localization of ionotropic glutamate receptor subunit-immunoreactivities in the median eminence of female rats: GluR2/3 and GluR6/7 colocalize with vimentin, not glial fibrillary acidic protein (GFAP). Brain Res. 858, 198-204.

Kendall, J. W., Jacobs, J. J., and Kramer, R. M. (1972). Studies on the transport of hormones from the cerebrospinal fluid to hypothalamus and pituitary. In "Brain-Endocrine Interaction" (K. M. Knigge, D. E. Scott, and A. Weindl, Eds.), Vol. I, pp. 342-349. Karger, Basel, Switzerland.

King, J. C., and Letourneau, R. J. (1994). Luteinizing hormone-releasing hormone terminals in the median eminence of rats undergo dramatic changes after gonadectomy, as revealed by electron microscopic image analysis. Endocrinology 134, 1340-1351.

King, J. C., and Rubin, B. S. (1994). Dynamic changes in LHRH neurovascular terminals with various endocrine conditions in adults. Horm. Behav. 28, 349-356.

King, J. C., and Rubin, B. S. (1995). Dynamic alterations in luteinizing hormone-releasing hormone (LHRH) neuronal cell bodies and terminals of adult rats. Cell. Mol. Neurobiol. 15, 90-106.

King, J. C., Parsons, J. A., Erlandsen, S. L., and Williams, T. H. (1974). Luteinizing hormonereleasing hormone (LH-RH) pathway of the rat hypothalamus revealed by the unlabeled antibody peroxidase-antiperoxidase method. Cell Tissue Res. 153, 211-217.

King, J. C., Kugel, G., Zahniser, D., Wooledge, K., Damassa, D. A., and Alexsavich, B. (1987). Changes in populations of LHRH-immunopositive cell bodies following gonadectomy. Peptides 8, 721-735.

Knigge, K. M., and Scott, D. E. (1970). Structure and function of the median eminence. Am. J. Anat. 129, 223-244.

Knigge, K. M., and Silverman, A. J. (1972). Transport capacity of the median eminence. In "Brain-Endocrine Interaction" (K. M. Knigge, D. E. Scott, and A. Weindl, Eds.), Vol. I, pp. 350-363. Karger, Basel, Switzerland. 
Knigge, K. M., Joseph, S. A., Sladeck, J. R., Notter, M. F., Morris, M., Sundberg, D. K., Holzwarth, M. A., Hoffman, G. E., and O' Brien, L. (1976). Uptake and transport activity of the median eminence of the hypothalamus. Int. Rev. Cytol. 129, 223-244.

Knowles, F., and Kumar, T. C. (1969). Structural changes, related to reproduction, in the hypothalamus and in pars tuberalis of the rhesus monkey. Phil. Trans. R. Soc. London 256, 357-375.

Kobayashi, H. (1975). Absorption of cerebrospinal fluid by ependymal cells of the median eminence. In "Brain-Endocrine Interaction" (K. M. Knigge, D. E. Scott, H. Kobayashi, and S. Ishii, Eds.), Vol. II, pp. 109-122. Karger, Basel, Switzerland.

Kobayashi, H., and Matsui, T. (1967). Synapses in the rat and pigeon median eminence. Endocrinol. Jpn. 14, 279-283.

Kobayashi, H., Matsui, T., and Ishii, S. (1970). Functional electron microscopy of the hypothalamic median eminence. Int. Rev. Cytol. 29, 281-381.

Kobayashi, H., Wada, M., Uemura, H., and Ueck, M. (1972). Uptake of peroxidase from the third ventricle by ependymal cells of the median eminence. Z. Zellforsch. 127, 545-551.

Korr, H. (1980). Proliferation of different cell types in the brain. Adv. Anat. Embryol. Cell Biol. 61, 1-72.

Kozlowski, G. P., and Coates, P. W. (1985). Ependymoneuronal specialization between LHRH fibers and cells of the cerebroventricular system. Cell Tissue Res. 242, 301-311.

Kriegstein, A. R., and Götz, M. (2003). Radial glia diversity: A matter of fate. Glia 43, $37-43$.

Krisch, B. (1978). The distribution of LHRH in the hypothalamus of the thirsting rat: A light and electron microscopic immunocytochemical study. Cell Tissue Res. 186, 135-148.

Krisch, B., Leonhardt, H., and Buchheim, W. (1978). The functional and structural border of the neurohemal region of the median eminence. Cell Tissue Res. 192, 327-339.

Krisch, B., Leonhardt, H., and Oksche, A. (1983). The meningeal compartments of the median eminence and the cortex. Cell Tissue Res. 228, 597-640.

Kumar, T. C. A. (1968). Sexual differences in the ependyma lining the third ventricle in the area of the anterior hypothalamus of adult rhesus monkeys. Z. Zellforch. 90, 28-36.

Langub, M. C., and Watson, R. E. (1992). Estrogen receptor-immunoreactive glia, endothelia, and ependyma in guinea pig preoptic area and median eminence: Electron microscopy. Endocrinology 130, 364-372.

Legait, H., Roux, M., Burlet, A., Burlet, C., Contet-Audonneacu, J. L., and Sirjean, D. (1973). Les images alvéolaires ou lacunaires de la région infundibulaire chez les mammifères. Bull. Ass. Anat. 57, 123-127.

Leloup, C., Arluison, M., Lepetit, N., Cartier, N., Marfaing-Jallat, P., Ferré, P., and Pénicaud, L. (1996). Glucose transporter 2 (GLUT2): Expression in specific brain nuclei. Brain Res. 638, 221-226.

Leonhardt, H. (1966). Über ependymale Tanycyten des III. Ventrikels beim Kaninchen in elektronenmikroskopishcer Betrachtung. Z. Zellforsch. 74, 1-11.

Leonhardt, H. (1980). Ependym und Circumventriculäre Organe. In "Handbuch der Mikroskopischen: Anatomie des Menschen" (A. Oksche and L. Vollrath, Eds.), Vol. IV/ 10, pp. 177-665. Springer-Verlag, Berlin.

Leonhardt, H., Krisch, B., and Erhardt, H. (1987). Organization of the neuroglia in the midsagittal plane of the central nervous system: A speculative report. In "Functional Morphology of Neuroendocrine Systems" (B. Scharrer, H. W. Korf, and H. G. Hartwig, Eds.), pp. 175-187. Springer-Verlag, Berlin.

Lerant, A., and Freeman, M. E. (1998). Ovarian steroids differentially regulate the expression of PRL-R in neuroendocrine dopaminergic neuron populations: A double label confocal microscopic study. Brain Res. 802, 141-154. 
Leveque, T. F., and Hofkin, G. A. (1961). Demonstration of an alcohol-chloroform insoluble, periodic acid-Schiff reactive substance in the hypothalamus of the rat. Z. Zellforsch. 53, 185-191.

Levitt, P., and Rakic, P. (1980). Immunoperoxidase localization of glial fibrillary acidic protein in radial glial cells and astrocytes of the developing rhesus monkey brain. J. Comp. Neurol. 193, 815-840.

Levitt, P., Cooper, M. L., and Rakic, P. (1983). Early divergence and changing proportions of neuronal and glial precursor cells in the primate cerebral ventricular zone. Dev. Biol. 96, 472-484.

Li, H., Babiarz, J., Woodbury, J., Kane-Goldsmith, N., and Brumet, M. (2004). Spatiotemporal heterogeneity of CNS radial glial cells and their transition to restricted precursors. Dev. Biol. 271, 225-238.

Löfgren, F. (1958). A new theory on the relationship between the hypothalamus and the adenohypophysis. Lunds Universitets Arsskrift, N.F. AVD 2-54, 1-15.

Löfgren, F. (1959). New aspects of the hypothalamic control of the adenohypophysis. Acta Morphol. Neerl. Scand. 2, 220-229.

Löfgren, F. (1960). The infundibular recess, a component in the hypothalamo-adenohypophysial system. Acta Morphol. Neerl. Scand. 3, 55-78.

Löfgren, F. (1961). The glial-vascular apparatus in the floor of the infundibular cavity: Further studies on the transport mechanism between the hypothalamus and the anterior pituitary. Lunds Universitets Arsskrift, N. F. AVD. 2-57, 1-18.

LoTurco, J. J., Owens, D. F., Heath, M. J. S., Davis, M. B. E., and Kriegstein, A. R. (1995). GABA and glutamate depolarize cortical progenitor cells and inhibit DNA synthesis. Neuron 15, 1287-1298.

Ma, Y. J., Kelly, M. J., and Ronnekleiv, O. K. (1990). Pro-gonadotropin-releasing hormone (ProGnRH) and GnRH content in the preoptic area and the basal hypothalamus of anterior medial preoptic nucleus/suprachiasmatic nucleus-lesioned persistent estrous rats. Endocrinology 127, 2654-2664.

Ma, Y. J., Berg-von der Emde, K., Moholt-Siebert, M., Hill, D. F., and Ojeda, S. R. (1994a). Region-specific regulation of transforming growth factor $\alpha(\mathrm{TGF} \alpha)$ gene expression in astrocytes of the neuroendocrine brain. J. Neurosci. 14, 5644-5651.

Ma, Y.J, Hill, D. F., Junier, M., Costa, M. E., Felder, S. E., and Ojeda, S. R. (1994b). Expression of epidermal growth factor receptor changes in the hypothalamus during the onset of female puberty. Moll. Cell. Neurosci. 5, 246-262.

Ma, Y. J., Berg von der Emde, K., Rage, F., Wetsel, W. C., and Ojeda, S. R. (1997). Hypothalamic astrocytes respond to transforming growth factor- $\alpha$ with the secretion of neuroactive substances that stimulate the release of luteinizing hormone-releasing hormone. Endocrinology 138, 19-25.

Ma, Y. J., Hill, D. F., Creswick, K. E., Costa, M. E., Cornea, A., Lioubin, M. N., Plowman, G. D., and Ojeda, S. R. (1999). Neuregulins signaling via a glial erbB-2-erbB-4 receptor complex contribute to the neuroendocrine control of mammalian sexual development. J. Neurosci. 19, 9913-9927.

Malatesta, P., Hartfuss, E., and Götz, M. (2000). Isolation of radial glial cells by fluorescentactivated cell sorting reveals a neuronal lineage. Development 127, 5253-5263.

Marchetti, B. (1997). Cross-talk signals in the CNS: Role of neurotrophic and hormonal factors, adhesion molecules and intercellular signaling agents in luteinizing hormonereleasing hormone (LHRH)-astroglial interactive network. Front. Biosci. 2, 88-125.

Martini, L., Motta, M., Piva, F., and Zanisi, M. (1997). LHRF, LHRH, GnRH: What controls the secretion of this hormone? Mol. Psychiatry 2, 373-376. 
Matsubara, M., Nakagawa, K., Takayashi, Y., Ito, K., Matsuoka, T., and Takeda, S. (1988). Immunoreactive LHRH in cerebrospinal fluid: The clinical significance in intracraneal disease. Endocrinol. Jpn. 35, 405-412.

Matsui, T. (1966). Effect of prolonged daily photoperiods on the hypothalamic neurosecretory system of the tree sparrow (Passer montanus saturatus). Endocrinol. Jpn. 13, 23-38.

Matsuo, A., Tooyama, I., Isobe, S., Oomura, Y., Akiguchi, I., Hanai, K., Kimura, J., and Kimura, H. (1994). Immunohistochemical localization in the rat brain of an epitope corresponding to the fibroblast growth factor receptor-1. Neuroscience 60, 49-66.

McQueen, J. K. (1994). Glial cells and neuroendocrine function. J. Endocrinol. 143, 411-415.

Meister, B., Hökfelt, T., Tsuruo, Y., Hemmings, H., Ouimet, C., Greengard, P., and Goldstein, M. (1988). DARPP-32, a dopamine- and cyclic AMP-regulated phosphoprotein in tanycytes of the mediobasal hypothalamus: Distribution and relation to dopamine and luteinizing hormone-releasing hormone neurons and other glial elements. Neuroscience 27, 607-622.

Meister, B., Ceccatelli, S., Hökfelt, T., Andén, N. E., Andén, M., and Theodorsson, E. (1989). Neurotransmitters, neuropeptides and binding sites in the rat mediobasal hypothalamus: Effects of monosodium glutamate (MSG) lesions. Exp. Brain Res. 76, 343-368.

Melcangi, R. C., Galbiati, M., Messi, E., Piva, F., Martini, L., and Motta, M. (1995). Type 1 astrocytes influence luteinizing hormone-releasing hormone release from the hypothalamic cell line GT1-1: Is transforming growth factor- $\beta$ the principle involved? Endocrinology 136, 679-686.

Melcangi, R. C., Cavarretta, I., Magnaghi, V., Martini, L., and Galbiati, M. (2001). Interactions between growth factors and steroids in the control of LHRH-secreting neurons. Brain Res. Brain Res. Rev. 37, 223-234.

Melcangi, R. C., Martini, L., and Galbiati, M. (2002). Growth factors and steroid hormones: A complex interplay in the hypothalamic control of reproductive functions. Prog. Neurobiol. 67, 421-449.

Merkle, F. T., Tramontin, A. D., García-Verdugo, J., and Alvarez-Buylla, A. (2004). Radial glia give rise to adult neural stem cells in the subventricular zone. Proc. Natl. Acad. Sci. USA 101, 17528-17532.

Messi, E., Galbiati, M., Magnaghi, V., Zucchi, I., Martini, L., and Melcangi, R. C. (1999). Transforming growth factor $\beta_{2}$ is able to modify mRNA levels and release of luteinizing hormone-releasing hormone in a immortalized hypothalamic cell line (GT1-1). Neurosci. Lett. 270, 165-168.

Mestres, P. (1981). The ventricular surface of the monkey mediobasal hypothalamus: A scanning electron microscopic study. Anat. Embryol. 161, 391-404.

Mestres, P., and Jaeschke, H. (1977). Structural changes in the ependymal surface of the rat hypothalamus during the ovarian cycle. Scanning Electron Microsc. II, 567-574.

Miaczynska, M., and Zerial, M. (2002). Mosaic organization of the endocytic pathway. Exp. Cell Res. 272, 8-14.

Millhouse, O. E. (1971). A Golgi study of third ventricle tanycytes in the adult rodent brain. $Z$. Zellforsch. 121, 1-13.

Millhouse, O. E. (1975). Lining of the third ventricle in the rat. In "Brain Endocrine Interaction” (K. M. Knigge, D. E. Scott, H. Kobayashi, and S. Ishii, Eds.), Vol. II, pp. 3-18. Karger, Basel, Switzerland.

Moenter, S. M., De Fazio, R. A., Pitts, G. R., and Nunemaker, C. S. (2003). Mechanisms underlying episodic gonadotropin-releasing hormone secretion. Front. Neuroendocrinol. 24, 79-93. 
Monroe, B. G., and Paull, W. K. (1974). Ultrastructural changes in the hypothalamus during development and hypothalamic activity: The median eminence. Prog. Brain Res. 41, 185-208.

Mostov, K. E., Verges, M., and Altschuler, Y. (2000). Membrane traffic in polarized epithelial cells. Curr. Opin. Cell Biol. 12, 483-490.

Nakai, Y., and Naito, N. (1975). Uptake and bi-directional transport of peroxidase injected into the blood and cerebral spinal fluid by ependymal cells of the median eminence. In "Brain-Endocrine Interaction" (K. M. Knigge, D. E. Scott, H. Kobayashi, and S. Ishii, Eds.), Vol. II, pp. 94-108. Karger, Basel, Switzerland.

Nichols, B. J., and Lippincott-Schwartz, J. (2001). Endocytosis without clathrin coats. Trends Cell Biol. 11, 406-412.

Noctor, S. C., Flint, A. C., Weissman, T. A., Dammermann, R. S., and Kriegstein, A. R. (2001). Neurons derived from radial glial cells establish radial units in neocortex. Nature 409, 714-720.

Nozaki, M. (1975). Tanycyte absorption affected by the hypothalamic deafferentation in Japanese quail, Coturnix coturnix japonica. Cell Tissue Res. 163, 433-443.

Nozaki, M., Kobayashi, H., Yanagisawa, M., and Bando, T. (1975). Monoamine fluorescence in the median eminence of the Japanese quail, Coturnix coturnix japonica, following medial basal hypothalamic deafferentation. Cell Tissue Res. 164, 425-434.

Nozaki, M., Uemura, H., and Kobayashi, H. (1980). Hypothalamo-hypophysial function following the lesion of tanycytes in the median eminence of the rat. Cell Tissue Res. 209, 225-238.

Ojeda, S. R., and Ma, Y. J. (1998). Epidermal growth factor tyrosine kinase receptors and the neuroendocrine control of mammalian puberty. Mol. Cell. Endocrinol. 140, 101-106.

Ojeda, S. R., and Ma, Y. J. (1999). Glial-neuronal interactions in the neuroendocrine control of mammalian puberty: Facilitatory effects of gonadal steroids. J. Neurobiol. 40, 528-540.

Ojeda, S. R., Urbanski, H. F., Costa, M. E., Hill, D. F., and Moholt-Siebert, M. (1990). Involvement of transforming growth factor- $\alpha$ in the release of luteinizing-hormone releasing hormone from the developing female hypothalamus. Proc. Natl. Acad. Sci. USA 87, 9698-9702.

Ojeda, S. R., Dissen, G. A., and Junier, M. P. (1992). Neurotrophic factors and female sexual development. Front. Neuroendocrinol. 13, 120-162.

Ojeda, S. R., Ma, Y. J., and Rage, F. (1997). The transforming growth factor- $\alpha$ gene family is involved in the neuroendocrine control of mammalian puberty. Mol. Psychiatry. 2, $355-358$.

Olney, J. W. (1971). GLUTamate-induced neuronal necrosis in the infant mouse hypothalamus: An electron microscopic study. J. Neuropathol. Exp. Neurol. 30, 75-90.

Ondo, J. E., Eskay, R. L., Mical, R. S., and Porter, J. C. (1973). Release of LH by LRF injected into the CSF: A transport role for the median eminence. Endocrinology 93, 231-237.

Oomura, Y., and Kita, H. (1981). Insulin acting as a modulator of feeding through the hypothalamus. Diabetologia 20, 290-298.

Oomura, Y., Ono, T., Ooyama, H., and Wayner, J. J. (1969). Glucose and osmosensitive neurons of the rat hypothalamus. Nature 222, 282-284.

Pardridge, W. M., Boado, R. J., and Farrel, C. R. (1990). Brain-type glucose transporter (GLUT-1) is selectively localized to the blood-brain barrier. J. Biol. Chem. 265, 18035-18040.

Pelletier, G., Luu-The, V., and Labrie, F. (1994). Immunocytochemical localization of $5 \alpha-$ reductase in rat brain. Mol. Cell Neurosci. 5, 394-399.

Pérez, J., Cifuentes, M., Alonso, F. J., Estivill, G., Schoebitz, K., Fernández-Llebrez, P., and Rodríguez, E. M. (1995). Light- and electron-microscopic immunocytochemistry of 
the subcommissural organ using a set of monoclonal antibodies. Histochemistry 104, 221-232.

Peruzzo, B., Pastor, F. E., Blázquez, J. L., Schöbitz, K., Peláez, B., Amat, P., and Rodríguez, E. M. (2000). A second look at the barriers of the medial basal hypothalamus. Exp. Brain Res. 132, 10-26.

Peruzzo, B., Pastor, F. E., Blázquez, J. L., Amat, P., and Rodríguez, E. M. (2004). Polarized endocytosis and transcytosis in the hypothalamic tanycytes of the rat. Cell Tissue Res. 317, 147-164.

Pestarino, M., Massari, M., Alberton, A., Candiani, S., and Vallarino, M. (1998). Distribution of immunoreactive multiple forms of gonadotropin-releasing hormone in the brain of the antarctic fish, Notothenia coriiceps. Polar Biol. 20, 352-356.

Petrov, T., Howarth, A. G., Krukoff, T. L., and Stevenson, B. R. (1994). Distribution of the tight junction-associated protein ZO-1 in circumventricular organs of the CNS. Brain Res. Mol. Brain Res. 21, 235-246.

Pilgrim, Ch. (1978). Transport function of hypothalamic tanycyte ependyma: How good is the evidence? Neuroscience 3, 277-283.

Pixley, S. K., and De Vellis, J. (1984). Transition between immature radial glia and mature astrocytes studied with a monoclonal antibody to vimentin. Brain Res. 317, 201-209.

Poorkhalkali, N., Juneblad, K., Jonsson, A. C., Lindberg, M., Karlsson, O., Wallbrandt, P., Ekstrand, J., and Lehmann, A. (2000). Immunocytochemical distribution of the GABA receptor splice variants $\mathrm{GABA}_{\mathrm{B}} \mathrm{R} 1 \mathrm{a}$ and $\mathrm{R} 1 \mathrm{~b}$ in the rat CNS and dorsal root ganglia. Anat. Embryol. 201, 1-13.

Porter, J. C., Ben-Jonathan, N., Oliver, C., and Eskay, R. L. (1975). Secretion of releasing hormones and their transport from CSF to hypophysial portal blood. In "Brain endocrine interaction" (K. M. Knigge, D. E. Scott, H. Kobayashi, and S. Ishii, Eds.), Vol. II, pp. 295-305. Karger, Basel, Switzerland.

Prevot, V. (2002). Glial-neuronal-endothelial interactions are involved in the control of GnRH secretion. J. Neuroendocrinol. 14, 247-255.

Prevot, V., Croix, D., Bouret, S., Dutoit, S., Tramu, G., Stefano, G. B., and Beauvillain, J. C. (1999). Definitive evidence for the existence of morphological plasticity in the external zone of the median eminence during the rat estrous cycle: Implication of neuroglio-endothelial interactions in gonadotropin-releasing hormone release. Neuroscience 94, 809-819.

Prevot, V., Bouret, S., Croix, D., Takumi, T., Jennes, L., Mitchell, V., and Beauvillain, J. C. (2000). Evidence that members of the TGF $\beta$ superfamily play a role in regulation of the $\mathrm{GnRH}$ neuroendocrine axis: Expression of a type I serine-threonine kinase receptor for TGR $\beta$ and activin in GnRH neurons and hypothalamic areas of the female rat. J. Neuroendocrinol. 12, 665-670.

Prevot, V., Cornea, A., Mungenast, A., Smiley, G., and Ojeda, S. R. (2003). Activation of erbB1 signalling in tanycytes of the median eminence stimulates transforming growth factor $\beta 1$ release via prostaglandin E2 production and induces cell plasticity. J. Neurosci. 23, 10622-10632.

Rasmussen, D. D. (1993). Episodic gonadotropin-releasing hormone release from the rat isolated median eminence in vitro. Neuroendocrinology 58, 511-518.

Redecker, P., Wittkowski, W., and Hoffmann, K. (1987). Glial cells positive for glial fibrillary acidic protein in the neurohypophysis of the Djungarian hamster (Phodopus sungorus). Cell Tissue Res. 249, 465-471.

Reese, T. J., and Brightmann, M. W. (1968). Similarity in structure and permeability to peroxidase of epithelia overlying fenestrated cerebral capillaries. Anat. Rec. 160, 414.

Réthelyi, M. (1984). Diffusional barrier around the hypothalamic arcuate nucleus in the rat. Brain Res. 307, 355-358. 
Rinne, U. K. (1966). Ultrastructure of the median eminence of the rat. Z. Zellforsch. 74, 98-122.

Riskind, P. N., Kolodny, J. M., and Larsen, P. R. (1987). The regional hypothalamic distribution of type II 5'-monodeiodinase in euthyroid and hypothyroid rats. Brain Res. 420, 194-198.

Rodríguez, E. M. (1969). Ependymal specializations. I. Fine structure of the neural region of the toad median eminence, with particular reference to the connections between ependymal cells and subependymal capillary loops. Z. Zellforsch. 102, 153-171.

Rodríguez, E. M. (1972). Comparative and functional morphology of the median eminence. In "Brain-Endocrine Interaction" (K. M. Knigge, D. E. Scott, and A. Weindl, Eds.), Vol. I, pp. 319-334. Karger, Basel, Switzerland.

Rodríguez, E. M. (1976). The cerebrospinal fluid as a pathway in neuroendocrine integration. J. Endocrinol. 71, 407-443.

Rodríguez, E. M., González, C. B., and Delannoy, L. (1979). Cellular organization of the lateral and postinfundibular regions of the median eminence in the rat. Cell Tissue Res. 201, 377-408.

Rodríguez, E. M., Peña, P., Rodríguez, S., Aguado, L. I., and Hein, S. (1982). Evidence for the participation of the CSF and periventricular structures in certain neuroendocrine mechanisms. Front. Horm. Res. 9, 142-158.

Rodríguez, E. M., Peña, P., Aguado, L. I., and Schoebitz, K. (1985). Involvement of tanycytes in the control of gonadotropin secretion. In "Current Trends in Comparative Endocrinology" (B. Lofts and W. N. Holmes, Eds.), pp. 113-116. Hong Kong University Press, Hong Kong.

Rojas, R., and Apodaca, G. (2002). Immunoglobulin transport across polarized epithelial cells. Nat. Rev. Mol. Cell. Biol. 3, 1-12.

Roncero, I., Alvarez, E., Vásquez, P., and Blásquez, E. (2000). Functional glucokinase isoforms are expressed in rat brain. J. Neurochem. 74, 1848-1857.

Rubin, B. S., and King, J. C. (1995). A relative depletion of luteinizing hormone-releasing hormone was observed in the median eminence of young but not middle-aged rats on the evening of proestrous. Neuroendocrinology 62, 259-269.

Rützel, H., and Schliebler, T. H. (1980). Prenatal and early postnatal development of the glial cells in the median eminence of the rat. Cell Tissue Res. 211, 117-137.

Schachenmayr, W. (1967). Über die entwicklung von ependym und plexus chorioideus der ratte. Z. Zellforsch. 77, 25-68.

Schiebler, T. H., Léranth, C., Zaborsky, L., Bitsch, P., and Rützel, H. (1978). On the glia of the median eminence. In "Brain-Endocrine Interaction" (D. E. Scott, G. P. Kozlowski, and A. Weindl, Eds.), Vol. III, pp. 46-56. Karger, Basel, Switzerland.

Schmechel, D. E., and Rakic, P. (1979). A Golgi study of radial glial cells in developing monkey telencephalon: Morphogenesis and transformation into astrocytes. Anat. Embryol. 156, $115-152$.

Schuit, F. C., Huypens, P., Heimberg, H., and Pipeleers, D. G. (2001). Glucose sensing in pancreatic $\beta$-cells: A model for study of other glucose-regulated cells in gut, pancreas, and hypothalamus. Diabetes 50, 1-11.

Scott, D. E. (1999). Post-traumatic migration and emergence of a novel cell line upon the ependymal surface of the third cerebral ventricle in the adult mammalian brain. Anat. Rec. 256, 233-241.

Scott, D. E. (2002). Ventricular system. "Encyclopedia of the Human Brain," Vol. 4, pp. 661-685. Elsevier, New York.

Scott, D. E., and Knigge, K. M. (1970). Ultrastructural changes in the median eminence of the rat following deafferentation of the basal hypothalamus. Z. Zellforsch. 105, 1-32.

Scott, D. E., and Paull, W. K. (1979). The tanycyte of the rat median eminence. I. Synaptoid contact. Cell Tissue Res. 200, 329-324. 
Scott, D. E., and Paull, W. K. (1983). Scanning electron microscopy of the mammalian cerebral-ventricular system. Micron 14, 165-186.

Scott, D. E., and Pepe, G. J. (1987). The fetal baboon median eminence as a circumventricular organ. I. Transmission electron microscopy. Brain Res. Bull. 19, 87-94.

Scott, D. E., Dudley, G. K., and Knigge, K. M. (1974). The ventricular system in neuroendocrine mechanisms. II. In vivo monoamine transport by ependyma of the median eminence. Cell Tissue Res. 154, 1-16.

Scott, E. D., and Hansen, S. J. (1997). Post-traumatic regeneration, neurogenesis and neuronal migration in the adult mammalian brain. Virginia Med. Q. 124, 249-261.

Seress, L. (1980). Development and structure of the radial glia in the postnatal rat brain. Anat. Embryol. 160, 213-226.

Sétáló, G., Vigh, S., Schally, A. V., Arimura, A., and Flerkó, A. (1975). LH-RH-containing neural elements in the rat hypothalamus. Endocrinology 96, 135-142.

Shibata, T., Yamada, K., Watanabe, M., Ikenaka, K., Wada, K., Tanaka, K., and Inoue, Y. (1997). GLUTamate transporter GLAST is expressed in the radial glia-astrocyte lineage of developing mouse spinal cord. J. Neurosci. 17, 9212-9219.

Silverman, R. C., Gibson, M. J., and Silverman, A. J. (1991). Relationship of glia to GnRH axonal outgrowth from third ventricular grafts in hpg hosts. Exp. Neurol. 114, 259-274.

Skinner, D. C., Malpaux, B., Delaleu, B., and Caraty, A. (1995). Luteinizing hormone (LH)releasing hormone in third ventricular cerebrospinal fluid of the ewe: Correlation with LH pulses and LH surge. Endocrinology 136, 3230-3237.

Steiner, H., Blum, M., Kitai, S. T., and Fedi, P. (1999). Differential expression of ErbB3 and ErbB4 neurregulin receptors in dopamine neurons and forebrain areas of the adult rat. Exp. Neurol. 159, 494-503.

Ströer, W. F. (1956). Studies on the diencephalon. I. The embryology of the diencephalon of the rat. J. Comp. Neurol. 105, 1-24.

Thomzig, A., Wenzel, M., Karschin, Ch., Eaton, M., Skatchkov, S. N., Karschin, A., and Veh, R. W. (2001). Kir6.1 is the principal pore-forming subunit of astrocyte but not neuronal plasma membrane K-ATP channels. Mol. Cell Neurosci. 18, 671-690.

Tramontin, A. D., García-Verdugo, J. M., Lim, D. A., and Alvarez-Buylla, A. (2003). Postnatal development of radial glia and the ventricular zone (VZ): A continuum of the neural stem cell compartment. Cerebr. Cortex 13, 580-587.

Trapp, B. D., and Hauer, P. E. (1994). Amyloid precursor protein is enriched in radial glia: Implications for neuronal development. J. Neurosci. Res. 37, 538-550.

Tu, H. M., Kim, S. W., Salvatore, D., Bartha, T., Legradi, G., Larsen, P. R., and Lechan, R. M. (1997). Regional distribution of type 2 thyroxine deiodinase messenger ribonucleic acid in rat hypothalamus and pituitary and its regulation by thyroid hormone. Endocrinology 138, 3359-3368.

Tuma, P. L., and Hubbard, A. L. (2003). Transcytosis: Crossing cellular barriers. Physiol. Rev. 83, 871-932.

Uemura, H., Nozaki, M., and Kobayashi, H. (1981). Luteinizing hormone-releasing hormone in the cerebrospinal fluid (CSF) of the rat: A technique for the collection of CSF from the third ventricle. Neuroendocrinol. Lett. 3, 159-163.

Ugrumov, M. V., and Mitskevich, M. S. (1980). The adsorptive and transport capacity of tanycytes during the perinatal period of the rat. Cell Tissue Res. 211, 493-501.

Vaala, S. S., and Knigge, K. M. (1974). Transport capacity of the median eminence: In vitro uptake of ${ }^{3}$ H-LRF. Neuroendocrinology 15, 147-157.

Van der Goot, F. G., and Gruenberg, J. (2002). Oiling the wheels of the endocytic pathway. Trends Cell Biol. 12, 296-299. 
Walsh, R. J., Brawer, J. R., and Lin, P. S. (1978). Early postnatal development of ependyma in the third ventricle of male and female rats. Am. J. Anat. 151, 377-408.

Wei, L. C., Shi, M., Chen, L. W., Cao, R., Zhang, P., and Chan, Y. S. (2002). Nestin-containing cells express glial fibrillary acidic protein in the proliferative regions of central nervous system of postnatal developing and adult mice. Dev. Brain Res. 139, 9-17.

Weindl, A., and Joynt, R. J. (1972). The median eminence as a circumventricular organ. In "Brain-Endocrine Interaction" (K. M. Knigge, D. E. Scott, and A. Weindl, Eds.), Vol. I, pp. 280-297. Karger, Basel, Switzerland.

Wingstrand, K. G. (1951). "The Structure and Development of the Avian Pituitary: From a Comparative and Functional Viewpoint." C. W. K. Gleerup, Lund, Sweden.

Wise, P. M., and Ratner, A. (1980). LHRH-induced LH and FSH responses in the aged female rat. J. Gerontol. 35, 506-511.

Wittkowski, W. (1967a). Zur Ultrastruktur der ependymalen Tanyzyten und Pituizyten sowie ihre synaptische Verknüpfund in der Neurohypophyse des Meerschweinchens. Acta Anat. 67, $338-360$

Wittkowski, W. (1967b). Synaptische Strukturen und Elementargranula in der Neurohypophyse des Meerschweinchens. Z. Zellforsch. 82, 434-458.

Wittkowski, W. (1968). Elektronenmikroskopische Studien zur intraventrikulären Neurosekretion in den Recessus infundibularis der Maus. Z. Zellforsch. 92, 207-216.

Wittkowski, W. (1969). Ependymokrinie und Rezeptoren in der Wand des Recessus infundibularis der Maus und ihre Beziehung zum kleinzelligen Hypothalamus. Z. Zellforsch. 93, 530-546.

Wittkowski, W. (1972). Ultrastructure of vascular processes of ependymal and glial cells in the infundibulum of the rat. Z. Zellforsch. 130, 58-69.

Wittkowski, W. (1998). Tanycytes and pituicytes: Morphological and functional aspects of neuroglial interaction. Microsc. Res. Tech. 41, 29-42.

Wu, W., Scott, D. E., and Gilman, A. M. (1989). Correlative scanning-immunoelectronmicroscopic analysis of neuropeptide localization and neuronal plasticity in the endocrine hypothalamus. Brain Res. Bull. 22, 399-410.

Xu, Y., Tamamaki, N., Noda, T., Kimura, K., Itokazu, Y., Matsumoto, N., Dezawa, M., and Ide, C. (2005). Neurogenesis in the epndymal layer of the adult rat 3rd ventricle. Exp. Neurol. 192, 251-264.

Zhen, S., Zakaria, M., Wolfe, A., and Radovick, S. (1997). Regulation of gonadotropinreleasing hormone $(\mathrm{GnRH})$ gene expression by insulin-like growth factor I in a cultured GnRH-expressing neuronal cell line. Mol. Endocrinol. 11, 1145-1155.

Zoli, M., Agnati, L. F., Tinner, B., Steinbusch, H. W. M., and Fuxe, K. (1993). Distribution of dopamine-immunoreactive neurons and their relationships to transmitter and hypothalamic hormone-immunoreactive neuronal systems in the rat mediobasal hypothalamus: A morphometric and microdensitometric analysis. J. Chem. Neuroanat. 6, 293-310.

Zoli, M., Ferraguti, F., Frasoldati, A., Biagini, G., and Agnati, L. F. (1995). Age-related alterations in tanycytes of the mediobasal hypothalamus of the male rat. Neurobiol. Aging 16, $77-83$.

\section{Further Reading}

Borson, S., Schatteman, G., Claude, P., and Bothwell, M. (1994). Neurotrophins in the developing and adult primate adenohypophysis: A new pituitary hormone system? Neuroendocrinology 59, 466-476. 
Buonanno, A., and Fischbach, G. D. (2001). Neuregulin and ErbB receptor signalling pathways in the nervous system. Curr. Opin. Neurobiol. 11, 287-296.

Cuevas, P., Gimenez-Gallego, G., Martinez-Murillo, R., and Carceller, F. (1991). Immunohistochemical localization of basic fibroblast growth factor in ependymal cells of the rat lateral and third ventricles. Acta Anat. (Basel) 141, 307-310.

Doetch, F., García-Verdugo, J. M., and Alvarez-Buylla, A. (1997). Cellular composition and three-dimensional organization of the subventricular germinal zone in the adult mammalian brain. J. Neurosci. 17, 5046-5061.

Hagg, T., Portera-Cailliau, C., Jucker, M., and Engvall, E. (1997). Laminins of the adult mammalian CNS; laminin- $\alpha_{2}$ (merosin $\mathrm{M}$-) chain immunoreactivity is associated with neuronal processes. Brain Res. 764, 17-27.

Harik, S. I., Kalaria, R. N., Andersson, L., Lundahl, P., and Perry, G. (1990). Immunocytochemical localization of the erythroid glucose transporter: Abundance in tissues with barrier functions. J. Neurosci. 10, 3862-3872.

Hockfield, S., and McKay, R. D. (1985). Identification of major cell classes in the developing mammalian nervous system. J. Neurosci. 5, 3310-3328.

Ikeda, T., Xia, X. Y., Xia, Y. X., Ikenoue, T., and Choi, B. H. (1999). Expression of glial cell line-derived neurotrophic factor in the brain and cerebrospinal fluid of the developing rat. Int. J. Dev. Neurosci. 17, 681-691.

Nishibori, M., Nakaya, N., Mori, S., and Saeki, K. (1997). Immunohistochemical localization of macrophage migration inhibitory factor (MIF) in tanycytes, subcommissural organ and choroid plexus in the rat brain. Brain Res. 758, 259-262.

Pérez, V. J., and Olney, J. W. (1972). Accumulation of glutamic acid in the arcuate nucleus of the hypothalamus of the infant mouse following subcutaneous administration of monosodium glutamate. J. Neurochem. 19, 1777-1782.

Tooyama, I., Akiyama, H., McGeer, P. L., Hara, Y., Yasuhara, O., and Kimura, H. (1991). Acidic fibroblast growth factor-like immunoreactivity in brain of Alzheimer patients. Neurosci. Lett. 121, 155-158. 